\title{
ZWISCHEN HUNNEN- UND GEPIDENZEIT. FRAUENGRÄBER AUS DEM 5. JAHRHUNDERT IM KARPATENBECKEN
}

\author{
ZSÓFIA RÁCZ
}

\author{
Institut für Archäologiewissenschaften, Eötvös Loránd Universität \\ Múzeum krt. 4/B, H-1088 Budapest, Ungarn \\ zsofia_racz@yahoo.de
}

\begin{abstract}
The aim of this study is to investigate the transition between Hunnic and Gepidic period on the basis of female burials in the Middle Danube Region. The analysis of burial practices, female dress accessories and artificial skull deformation prove that there was a continuous cultural transformation during the $5^{\text {th }}$ century, not a radical change. The power structure changed in the middle of the century but it didn't cause the disappearance of the phenomena which formed from the beginning of the century. The new female representation that emerged after the end of Roman rule in the Carpathian basin can be widely observed from a geographical as well as from a social point of view. The early graves of the Gepidic cemeteries (Reihengräberfelder) fit perfectly in the general archaeological features of the $5^{\text {th }}$ century.

Keywords: $5^{\text {th }}$ century, Hunnic Period, Gepidic Period, Middle Danube Region, continuity, female burials, burial practices, female dress accessories, female representation, artificial skull deformation, Reihengräberfelder, PCA
\end{abstract}

\section{EINLEITUNG: DIE VERÄNDERUNGEN DER BESTATTUNGSWEISE IM 5. JAHRHUNDERT}

Nach dem Untergang des Hunnenreiches ist im archäologischen Bild der östlichen Hälfte des Karpatenbeckens eine wichtige Veränderung das Auftauchen der sog. Reihengräberfelder mit hoher Gräberzahl - wie überall im nordwestlichen Genzgebiet des Römischen Reiches. ${ }^{1}$ In der vorliegenden Studie beschäftige ich mich mit der Frage des Übergangs von der Hunnen- zur Gepidenzeit und mit den frühen Bestattungen der gepidenzeitlichen Reihengräberfelder, vor allem aufgrund der Charakteristiken der Frauengräber des 5. Jahrhunderts. Die Frage untersuche ich nicht aus ethnischer Sicht. Ich habe nicht die Absicht, mit der Analyse von gewissen Gegenstandstypen, Kleidungsbestandteile oder Bestattungsbräuchen frühmittelalterliche Gentes archäologisch nachzuweisen. ${ }^{2}$ Ich untersuche vielmehr, ob sich zwischen den in der historischen und archäologischen Terminologie als Hunnen- und Gepidenzeit bezeichneten Perioden - aufgrund der Bestattungen - radikale Veränderung, kulturelle Diskontinuität beobachten lässt oder eher fortlaufende Umgestaltung typisch ist. Aufgrund der Quellenbasis nähere ich mich dem

\footnotetext{
${ }^{1}$ Ament 2003; Fehr 2008; Halsall 2010, 93-106. Den Ausdruck „Reihengräberfeld“ verwende ich als terminus technicus für die Bezeichnung der Gräberfelder mit hoher Gräberzahl der Epoche, ungeachtet dessen, dass in einzelnen gepidenzeitlichen Gräberfeldern die gruppenweise Anordnung der Gräber wichtiger gewesen zu sein scheint als die Schaffung von Reihen. In gut unterscheidbare Gruppen gliedern sich beispielsweise die Gräberfelder von Hajdúnánás-Fürjhalom (unpubliziert, Ausgrabung der Eötvös Loránd Universität im Jahr 2004), von Szentes-Kökényzug (CsALLÁNY 1961, 25; NAGY 1997, 51) und von Egerlövő (LovÁsz 1991, 57).
}

\begin{abstract}
${ }^{2}$ In der ungarischen Forschung der Völkerwanderungszeit herrschte lange Zeit eine erheblich statische Anschauung: die scharfe Unterscheidung historisch-archäologischer Epochen aufgrund der neuen Einwanderungswellen. Dazu kam eine typische Forschungsrichtung - ihre bedeutende Vertreter waren István Bóna und Attila Kiss -, die sich auf die Bestimmung der in den historischen Quellen tradierten Gentes konzentrierte. (Siehe die Bestrebung, hunnische, alanische, ostgermanische Neuankömmlinge sowie lokale sarmatische spätantike, suebische Bevölkerung zu identifizieren und zu unterscheiden, als wichtigste Fragestellung.) S. dazu noch TeJRAL 2007, 56-57.
\end{abstract}


genannten Problem vor allem von der Beobachtung des Ritus, der Totenkleidung, einzelnen Gegenstandstypen und den physischen anthropologischen Charakteristiken her an, was innerhalb des Fragenkreises der - in der Archäologie vorwiegend im Sinne der Bevölkerungs-, Siedlungs- und kulturellen Kontinuität erforschten - Kontinuität ein schmales, aber wegen des Reichtums an Grabbeigaben gut erforschbares Segment ist.

Von der historischen Periodisierung der Völkerwanderungszeit im Karpatenbecken her gesehen ist es ein Spezifikum des Beginns der Gepidenzeit, dass in diesem Fall die Epochengrenze nicht mit Migration, nicht mit einer neu eingewanderten Bevölkerung zu verbinden ist - wie bei der Bestimmung der Hunnen-, Langobarden-, Awaren- oder ungarischen Landnahmezeit -, sondern mit einem Wechsel der politischen und Machtsituation: 454, nach der Hunnenherrschaft wurde der König eines der wichtigsten früheren Hilfsvölker zum Herrscher in den zentralen hunnischen Gebieten. Die in der Studie gestellte Frage kann demnach auch so formuliert werden, ob die Umorganisierung der Machtstruktur mit kultureller Diskontinuität verbunden war. ${ }^{3}$

Jaroslav Tejral kam in einer 2012 erschienenen Studie über die Untersuchung der typischen Bestattungsformen, Einzelgräber und kleinen Grabgruppen des 5. Jahrhunderts zu der Folgerung, dass für die Osthälfte des Karpatenbeckens nach der Hunnenzeit eine fortwährende Umgestaltung typisch war - anders als in den westlichen, pannonischen und nördlich der Donau gelegenen Gebieten, wo das Erscheinen der Langobarden einen definitiven Bruch in der Siedlungsstruktur und Gräberfeldnutzung verursachte. ${ }^{4}$ „The striking uniformity of the archaeological record from burial sites in the broad zone from the Middle Danube to the Balkans confirms the existence of a fairly homogeneous cultural circle on the middle and probably lower Danube, which developed parallel to the proto- and Early Merovingian culture in the West and, despite mutual influences and some common features, retained its individual characters. This culture is genetically linked with the later material culture of the so-called Gepidian large cemeteries in the Great Alföld... “5 Diese Frage kann auch anhand der Charakteristiken der frühen Gräber in den Reihengräberfeldern im Theißgebiet untersucht werden, die in der zweiten Hälfte des 5. Jahrhunderts einsetzten, indem man sie mit den Bestattungen der Hunnenzeit einerseits, andererseits mit den zum Teil zeitgleichen Einzelgräbern/Gräbergruppen, außerdem mit Fundorten in anderen Gebieten des Mitteldonaugebiets vergleicht.

Wichtige Veränderungen im Theißgebiet brachte die Auflassung eines großen Teils der sarmatischen Gräberfelder an der Wende vom 4. zum 5. Jahrhundert. ${ }^{6}$ Eine andere Entwicklung in diesem Gebiet lässt sich in einzelnen Teilen der südlichen Tiefebene, der Batschka und des Banats feststellen: Dort finden sich bis in die Mitte des 5. Jahrhunderts ständig genutzte Gräberfelder und Siedlungen. ${ }^{7}$ Anstelle der aufgelassenen sarmatischen Bestattungsorte wurden danach einerseits neue Gräberfelder, solche mit kleinerer Gräberzahl, eröffnet, ${ }^{8}$ andererseits erschienen Einzelgräber und kleine Gräbergruppen. Parallel damit - stufenweise, regional unterschiedlich - änderte sich auch die Graborientierung, von der für die Spätkaiserzeit typischen S-N- zur W-O-Orientierung, die von der zweiten Hälfte des 5. Jahrhunderts an fast ausschließlich wurde. ${ }^{9}$

Die neu eröffneten ostungarischen Gräberfelder behandelt die Forschung in drei Gruppen, allgemein den in den Bestattungsbräuchen und Waffenbeigaben feststellbaren Unterschieden ethnische Bedeutung zueignend. ${ }^{10}$

${ }^{3}$ Mit der frühen Geschichte der Gepiden, vor der AttilaPeriode, und ihrer unsicheren archäologischen Hinterlassenschaft beschäftige ich mich in dieser Studie nicht. Zur Frage - bezüglich des 3.-4. Jahrhunderts sowie des Endes des 4. und der ersten Hälfte des 5. Jahrhunderts gleicherweise zusammenfassend s. BIERBRAUER 2006; PoHL 1980; POHL 1998; NAGY-B. Tóth 1998.

${ }^{4}$ Ähnliche Feststellungen trifft er bei seiner Beschäftigung mit dem Theißgebiet: BIERBRAUER 2006, 191-192.

${ }^{5}$ TEJRAL 2012, 122. Dann weiter: ,... important groups of finds in different parts of eastern Hungary and the Upper Tisza region do not suggest a sudden break in the aftermath of the battle of Nedao, but rather an uninterrupted development... Numerous assemblages suggest that settlement- and power structures may not have changed much on the Upper Tisza and in the Eastern Great Hungarian Plain for the entire second half of the $5^{\text {th }}$ century“ (TEJRAL 2012, 125).

${ }^{6}$ Siehe z. B. Madaras-Halmok: KöHEGYI-VÖRÖs 2011, 360.

${ }^{7}$ PÁRducz 1959; BugarsKi 2012, 17-25.

${ }^{8}$ Siehe die Gräberfelder des sog. Tiszadob-Kreises (IsTVÁNOVITS 1993, GARAM-VADAY 1990).

${ }^{9}$ Über das Erscheinen der W-O-Orientierung zusammenfassend siehe z. B. FEHR 2008, 79-81.

${ }^{10}$ Darüber zusammenfassend: BIERBRAuer 2006, 175 184; IstvánOVITS 1998; IsTVÁNOVITS 2000. Als Beispiel: Im Tiszadob-Kreis „dominieren die iranischen Elemente bei gleichzeitiger germanischer Infiltration, während in Ártánd neben einem starken iranischen Einfluss die germanischen Elemente vorherrschen" (ISTVÁNOVITS 2000, 204). 
1. Fundorte des sog. Tiszadob-Kreises im oberen Theißgebiet: ${ }^{11}$ Gräberfelder mit 30-50 Bestattungen, Ende 4. - Anfang 5. Jahrhundert. ${ }^{12}$

2. Fundorte Ártánd-Kis- und Nagyfarkasdomb am Ostrand der Großen Ungarischen Tiefebene: Gräberfelder mit 30-50 Bestattungen, die vom Ende 4. - zweite Hälfte 5. Jahrhundert bzw. bis ans Ende des Jahrhunderts genutzt wurden. ${ }^{13}$

Für beide Gruppen ist bezeichnend, dass sie starke Bande mit der lokalen sarmatischen und gleicherweise der Marosszentanna-Tschernjachow-Kultur verknüpfen.

3. Mit ihnen verbunden sind von der südlichen Tiefebene her einige in spätsarmatischer Zeit eröffnete und auch in der Hunnenzeit belegte Gräberfelder wie Csongrád-Kenderföldek, die einen konservativen Bestattungsritus bewahren (z. B. S-N-Orientierung), den früheren Traditionen entsprechend. ${ }^{14}$

Aufgrund von einigen neuerdings freigelegten Fundorten lassen sich weitere Informationen über diese Epoche gewinnen: Ein Gräberfeld in der Gemarkung von Sajószentpéter (Nordostungarn) mit 22 Gräbern wechselnder Orientierung (Wende 4.-5. Jh.) weist die Merkmale der Marosszentanna-Kultur auf. ${ }^{15}$ In Makó-Mikócsa-halom (Südungarn) wurde eine weitere spätsarmaten-hunnenzeitliche Bestattungsstätte mit hoher Gräberzahl gefunden. ${ }^{16}$ In großem Maße werden unsere bisherigen Kenntnisse auch durch die Entdeckungen in der nördlichen Tiefebene, der Umgebung von Nyíregyháza, umgestaltet: ${ }^{17}$ Ein hunnenzeitlicher Goldsattel von einer Siedlung des 4.-5. Jahrhunderts erweitert wahrscheinlich den Kreis der steppentypischen Opferfunde. ${ }^{18}$ An anderen Fundorten - Kótaj, ${ }^{19}$ Níregyháza-Oros ${ }^{20}$ und Nyíregyháza-Rozsrétszőlö ${ }^{21}$ - wissen wir von hunnenzeitlichen Einzelgräbern und kleinen Gräberfeldern des 5.-6. Jahrhunderts. Die Fundstellen mit vor allem W-O orientierten Gräbern von NagykállóHarangod (24 Gräber) und Nyíregyháza-Rozsrétszőlő (33 Gräber) (Mitte 5. Jh. - Wende 5./6. Jh.) erinnern schon an die gepidenzeitlichen Reihengräberfelder - bisher gab es keine ähnlichen in der Nordostecke der Tiefebene. ${ }^{22}$ Nicht weit von den genannten wurden in der Gemarkung von Hajdúnánás eine kleine Grabgruppe (zweite Hälfte 5. Jh.) und ein Reihengräberfeld des 5.-6. Jahrhunderts (73 Gräber) bekannt. ${ }^{23}$ Aufgrund dieser Fundorte muss die Grenze des Siedlungsgebiets des gepidischen Königtums weiter nördlich gezogen werden, als früher angenommen wurde. ${ }^{24}$

Aufgrund dessen entfaltet sich in der Osthälfte des Karpatenbeckens ein abwechslungsreiches, kulturell vielfarbiges archäologisches Bild: Am Anfang der Epoche, an der Wende vom 4. zum 5. Jahrhundert, sind das mosaikartige Nebeneinanderleben - und im gewissen Maße Vermischen - der Charakteristiken der TschernjachovMarosszentanna-Kultur, der sarmatischen Gebieten und der neuen östlichen Steppenelementen, was eine ihrer Herkunft nach heterogene Bevölkerung anzeigt. Die in der Bestattungsweise, im Ritus eintretenden Veränderungen - sowie die nach dem Zerfall der früheren Strukturen feststellbare erneute Vereinheitlichung - geschahen nicht

${ }^{11}$ Über die Bedeutung des oberen Theißgebietes in der ersten Hälfte des 5. Jahrhunderts: IsTVÁNOVITS-KULCSÁR 1999. Die herausragende Rolle des Gebietes zeigen nicht nur die neu eröffneten Gräberfelder, sondern auch Fundmaterial anderen Typs, wie z. B. Solidus-Funde aus der ersten Hälfte des 5. Jahrhunderts, später die Frauengräber (der Elite) mit großen Blechfibeln und die Verdichtung der Bestattungen mit Waffen im mittleren Drittel und der zweiten Hälfte des 5. Jahrhunderts (IsTVÁNOVITS 1996).

${ }^{12}$ Tiszadob-Sziget (Istvánovits 1993); Tiszavalk (GARAM-VADAY 1990); Tiszakarád-Inasa (LovÁsZ 1986). Zusammenfassend: IsTVÁNOVITS 1996; ISTVÁNOVITS-KULCSÁR 1999.

${ }^{13}$ Diese Gräberfelder sind unpubliziert. MESTERHÁZY 1965; IstVÁNOVITS-MESERHÁZY-NePPER 1996; MesterhÁZy 2009. Die Hypothese, die Ártánd-Fundorte als gepidisch zu identifizieren, siehe z. B.: BónA 1988, 123; IsTVÁNOVITS 2000, 204; IsTVÁNOVITS 1998, 315.

${ }^{14}$ PÁRDUCZ 1959.

${ }^{15}$ Ausgrabung von Krisztián Tóth (HOMÉ): Sajószentpéter-Harmadik vető, 3. Fo. K. Tóth: 2-3. századi germán település és 5 . századi germán temető a Sajó mentén. Előadások a Nemzeti Múzeumban - A 2012. év néhány jelentősebb feltárási eredményének bemutatása. 2013. május 28-29. (Germanische Siedlung des 2.-3. Jh. und germanisches Gräberfeld des 5. Jh. am Sajó. Vorträge im Ungarischen Nationalmuseum - Vorstellung einiger bedeutenderer Freilegungsergebnisse des Jahres 2012. 28.-29. Mai 2013).
${ }^{16}$ Freilegung von Csilla Balogh (2009-2010); freundliche mündliche Mitteilung der Ausgräberin.

${ }^{17}$ Einen zusammenfassenden Vortrag über diesen Themenkreis hielt Eszter Istvánovits bei der Konferenz „Kollaps - Neuordnung - Kontinuitäten. Das Theißgebiet nach dem Untergang des Hunnenreiches“. Internationale Tagung im Archäologischen Institut der Eötvös Loránd Universität (Budapest) am 14.-15. Dezember 2015.

${ }^{18}$ E. IsTVÁNOVITS-V. KULCSÁR: Hunkori nyereg Északkelet-Magyarországról [Ein hunnenzeitlicher Sattel aus Nordostungarn]. XI. Erdélyi magyar régészeti konferencia. Marosvásárhely, 8.-9. November 2012

${ }^{19}$ Kótaj-Verba-tanya; s. Anm. 18.

${ }^{20}$ Nyíregyháza-Oros, Úr-Csere: Gindele et al. 2004.

${ }^{21}$ Nyíregyháza-Rozsrétszőlö, Nevelős-homokbányától D-re (Varga-tábla): Almássy et al. 2005; PINTYE 2014.

${ }^{22}$ Ausgrabung (2009) von András Markó (UNM). A. BECK: V. századi germánok Nyíregyháza-Harangod mellett. Előadások a Nemzeti Múzeumban - A 2011. év néhány jelentősebb feltárási eredményének bemutatása. 2012. május 15-16. [Germanen im 5. Jh. bei Nyíregyháza-Harangod. Vorträge im Ungarischen Nationalmuseum - Vorstellung einiger bedeutenderer Freilegungsergebnisse des Jahres 2011. 15.-16. Mai 2012].

${ }^{23}$ RÁCZ 2014.

${ }^{24}$ Vgl. NaGY-B. Tóth 1998, 121, Abb. 6. 
gleichzeitig, sondern regional unterschiedlich. All das verlangt eine sehr flexibile Anschauung von den Erforschern der Epoche: Eine aufgrund der archäologischen Erscheinungen große Gebiete umfassende Gruppenbildung (und ethnische Bestimmung der Gruppen) scheint unmöglich zu sein..$^{25}$ Das zweckmäßigste Verfahren ist die vollständige archäologische Aufarbeitung je eines Fundortes und einer kleineren Region, dann deren Vergleichung, wie es beispielsweise bei der Veröffentlichung des Gräberfeldes von Tiszadob verwirklicht wurde. ${ }^{26}$

Neben den oben erwähnten Nekropolen mit einigen zehn Gräbern wurden die Einzelgräber und Gräbergruppen aus 2-10 Bestattungen im 5. Jahrhundert typisch für das ganze Mitteldonaugebiet. ${ }^{27}$ Der Prozess wurde unterschiedlich interpretiert: Radu Harhoiu hebt die Veränderung des Bestattungsritus hervor, ${ }^{28}$ Jaroslav Tejral die Rolle der hunnenzeitlichen bewaffneten Elitenschicht und der Besetzung der strategischen Punkte. ${ }^{29}$ Margit Nagy argumentiert mit den für die Epoche typischen kleineren Siedlungseinheiten. ${ }^{30}$ Péter Prohászka berücksichtigt sowohl die soziale Stellung der Verstorbenen (einzeln oder von Kindern begleitet bestattete Frauen der Elite) als auch das damalige Siedlungssystem und die Lebensweise (Gräberfelder von Gehöfte und kleine Siedlungen) bei seiner Erklärung der Bestattungsform. ${ }^{31}$

In die Reihe der Typen von Bestattungsorten des 5. Jahrhunderts muss - wie bei der Erforschung der Frühawarenzeit ${ }^{32}$ - auch der Begriff „Bestattungsareal“ aufgenommen werden: Dank der großflächigen Freilegungen stellte sich heraus, dass sich die zeitgleichen Gräber auf einem größeren Gebiet verstreut befinden konnten, einzeln oder kleine Gruppen bildend. ${ }^{33}$

Die Bestattungen des 5. Jahrhunderts verbindet - über die Bestattungsform hinaus - auch die auffallend ähnliche Ausstattung der Frauengräber (Ohrring mit Polyederknopf, Fibel, Perlen um den Hals, als Schmuck des Gürtels oder der Tasche, Gürtelschnalle, Spiegelbeigabe, Kamm, Spinnwirtel, Gefäßbeigabe), ${ }^{34}$ die sich nach dem mosaikartigen Bild von der Wende des 4.-5. Jahrhunderts (Phase D1) ${ }^{35}$ im gesamten Mitteldonaugebiet verbreitete. Diese Ausstattung der Frauen - die sog. mode danubienne - lässt sich in Einzelgräbern, kleinen Grabgruppen und auch in den größeren Gräberfeldern entdecken, anscheinend unabhängig von ethnischer Identität und gesellschaftlichem Status. ${ }^{36}$

\section{RITUS UND AUSSTATTUNG DER FRAUENGRÄBER DES 5. JAHRHUNDERTS IM MITTELDONAUGEBIET}

Eine gute Basis für die Untersuchung der Zusammenhänge von Hunnen- und Gepidenzeit bieten die Frauenbestattungen: Ihre variablen, reichen Beigaben und Schmuckstücke schaffen einen breiten Raum zur Verglei-

\footnotetext{
${ }^{25}$ Die Unhaltbarkeit früherer Gruppierungsversuche der Gräberfelder bezüglich des pannonischen Raumes fasst Tivadar Vida gut zusammen: VIDA 2011, 616-620. Statt erneuter Gruppenbildung stellt er aufgrund der Nutzungszeit der Gräberfelder chronologische Phasen fest. Orsolya Heinrich-Tamáska und Péter Straub teilen die pannonischen, im Gebiet Ungarns liegenden Gräber und Gräberfelder des 5. Jahrhunderts in Gruppen ein aufgrund ihres Verhältnisses zu spätrömischen Fundorten, ihrer Größe und Nutzungsdauer (HEINRICHTAMÁSKA-STRAUB 2015).

${ }^{26}$ IsTVÁNOVITS 1993.

${ }^{27}$ Die Sammlung und Analyse der Einzelgräber und Grabgruppen des 5. Jahrhunderts im Karpatenbecken wird im Institut für Archäologiewissenschaften, Eötvös Loránd Universität vorgenommen, dank Alpár Kiss (MA-Facharbeit). Aufgrund dieser Sammlung scheint es, dass in der Mehrheit der betreffenden Fundorte wirklich nur ein Grab gefunden wurde (etwa 70 Fälle), weit weniger - und der Gräberzahl nach mit ständig sinkender Tendenz - sind kleine Bestattungsstätten mit 2-10 Gräbern.

${ }^{28}$ HARHOIU 1997, 30-31.

${ }^{29}$ TeJRAL 1999, 255-274; TEJRAL 2012, 118.

${ }^{30}$ NAGY 1993, 60. Über die kleineren Siedlungseinheiten aufgrund der Erforschung der Siedlungen: B. То́тн 2006, 52.

${ }^{31}$ PROHÁsZKA 2003, 77-78. Ich muss noch erwähnen, dass auch bei der Interpretation der Gräberfelder mit kleiner Grabzahl die
}

ethnische Anschauung auftaucht, selbst in Studien, die sich von ihr lösen wollen. Als ostgermanische Grabgruppen und Einzelgräber behandelt sie z. B. Volker Bierbrauer (BIERBRAUER 2006, 192, 195).

${ }^{32}$ TOMKA 2005, 160-161; LŐRINCZY-RÁCZ 2015, 166-171.

${ }^{33}$ Beispielsweise Mezőkövesd-Mocsolyás (LovÁsz 2005); Tápé-Széntéglaégető (B. TóTH 1994, 288). Die Erscheinung des „Bestattungsareales“ erwähnte auch Eszter Istvánovits in der Konferenz in Budapest am 14.-15. Dezember 2015 (s. Anm. 17).

${ }^{34}$ Über die charakteristischen Gegenstandstypen der Elitengräber zusammenfasend s. KAZANSKI-MASTYKOVA 2003; bezüglich des Elitenfrauengrabes von Mezőkövesd-Mocsolyás: LovÁsz 1999.

${ }^{35}$ Einige Beispiele der Frauengräber mit unterschiedlichem Ritus und verschiedener Ausstattung der Periode D1: Zagyvarékas, spätsarmatisches Frauengrab (Theißgebiet) (VADAY 1975); Kilimán, den Einfluss der Tschernjakow-Marosszentanna-Kultur aufweisende Gräber (Westungarn) (SzŐKE 1996).

${ }^{36}$ Die charakteristische Frauenausstattung bildet einen Teil jener „,kulturellen Einheit“, für die Jaroslav Tejral den Ausdruck „Danubian-Eastern Germanic cultural complex“, donauländischer/donauländisch-ostgermanischer Kulturkomplex (zuletzt TEJRAL 2012, 117-126), Volker Bierbrauer den Ausdruck „ostgermanische Koiné“ (z. B. Bierbrauer 2006, 191-192, 195) und Michel Kazanski den allgemeineren Ausdruck „mode danubienne“ verwendet (KAZANSKI 1990). 
chung. In den folgenden Kapiteln werden also die Frauengräber der Phasen D2- $\mathrm{E}^{37}$ des Mitteldonaugebiets, unter ihnen die älteren Bestattungen der - mit der zweiten Hälfte des 5. Jahrhunderts einsetzenden - gepidenzeitlichen Nekropolen, verglichen.

\section{Methode}

Die frühere Forschung hat in erster Linie aufgrund ausgewählter Gegenstandstypen (Blechfibel), spezieller Fundkombinationen (Blechfibel und Gürtelschnalle) ${ }^{38}$ sowie von Schmuck und Kleidungsbestandteile der Elitengräber die Frauenbestattungen des 5. Jahrhunderts untersucht und sich dabei vor allem auf chronologische und ethnische Probleme konzentriert. Man kann von einem neuen Gesichtspunkt an die Frage herangehen, wenn die Charakteristiken der Frauengräber umfassend betrachtet und auch für statistische Analysen geeignet gemacht werden. $\mathrm{Zu}$ diesem Zweck habe ich eine Tabelle zusammengestellt, in die die Bestattungen der Epoche in vier große - einander überlappende - chronologische Einheiten geteilt (erste Hälfte 5. Jh., mittleres Drittel 5. Jh., zweite Hälfte 5. Jh., zweite Hälfte 5. Jh./Anfang 6. Jh.) und innerhalb dieser katalogartig, alphabetisch geordnet aufgenommen wurden, sowohl die mit bekannten als auch die mit unbekannten Fundumständen (Tabelle 1, Abb. 1).$^{39}$ In die Tabelle fügte ich auch die frühen, datierbaren Frauengräber der gepidenzeitlichen Reihengräberfelder mit ein. Die Absicht war, nicht nur die reich ausgestattete Elite, sondern die breitere Schicht der Gesellschaft zu untersuchen; so war ich bestrebt, jede Bestattung festzuhalten, die zumindest zwei Fundobjekte enthielt. ${ }^{40}$ Die Tabelle enthält die Merkmale der Bestattungsform (Einzelgrab, Gräbergruppe, Kleingräberfeld, Gräberfeld) ${ }^{41}$ der Orientierung, der anthropologischen Angaben (Lebensalter, artifizielle Schädeldeformation), des Schmucks und des Kleidungszubehörs (Ohrring, Fibel und Kleidernadel in unterschiedlicher Position, Perlen in verschiedener Funktion, Anhänger, Armring, Fingerring, Gürtelschnalle, Schuhschnalle) sowie der Beigaben (Spiegel, Toilettengarnitur, ${ }^{42} \mathrm{Kamm}$, Spinnwirtel, Keramik- und Glasgefäß, Messer). Bei der Aufnahme der Gegenstände war nicht die Typologie, sondern ihre Funktion und ihre Lage im Grab der vorrangige Gesichtspunkt. Zugleich habe ich auch einige typische Gegenstandsgruppen (z. B. große Bernsteinperle, fassförmige Metallperle, Blechfibel, gegossene Fibel) zur einfacheren Orientierung aufgeführt. Der Vorteil dieser Sammlung ist, dass dadurch das Fundmaterial auch für statistische Untersuchungen geeignet wird.

Es war schwer zu entscheiden, wie ich die Grenze der untersuchten Mustergruppe - außer der Bestimmung von Zeit und Raum - aus ,kulturellem“ Gesichtspunkt ziehen sollte. Letztendlich wurden die spätantiken pannonischen Nekropolen, die auch im 5. Jahrhundert im Gebrauch waren - nachdem das Objekt der jetztigen Untersuchung vor allem die älteren gepidenzeitlichen Gräber sind -, nicht aufgenommen. Die wichtigeren Fundstellen dieser Gruppe sind Solva-Castellum (Esztergom),${ }^{43}$ der Südostfriedhof von Intercisa (Dunaújváros) ${ }^{44}$ das Gräberfeld vor der Südmauer in Keszthely-Fenékpuszta ${ }^{45}$ und $\operatorname{Tokod}^{46}$ (die mit spätrömischen Festungen verbunden sind), das „dörfliche“ Gräberfeld von Budapest-Gazdagrét ${ }^{47}$ und die „städtischen“ Nekropolen von Scarbantia (Sopron) ${ }^{48}$ und Arrabona ${ }^{49}$ (Györ-Széchenyi tér) ${ }^{50}$ Die Nekropole von Solva enthielt in größerer Zahl Frauengräber, die ins 5. Jahrhundert datierbar sind. ${ }^{51}$ Ihre häufigen Fundkombinationen (Ohrringe mit Polyederknopf, Perlen, Kamm, Spinn-

${ }^{37}$ Nach TeJRAL 2005b: D1:360/370-400/410, D2:390/400430/440, D2/D3: 430-460, D3: 450-470/480; E: 470/480-510.

${ }^{38}$ Zusammenfassend: RuMMEL 2007, 37, 275, 314-316.

${ }^{39}$ Bei der Datierung behielt ich die Vorschläge der einzelnen Publikationen bei (wo eine detaillierte Analyse angefügt war) bzw. stützte mich in etwa auf das chronologische System von Jaroslav Tejral und Volker Bierbrauer (BIERBRAUER 1995; TeJRAL 1988; TEJRAL 2005).

${ }^{40}$ Das Minimum von zwei Fundgegenständen ist eine „willkürliche“ Entscheidung und ist wegen der späteren statistischen Analysen vorteilhaft.

${ }^{41}$ In der Tabelle 1 wurden die Bestattungsplätze mit 2-10 Gräbern Gräbergruppe, die Friedhofe mit 11-20 Bestattungen Kleingräberfeld und die größeren Bestattungsorten Gräberfeld genannt, was natürlich auch eine „willkürliche Konstruktion“ ist.
${ }^{42}$ Einige Funde, wie Toilettengarnitur und Messer, können auch als Teil der Kleidung interpretiert werden.

${ }^{43}$ H. KELEMEN 2008.

${ }^{44}$ B. VÁGÓ-BÓNA 1976.

${ }^{45}$ MÜLLER 2010

${ }^{46}$ LÁNYI 1981.

${ }^{47}$ ZSIDI 1987.

${ }^{48}$ TоMKA 1967; TOMKA 2015.

${ }^{49}$ Bíró-TOMKA im Druck.

${ }^{50}$ Weitere, aus vorläufigen Berichten bekannte Nekropolen sind noch Visegrád-Gizellamajor (GRÓF 1992) und Csákvár (NÁDORFI 1996).

${ }^{51}$ H. KeLEMEN 2008, 164. 


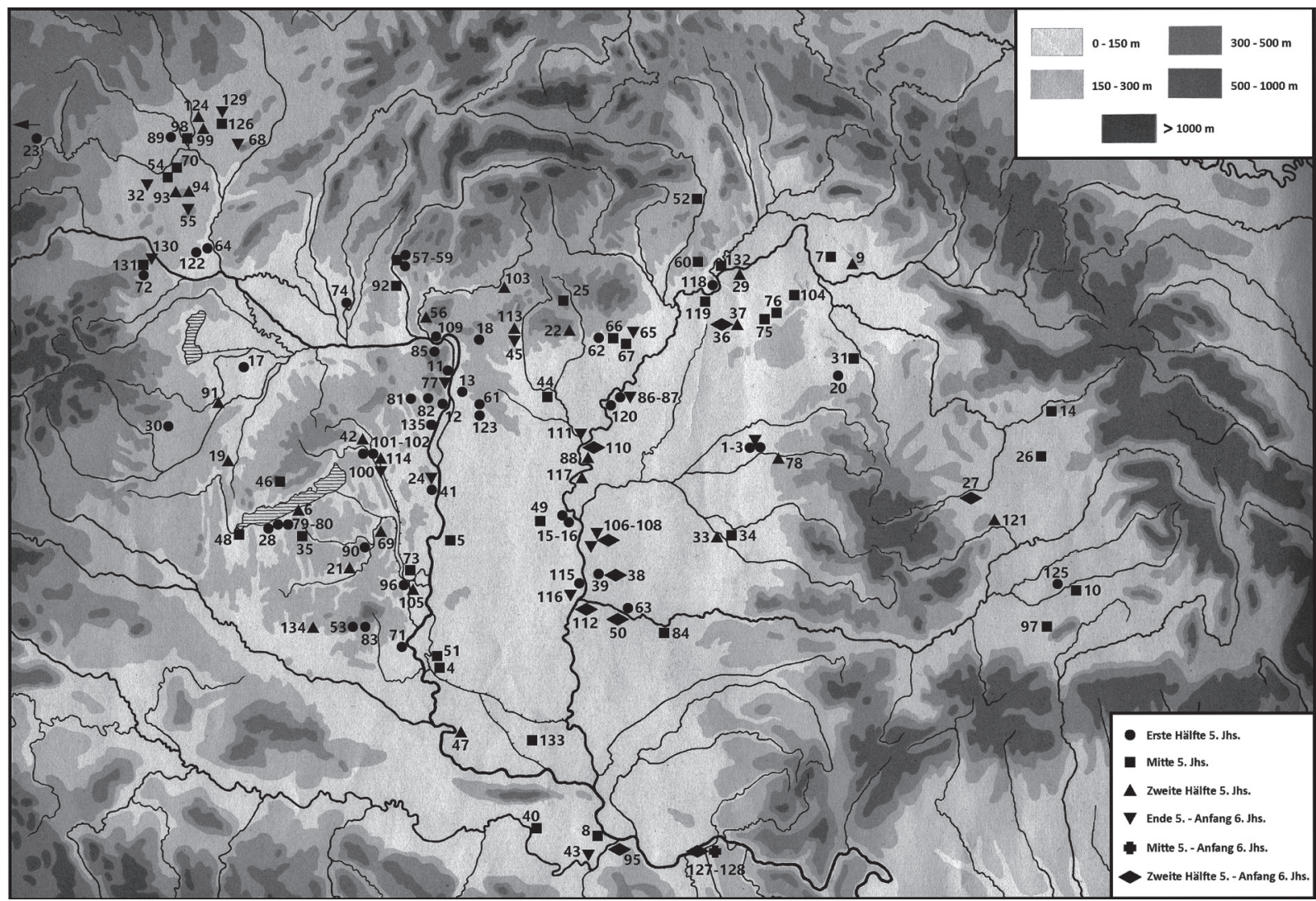

Abb. 1. Frauengräber mit wenigstens zwei Fundobjekten aus dem 5. Jahrhundert im Mitteldonaugebiet (vgl. Tabelle 1).

1: Ártánd-Kisfarkasdomb; 2: Ártánd-Lencsésdomb; 3: Ártánd-Nagyfarkasdomb; 4: Bački Monoštor (Bodrogmonostorszeg); 5: Bakodpuszta (Dunapataj-Bödpuszta); 6: Balatonszemes-Szemesi-berek; 7: Barabás-Bagolyvár; 8: Belgrad-Zemun; 9: Beregszász (Beregovo) oder Beregvidék; 10: Bratei (Baráthely); 11: Budakalász-Csajerszke; 12: Budapest XI. Budafoki út 78; 13: Budapest XVI. Zalavár u.; 14: Cepari (Csépán); 15: Csongrád-Kenderföldek; 16: Csongrád-Werbőczy u.; 17: Csorna; 18: Csővár; 19: Dabronc-Ötvöspuszta; 20: Dindești (Érdengeleg); 21: Dombóvár-Téglagyár; 22: Domoszló-Víztároló; 23: Drslavice; 24: Dunaújváros-Öreghegy (Intercisa); 25: Erdőkövesd; 26: Fântânele (Újős) „Dâmbul Popii“; 27: Floreşti (Szászfenes)-Polus center; 28: Fonyód-Mérnöki-telep; 29: Gáva; 30: Gencsapáti; 31: Ghenci (Gencs); 32: Großharras; 33: Gyula-Körösufer; 34: Gyulavári; 35: Hács-Béndekpuszta; 36: Hajdúnánás-Fürj-halom-dűlő; 37: Hajdúnánás-Fürj-halom-járás; 38: Hódmezővásárhely-Kishomok; 39: Hódmezővásárhely-Sóshalom; 40: Hrtkovci (Herkóca)-Vranja; 41: Intercisa (Dunaújváros); 42: Iszkaszentgyörgy-Zsidóhegy; 43: Jakovo-Kormadin; 44: Jászberény-Szőlő-dülő; 45: Jobbágyi, Petőfi u.; 46: Kapolcs; 47: Karavukovo (Bácsordas); 48: Keszthely-Fenékpuszta; 49: Kiskunfélegyháza; 50: Kiszombor B; 51: Kolut (Küllőd);

52: Kosice (Kassa)-Magnezitbánya; 53: Kővágószőlős; 54: Laa a.d. Thaya; 55: Ladendorf; 56: Letkés-Vízfogó; 57: Levice (Léva)-Alsórétek; 58: Levice (Léva)-Kálváriadomb; 59: Levice (Léva)-Kusá Horá; 60: Mád; 61: Maglód Fundstelle 1; 62: Maklár; 63: Makó; 64: Marchegg; 65: Mezőkeresztes-Cethalom; 66: Mezőkövesd, Nyárfa u.; 67: Mezőkövesd-Mocsolyás; 68: Mistřin; 69: Miszla; 70: Mitterhof (bei Laa); 71: Mohács, Jerney u.; 72: Mödling-Lerchengasse; 73: Mözs-Icsei-dülő; 74: Nove Zamky (Érsekújvár); 75: Nyíregyháza-Oros, Úr-Csere; 76: Nyíregyháza-Stadion; 77: Óbuda-Aquincum (Budapest); 78: Oradea (Nagyvárad)-Salca Gheţărie; 79: Ordacsehi-Csereföld; 80: Ordacsehi-Kistöltés; 81: Páty, Alsó-Hegy-Alja; 82: Páty-Malom-dűlő; 83: Pécs-Málom; 84: Periam (Perjámos); 85: Pilismarót-Öregek-dűlő;

86: Pusztataskony-Ledence Fundstelle 1; 87: Pusztataskony-Ledence Fundstelle 2; 88: Rákóczifalva-Bivalytó-Rokkant föld I; 89: Rakšice; 90: Regöly-Pénzesdomb; 91: Répcelak; 92: Šarovce (Nagysáró)-Makócza-domb; 93: Schletz (1889); 94: Schletz; 95: Singidunum (Belgrad); 96: Sióagárd; 97: Slimnic; 98: Smolin; 99: Sokolnice; 100: Soponya; 101: Szabadbattyán „1909“; 102: Szabadbattyán, Mária-telep;

135: Százhalombatta; 103: Szécsény; 104: Székely; 105: Szekszárd-Palánk; 106: Szentes-Berekhát; 107: Szentes-Kökényzug; 108: SzentesNagyhegy; 109: Szob-Kálváriadomb; 110: Szolnok-Szanda; 111: Szolnok-Zagyvapart; 112: Szőreg-Téglagyár; 113: Szurdokpüspöki;

114: Tác-Fövenyi temető; 115: Tápé-Lebő; 116: Tápé-Széntéglaégető; 117: Tiszaföldvár-Érhalom; 118: Tiszaladány; 119: Tiszalök, Árpád u.; 120: Tiszaroff, katolikus temető; 121: Turda (Torda); 122: Untersiebenbrunn; 123: Üllö Fundstelle 5; 124: Velatice; 125: Velţ;

126: Vicemilice; 127: Viminacium-Burdelj; 128: Viminacium-Više grobalja; 129: Vyskov; 130: Wien 1-Salvatorgasse-Stoß im Himmel; 131: Wien-Atzgersdorf; 132: Zalkod-Bánkódó-dülő; 133: Zmajevo (Ókér); 134: Zsibót-Domolospuszta; 135: Százhalombatta (Matrica) 
wirtel, Ring, Armring und Gefäßbeigabe $)^{52}$ zeigen eine enge Beziehung mit den „nichtrömischen“ Bestattungen dieser Zeit. ${ }^{53}$ Das weist darauf hin, dass zwischen der Bevölkerung, die die alten Nekropolen verwendete, und der von den neuen Bestattungsorten - was die Mode und den Bestattungsritus betrifft - viele gemeinsame Züge zu entdecken sind. All dies macht die Kategorien von „spätantik“ und „barbarisch“ schwerfällig. Die tiefere Erkennung dieser Zusammenhänge, der Vergleich der Bevölkerungen, die innerhalb der Mauer der römischen Festungen und Städten lebten und römische handwerkliche Traditionen fortsetzten, bzw. die „die Umgebung besetzten“, verlangt noch weitere Studien. ${ }^{54}$

Eine Forschungsschwierigkeit ist ferner, dass es am Anfang und Ende der von mir untersuchten Epoche in den - spätsarmatischen und spätantiken bzw. gepidischen Reihen- - Gräberfeldern mit hoher Gräberzahl viele schwer datierbare und beigabenlose Gräber gibt. Von den größeren gepidenzeitlichen Gräberfeldern steht von Hódmezővásárhely-Kishomok und von Szőreg-Téglagyár eine typo- und belegungschronologische Analyse zur Verfügung, aber auch in diesen Fällen ist die Zahl jener Frauengräber sehr gering, die ins 5. oder an die Wende 5.-6. Jahrhundert datiert werden können. ${ }^{55}$ Zugleich kann im Fall einer kleinen Grabgruppe schon eine einzige gut datierbare Bestattung bei der zeitlichen Einordnung des ganzen Fundortes helfen. Ebenso verursacht es ein Problem, dass die anthropologische Analyse bei vielen Gräbern fehlt, was die Identifizierung der Frauenskelette erschwert. Ich bin aber der Ansicht, dass durch all dies die in der Studie aufgeworfenen Fragen nicht wesentlich beeinflusst werden: Mit Hilfe dieser Sammlung kann ich die Veränderungen untersuchen, die sich in dem Bestattungsritus, der weiblichen Ausstattung, in der Repräsentation durch die Beisetzung und Bekleidung zeigen, sowie auch die Frage, wie sich in diese Prozesse die Frauengräber der gepidenzeitlichen Nekropolen einfügen.

\section{Bestattungsritus}

Orientierung. In der ersten Hälfte des 5. Jahrhunderts lässt sich ein vielfarbiger Bestattungsritus beobachten, der mit der Variabilität der Orientierungsangaben gut charakterisiert werden kann (Abb. 2). Bei diesen frühen Gräbern der von mir untersuchten Gruppe stellen die in der Epoche allgemein übliche W-O-Richtung sowie die in der Hunnenzeit typische, auf osteuropäischen Steppeneinfluss erscheinende N-S-Richtung die Mehrheit (je 32,6\%) dar. ${ }^{56}$ Während es die Erstere vor allem in Transdanubien gibt - als Fortsetzung der spätantiken Tradition $-{ }^{57}$ taucht Letztere von Niederösterreich bis in die östliche Hälfte des Karpatenbeckens auf, hauptsächlich in den nördlichen Gebieten. ${ }^{58}$ Die NW-SO-Orientierung $(8,7 \%)$ ist als Variante der W-O-, eventuell der N-S-Orientierung zu betrachten. ${ }^{59}$ In den einstigen sarmatischen Gebieten sind auch weiterhin die S-N- $(10,9 \%)$ und die SO-NW- $(8,7 \%)^{60}$ Orientierung typisch, den früheren Traditionen entsprechend. ${ }^{61}$

In der Periode D2/D3, in der Mitte des 5. Jahrhunderts, wird die W-O-Orientierung weit häufiger (62\%), immer noch mit bedeutender pannonischer Mehrheit (Abb. 3). Östlich und nördlich der Donau zeigen die Orientierungsangaben ein „weniger diszipliniertes“ Bild. Neben der zahlenmäßig wachsenden W-O-Richtung sind O-W sowie NW-SO und SW-NO vielleicht ebenfalls Varianten der W-O-Orientierung. ${ }^{2}$ Das für die Sarmatenzeit typische S-N (Csongrád, Hrtkovci, Laa) bzw. das - hierzu gerechnete - SW-NO sowie das SO-NW (Smolin, Viminacium) gibt es außer im einstigen sarmatischen Gebiet in den Nord- und Südgebieten des Mitteldonauraumes. Eine inter-

\footnotetext{
${ }^{52}$ H. Kelemen 2008, 163; s. noch B. VÁGÓ-BóNA 1976, 196-206.

${ }^{53}$ Über die Chronologie der spätantiken Fundplätze in Pannonien s. VIDA 2011.

${ }^{54}$ Darüber s. im Fall von Scarbantia: ToMKA 2015.

${ }^{55}$ BÓNA-NAGY 2002b, 149-150; NAGY 2005c, 195-197.

${ }^{56}$ Diese Ergebnisse stützen Péter Tomkas frühere Beobachtungen (TOMKA 2001, 165)

${ }^{57}$ Vgl. LÁNYI 1972, 59-64.

${ }^{58}$ Die N-S-Orientierung bringt ein Teil der Forschung mit den Hunnen und den ihnen angeschlossenen Hilfsvölkern in Verbindung. Nach Meinung anderer sind die Wurzeln des Brauchs in der spätsarmatischen und der Tschernjachow-Kultur zu suchen. Darüber ausführlicher: TомKA 2001, 165.
}

${ }^{59}$ Die Fundorte befinden sich in Transdanubien (Regöly, Fonyód, Szabadbattyán).

${ }^{60}$ Zusammenfassend über die SO-NW-Orientierung im Zusammenhang mit dem Grab von Budapest-Sashalom, Zalavár utca s. NAGY 2006, 103-104. Sie erscheint auch bei den frühvölkerwanderungszeitlichen Gräbern von Szob.

${ }^{61}$ Hinzufügen ist jedoch, dass sich die hier beobachteten Relationen modifizieren, wenn man auch die schwer datierbaren Gräber der in der Hunnenzeit weiter benutzten großen S-N-orientierten sarmatischen (z. B. Csongrád-Kenderföldek) und W-O-orientierten spätantiken Gräberfelder (z. B. Csákvár) untersuchen würde.

${ }^{62} \mathrm{O}-\mathrm{W}$ : Jászberény, NW-SO: Mád und Singidunum, SW-NO: Sarovce, Vicemilice bzw. Singidunum, Viminacium. 


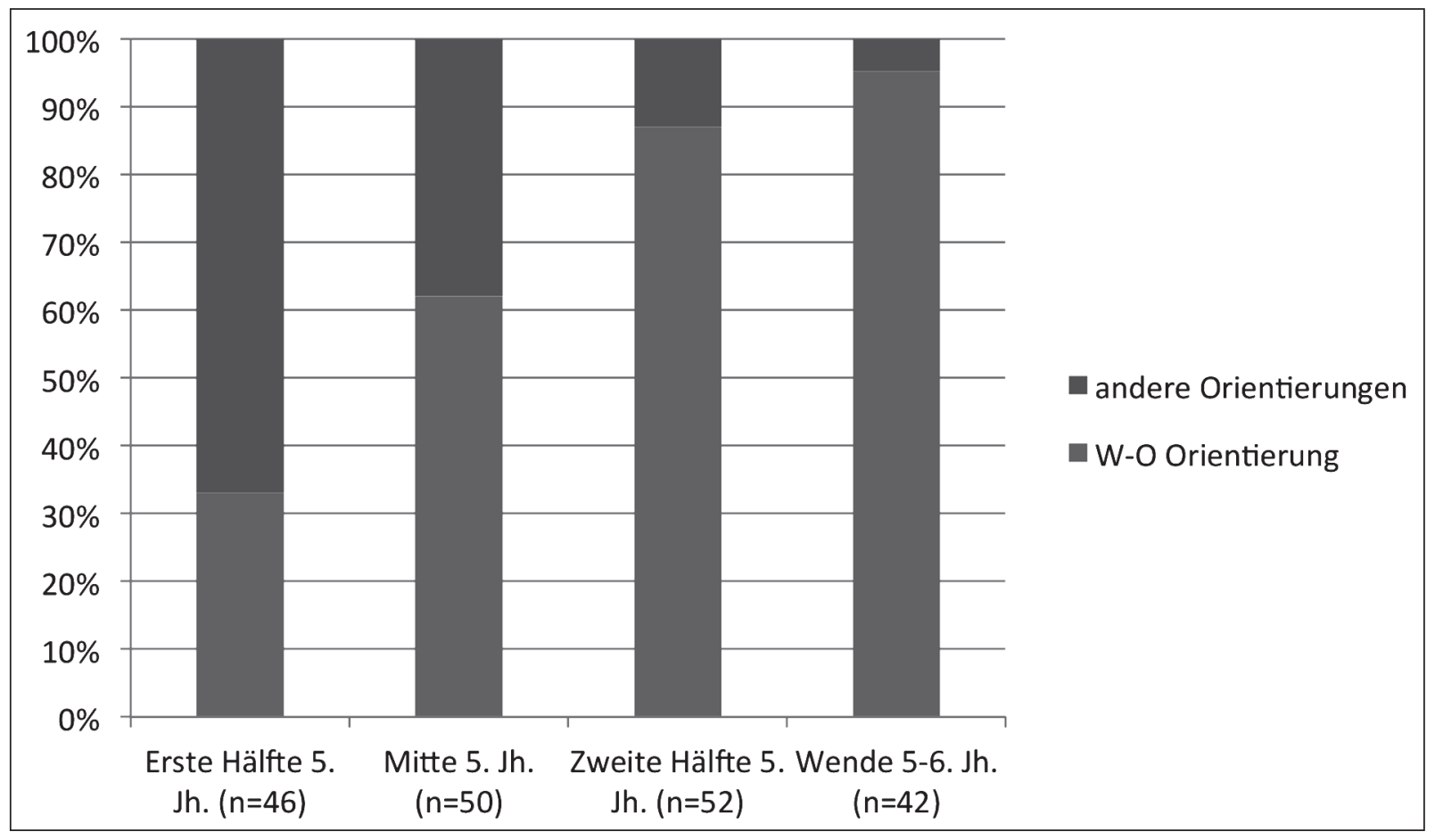

Abb. 2. Orientierung der Gräber aus der ersten Hälfte des 5. Jahrhunderts im Mitteldonaugebiet (aufgrund der beigabenführenden Frauengräber, Tabelle 1)

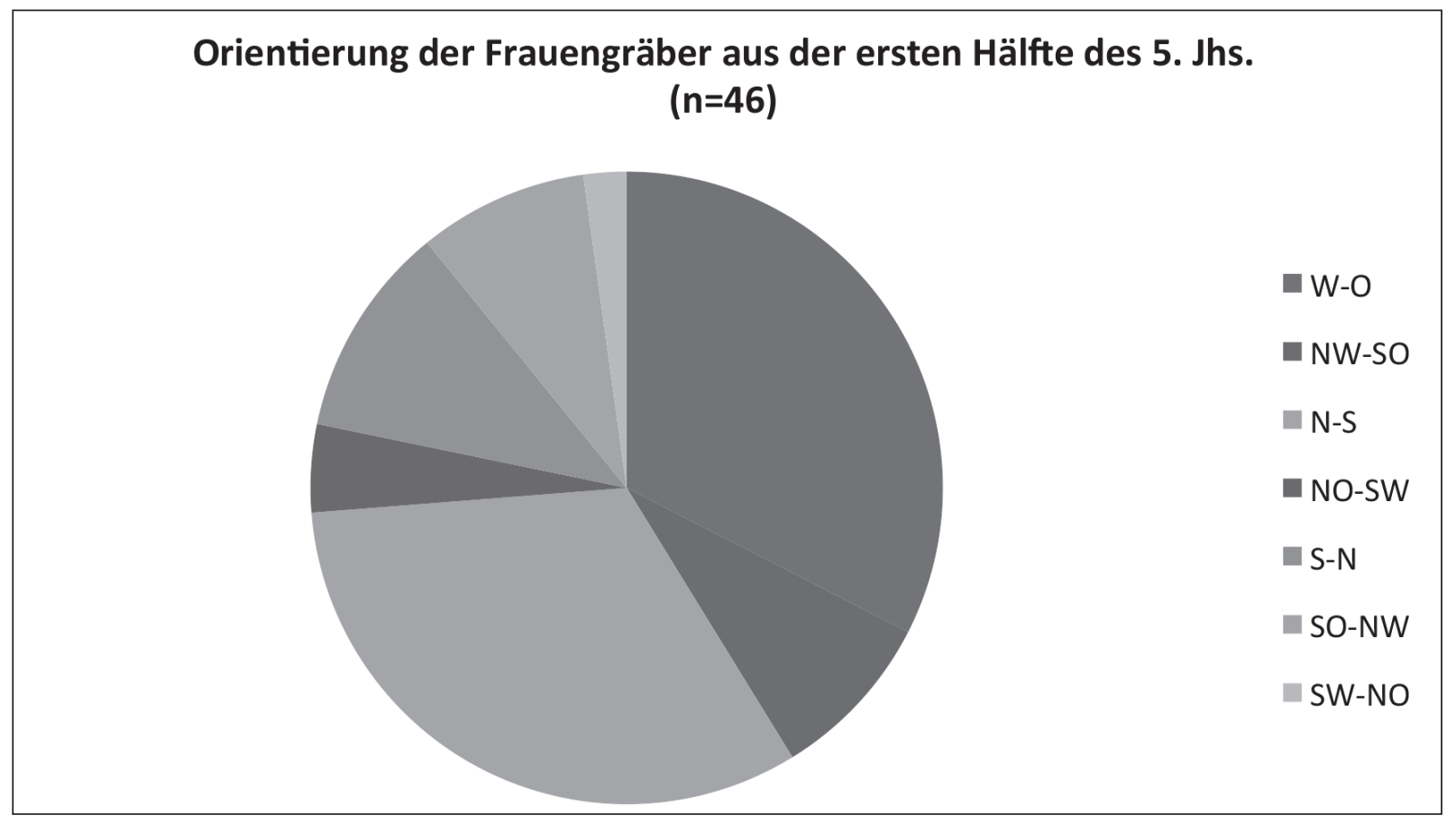

Abb. 3. Die Häufigkeitsverteilung der W-O orientierten Gräber in den verschiedenen Phasen des 5. Jahrhunderts im Mitteldonaugebiet (aufgrund der beigabenführenden Frauengräber, Tabelle 1) 
essante Variante ist die NO-SW-Richtung, die nur in Mezőkövesd-Mocsolyás sowie bei Grab 17 vom Gräberfeld Šarovce festgestellt wurde - wahrscheinlich als eine Variation der hunnenzeitlichen N-S-Orientierung.

In der zweiten Hälfte des 5. Jahrhunderts wird die Ostung der Gräber absolut vorherrschend (87 \%); frühere Traditionen zeigende Ausnahmen sind in Transdanubien die Fundorte Dabronc-Ötvöspuszta (N-S) und ZsibótDomolospuszta (SO-NW). Mehrfach kommt die SW-NO-Orientierung der Gräber an Fundstellen oder in Gebieten vor, in denen die W-O-Richtung allgemein ist, so dass sie deren Variation sein kann. ${ }^{63}$

Beigaben. Die Vereinheitlichung des Bestattungsritus spiegeln auch die ins Grab gelegten Beigaben: Kämme, Spiegel, Gefäße, Spinnwirtel, selten Tierknochen und Grabobolen.

Die Kämme sind auch schon in der ersten Hälfte des 5. Jahrhunderts häufige Beigaben (26,8\%), ${ }^{64}$ damals vor allem in den Gebieten westlich der Donau. Ihr Vorkommen steigt in den einzelnen Phasen ständig, in der untersuchten Gruppe bis zu einem Anteil um 50 \% (Abb. 4.). Die Rolle der Spiegel zeigt eine gerade umgekehrte Entwicklung: Während ihr Anteil in der ersten Hälfte und der Mitte des Jahrhunderts etwa mit den Kämmen übereinstimmt ( $29 \%$ und $31 \%$ ), sind sie nach ständigem Rückgang an der Wende des 5./6. Jahrhunderts nur noch ausnahmsweise Beigaben (Abb. 5.).

Ein ähnlicher Vorgang - d. h. ein drastischer Rückgang - ist auch bei den Gefäßbeigaben zu beobachten: In der ersten Hälfte des 5. Jahrhunderts kommen sie in jedem zweiten Grab vor ${ }^{65}$ (eventuell sogar zwei, in Grab 2 von Untersiebenbrunn sogar vier Glas- oder Keramikgefäße), ${ }^{66}$ dagegen haben sie in der zweiten Jahrhunderthälfte und an der Wende des 5./6. Jahrhunderts nur noch eine Häufigkeit von 9-12 \% (Abb. 6.). ${ }^{67}$ Mit dem Brauch der Gefäßbeigaben kann auch ein spezieller Ritus verbunden werden, bei dem der Krug oder Becher in der Grabgrube nahe am Kopf, in einer kleinen Nische steht. Für diese Erscheinung gibt es, wenn auch in einem breiten geographischen Streifen, nur im Nordteil des Karpatenbeckens Beispiele - eine ähnliche Tendenz konnte auch bei der Untersuchung der N-S-Orientierung beobachtet werden. ${ }^{68}$ Die Tierknochen als Reste von Speisebeigaben sind ausgesprochen selten; gegenüber dem ca. 10-prozentigen Vorkommen in der Hunnenzeit verschwindet sie bis zum Ende des 5. Jahrhunderts fast völlig.

Interessant gestaltet sich der Brauch der Spindelbeigabe: Der Anteil der Spinnwirtel wächst von der in der ersten Hälfte und Mitte des 5. Jahrhunderts beobachteten 15-prozentigen Häufigkeit ständig (auf $25 \%$ und dann $43 \%$ ). Ihre Bedeutung kommt auch darin zum Ausdruck, dass häufig mehrere Spinnwirtel in den Gräbern gefunden wurden.

Den Grabobolus gibt es am Beginn der Epoche im von mir untersuchten Muster nicht, von der Mitte des Jahrhunderts an erscheint er jedoch. Bei seinem Gebrauch lässt sich eine leichte Zunahme, 4-6-prozentige Häufigkeit feststellen.

Die obigen Werte (Prozentanteile) würden sich bei einer Untersuchung der gesamten Bevölkerung - im Vergleich zu den Frauen- und Mädchengräbern mit mindestens zwei Fundobjekten - selbstverständlich modifizieren (verringern), doch es lassen sich auch so gewisse Tendenzen gut verfolgen.

\section{Künstliche Schädeldeformation}

Individuen mit künstlich deformiertem Schädel sind bestimmende Elemente des anthropologischen Bildes im 5. Jahrhundert: Im untersuchten Muster zeigt sich in der ersten Hälfte des 5. Jahrhunderts ein Anteil von $29 \%$, im mittleren Jahrhundertdrittel ein herausragend hoher Wert, 37,5 \%, dann in der zweiten Hälfte und am Ende des

\footnotetext{
${ }^{63}$ Das ist auch schon bei den spätrömischen pannonischen Gräberfeldern zu beobachten: LÁNYI 1972, 63.

${ }^{64}$ In die folgenden Prozentberechnungen habe ich auch das Material der gestörten bzw. mangelhaft beobachteten Gräber einbezogen.

${ }^{65}$ Das entspricht dem Bild, das man aus dem spätrömischen Pannonien und dem sarmatenzeitlichen Barbaricum kennt; s. LÁNYI 1972, 112-122; KULCSÁR 1998, 66-69.

${ }^{66}$ Ein Beispiel für Gräber mit vier Gefäßen ist noch das Jungengrab von Árpás-Dombiföld (TOMKA 2001).

${ }^{67}$ Für weitere Untersuchungen im Zusammenhang mit den Gefäßbeigaben siehe die Kartierung der Häufigkeit von Gefäßen, die
}

\begin{abstract}
an den Füßen bzw. am oberen Körperteil oder Kopf abgesetzt wurden. Diese Frage untersuche ich hier nicht im Einzelnen, aber es scheint, dass das für die spätrömische und Sarmatenzeit typische Ritenelement - das Gefäß an den Unterschenkel oder Fuß zu stellen - allmählich von der Lage des Gefäßes am Kopf abgelöst wird. Eine wichige Frage ist auch, welche Typen von Gefäßen (Becher, Krüge, Töpfe) in erster Linie als Grabbeigaben vorkommen.

${ }^{68}$ Diese Beobachtung unterstützt die frühere Meinung von B. Novotný, dass die Sitte nicht von römischer, sondern von östlicher Herkunft ist (NovotNÝ 1976, 82-84).
\end{abstract}




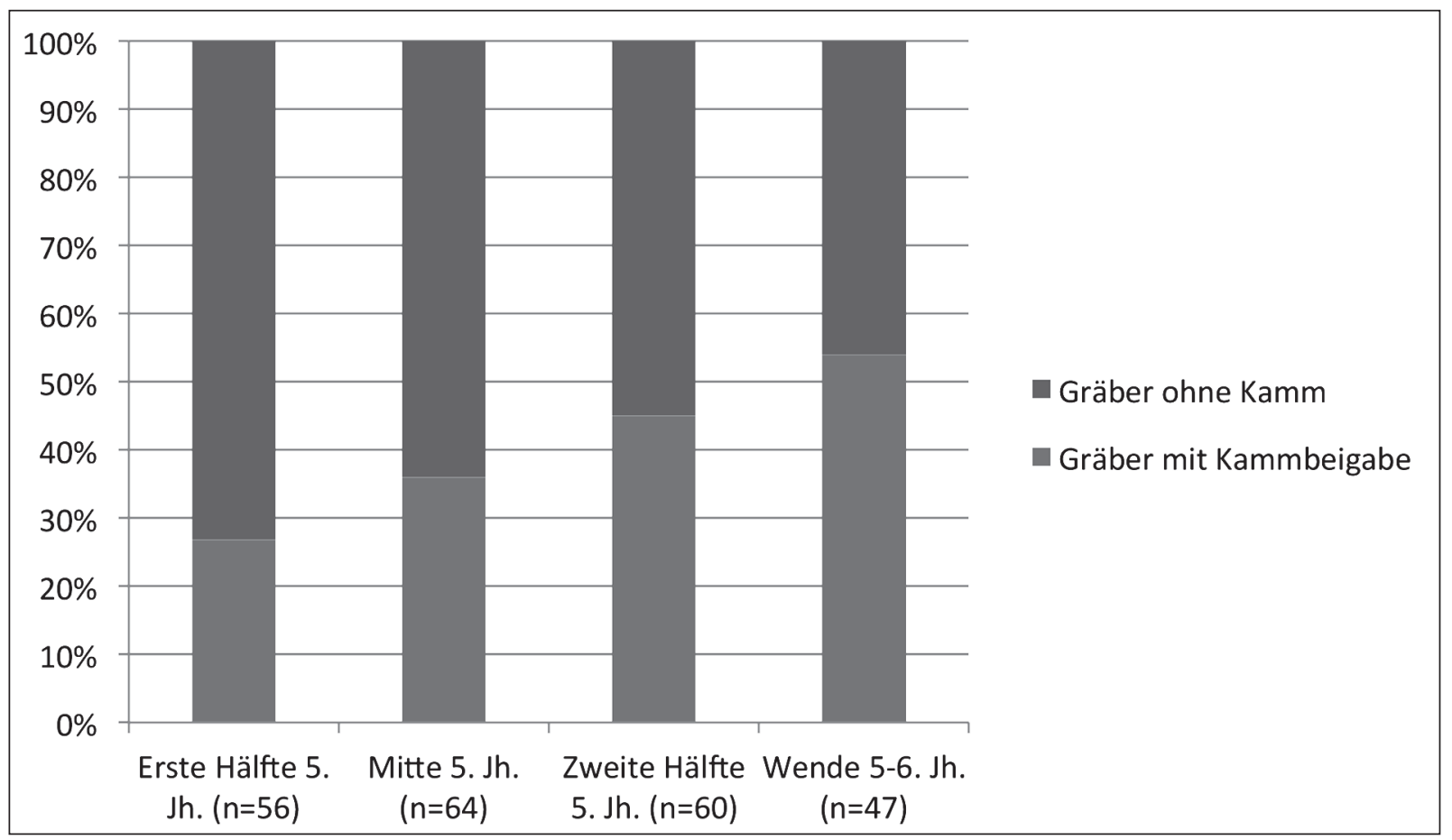

Abb. 4. Die Häufigkeitsverteilung der Kammbeigabe in den verschiedenen Phasen des 5. Jahrhunderts im Mitteldonaugebiet (aufgrund der beigabenführenden Frauengräber, Tabelle 1)

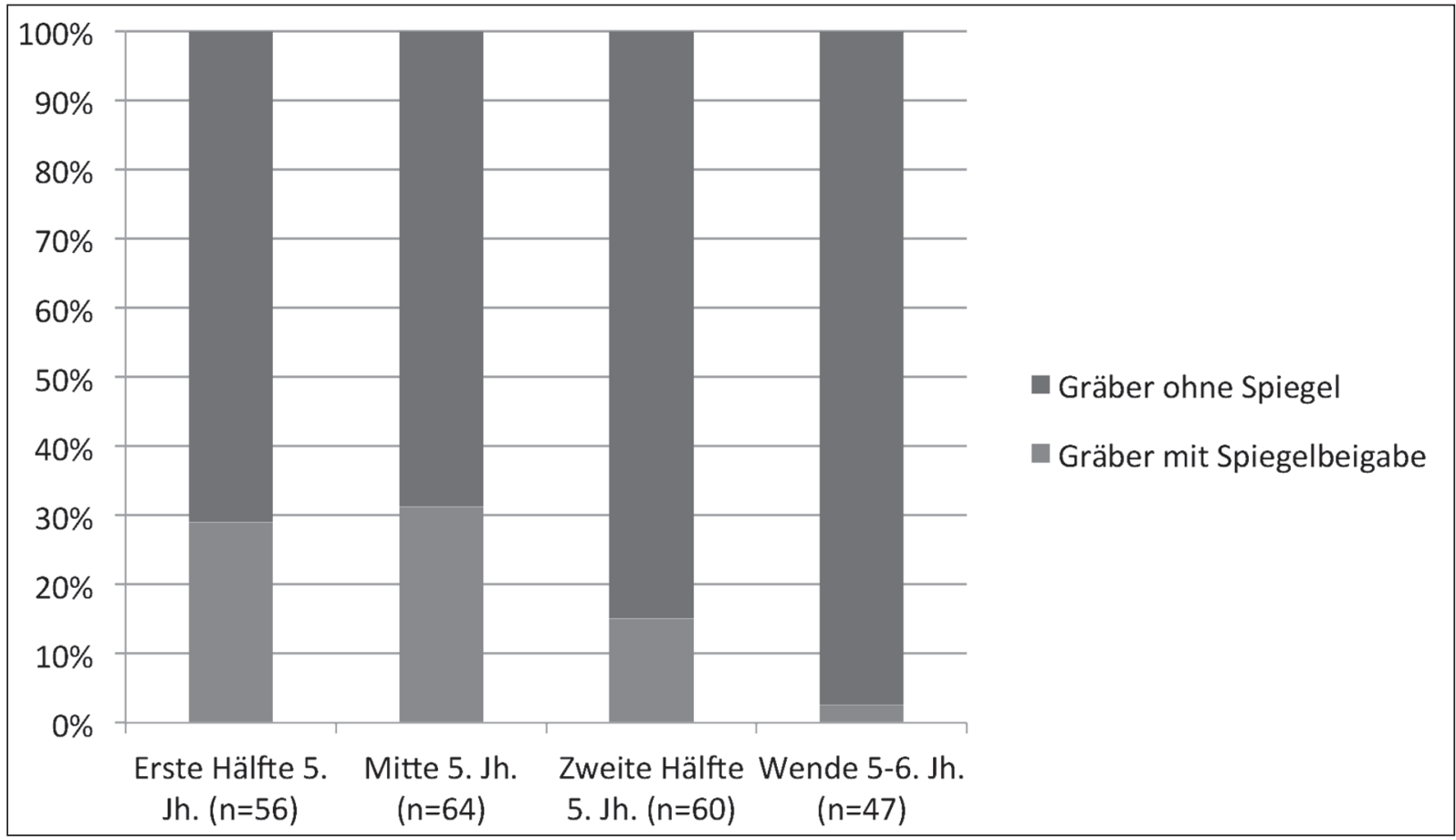

Abb. 5. Die Häufigkeitsverteilung der Spiegelbeigabe in den verschiedenen Phasen des 5. Jahrhunderts im Mitteldonaugebiet (aufgrund der beigabenführenden Frauengräber, Tabelle 1) 


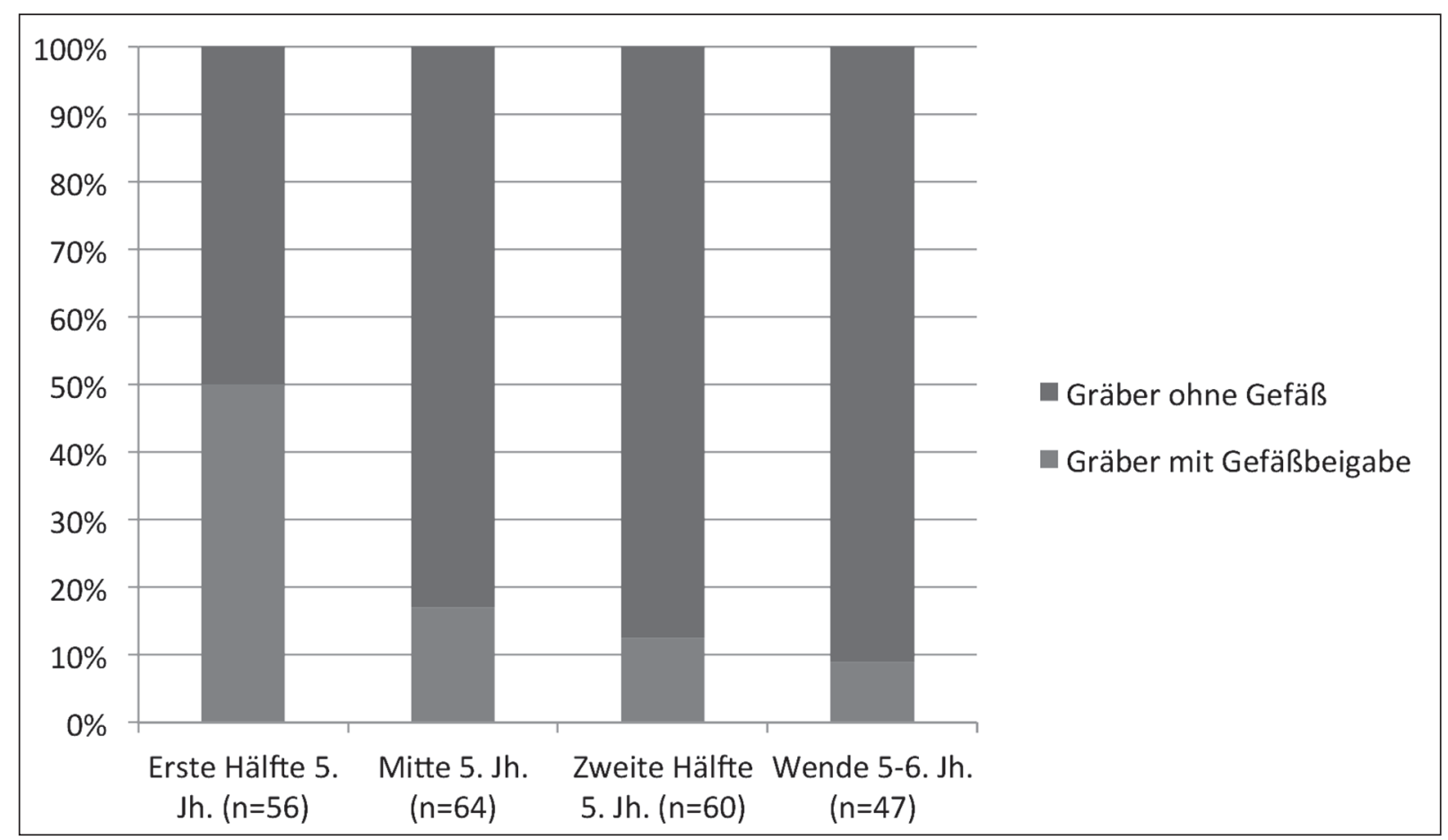

Abb. 6. Die Häufigkeitsverteilung der Gefäßbeigabe in den verschiedenen Phasen des 5. Jahrhunderts im Mitteldonaugebiet (aufgrund der beigabenführenden Frauengräber, Tabelle 1)

Jahrhunderts eine leicht sinkende Tendenz ( $25 \%$ und $29 \%$ ) (Abb. 7) ${ }^{69}$ In diesem Zusammenhang muss ich bemerken, dass anders als andere Bräuche und Modeerscheinungen die Deformierung der Schädelform - abhängig vom Sterbealter des Einzelnen - ,auf verzögerte Weise“ erhalten blieb. Die bei ihrer Entstehung (im Fall der untersuchten Individuen meist wahrscheinlich noch in oder unmittelbar nach der Hunnenzeit) als progressiv geltende, die kulturellen Eigenheiten der Periode spiegelnde Schädeldeformation konnte im Laufe des Lebens des Einzelnen sogar ihre frühere Bedeutung verlieren. ${ }^{70}$ Die Untersuchung der in der Kindheit Verstorbenen kann dabei helfen, auf die „Lebendigkeit“ des Brauchs in einer engeren Periode zu folgern. Für diese Untersuchung ist das von mir analysierte Muster nicht geeignet, denn es enthält ja nur die Frauengräber bzw. Kindergräber mit zur Frauenkleidung gehörenden Gegenständen. Aber aus Tabelle 1 geht auch hervor, dass sowohl in Periode D2/D3 als auch D3 Kindergräber mit deformiertem Schädel noch vorkamen, vor allem in der Bevölkerung von Keszthely, Viminacium und Mözs. ${ }^{71}$ Über das in den gepidischen Reihengräberfeldern gefundene Bild berichte ich im folgenden Kapitel.

Eine spezielle Forschungssituation bedeutet, dass wir die betreffenden Bestattungen durch solche Erscheinungen und Filter untersuchen, die die Bestatteten selbst nicht beeinflussen konnten: Die komplizierte und langwierige Umgestaltung der Schädelform geschah noch im Säuglingsalter, aufgrund der Entscheidung der Eltern bzw. der Umgebung des Kindes, von da an war sie aber unabhängig vom Schicksal des Einzelnen oder der Veränderung der Umgebung. ${ }^{72}$ Die Art der Bestattung wie auch die Totenkleidung wurden nach dem Tod festgelegt und ausgewählt.

${ }^{69}$ Bei diesen Berechnungen berücksichtigte ich nur die Gräber, von denen mir anthropologische Beobachtung zur Verfügung stand.

${ }^{70}$ In dieser Hinsicht ist die viel umstrittene Frage irrelevant, ob die Schädeldeformation ,nur“ eine Modeerscheinung oder ein Symbol tieferen Inhaltes war. Die physischen Körpermodifizierungen schaffen einerseits einen Unterschied in solchen Gesellschaften, in denen es keinen echten biologischen Unterschied gibt, andererseits, als gerade umgekehrter Prozess, mochten sie einen Zusammenhalt in einem polyethnischen Medium symbolisieren. In der Hunnenzeit kommt die Verformung bei Individuen mit sehr unterschiedlichem physischen Aussehen und gesellschaftlichem Status vor - es wird also eher die letztere, den Zusammenhalt betonende Bedeutung im Vordergrund gestanden haben. Vgl. HAKEnBECK 2009, 67; KNUdson-STOJANOWSKI 2008, 411.

${ }^{71}$ Siehe noch SzÉCSÉNYI-NAGY 2008; TOBIAS-WILTSCHKESCHROTTA-BINDER 2010.

${ }^{72}$ Siehe westeuropäische Bestattungen erwachsener Frauen mit deformiertem Schädel, die in Einzelfällen nachweislich der Migration zuzuschreiben sind (HAKENBECK 2009). 


\section{Schmuck und Kleidung}

Die Kleidung untersuche ich an dieser Stelle vor allem aus der Sicht der Funktion und Kombination der archäologisch bewertbaren Kleidungsbestandteile bzw. deren Veränderungen: Mit all dem möchte ich in erster Linie gewisse kulturelle Zusammenhänge zwischen der Hunnen- und der Gepidenzeit beleuchten. ${ }^{73}$ Parallel mit der Vereinheitlichung des Ritus entsteht auch in der Frauenkleidung eine recht homogene Mode, die in Phase D2/D3 ihre vollständige Form erhält, in Phase D3 weiter in Blüte steht und auch am Ende des 5. und Anfang des 6. Jahrhunderts eindeutig zu verfolgen ist ( $A b b .11-12$ ). Ihre am häufigsten vorkommenden Elemente (zusammen mit den gestörten Bestattungen und Gräbern mit unbekannten Fundumständen) sind:

- Perlen in verschiedenen Funktionen (insgesamt $78 \%$ )

- Fibel $(70 \%)$

- Gürtelschnalle (52,5\%)

- Ohrring (überwiegend mit Polyederknopf) (40,1\%)

- Armring (mehrheitlich mit verbreiterten Enden) (15,5\%)

- Fingerring (12,3\%)

- Pinzette oder Toilettengarnitur (5\%)

Ohrringe. Die überwiegende Mehrheit der Ohrringe bilden die Typen mit Polyederknopf. Das Tragen von Ohrring ist ein wichtiges Charakteristikum bis ans Ende der Epoche (über $30 \%$ ); herausragende Werte (ca. 45 \%) finden sich in den Perioden D2/D3 und D3.

Perlen, Anhänger. Die Perle ist - in wechselnden Formen - einer der wichtigsten Bestandteile der Kleidung des 5. Jahrhunderts. Aufgrund ihrer Lage im Grab können die Perlen in folgenden Funktionen auftreten: Kopfschmuck, Halskette, von der Fibel herabhängende Perle (?), Brustschmuck (?), Armband, Gürtelschmuck, Zier an einem vom Gürtel herabhängenden Band (Gürtelgehänge), Taschenzier, Verzierung am unteren Rand des Kleides.

Die Halskette aus Perlen war in den betreffenden Perioden gleichmäßig vorhanden, zumindest in der Hälfte der hier untersuchten Frauengräber; ein herausragender Wert (73,8 \%) zeigt sich in der Periode D2/D3. Um den Hals konnte eine lange Kette ${ }^{74}$ getragen werden oder auch eine eng in mehreren Reihen gewundene. ${ }^{75}$ Häufige Erscheinung ist, dass die Halskette eher aus kleinen Perlen besteht, eventuell mit einigen größeren Perlen oder Anhängern in der Mitte, und dass Fibel, Brustschmuck, Gürtel und Tasche mit großen Bernstein- und Glasperlen verziert werden. ${ }^{76}$

In einigen Fällen ist auch die Möglichkeit zu erwägen, dass die Perlen zu einem zweiseitig auf der Schulter oder dem Brustkorb (mittels Fibel oder aufgenäht) befestigten Brustschmuck gehörten ${ }^{77}$ oder halbseitig von der Schulter oder Fibel herabhingen: Dann finden sich am unteren Teil des Brustkorbes, in der Nähe der Fibel oder in deren Linie, ein paar größere Perlen, deutlich getrennt von der Halskette. ${ }^{78}$

Der Anteil der in der Körpermitte ${ }^{79}$ (innen am Unterarm, im Bauchbereich, auf dem Becken oder am Oberschenkelknochen) gefundenen, wahrscheinlich den Gürtel, das vom Gürtel herabhängende Band, fallweise die

${ }^{73}$ Vgl. BRATHER 2002, 390-412. Ich beschäftige mich also nicht mit so wichtigen Fragen wie dem eventuellen Unterschied zwischen „Alltagskleid“ und ,Totenkleid“ oder der lebensaltergemäß unterschiedlichen Repräsentation (alterspezifische Kleidungen).

${ }^{74}$ Im einsamen Frauengrab von Budapest-Sashalom aus der ersten Hälfte des 5. Jahrhunderts lag eine unübliche, sehr lange Halskette aus wechselnden Perlen (71 Perlen, $72 \mathrm{~cm}$ lange Kette). Ihre detaillierte Analyse s. NAGY 2006, 106-107. Auch im Grab von Slimnic (zweite Hälfte 5. Jh.) lagen mindestens 170 Perlen um den Hals; die Größeren befanden sich in der Mitte der Kette.

${ }^{75}$ Mezőkövesd-Mocsolyás 2, Bodrogmonostorszeg 1898/2, Szekszárd-Palánk 217.

${ }^{76}$ Die Verwendung der großen Bernsteinperlen war sehr abwechslungsreich; wir kennen auch längere Halsketten mit gestaucht kugelförmigem Bernstein in größeren Mengen (Budapest-Zalavár u., Laa a. d. Thaya - 35 Bernsteinperlen).

${ }^{77}$ MARTIN 1995, 670-673.

${ }^{78}$ Siehe z. B. Untersiebenbrunn Grab 2, Mitterhof Grab 3, Mezőkövesd-Mocsolyás Grab 2, Ártánd-Lencsésdomb Grab 1, Szen-
tes-Kökényzug Grab 81, Pusztataskony-Ledence Fo. 1, Grab 298. Im Fall von Szentes nimmt D. Csallány an, dass die Perlen zur Fibel gehörten (CsAlLÁNY 1961, 38). Emese Lovász erwähnt bei der Analyse des Frauengrabes von Mezőkövesd auch die Möglichkeit, dass die Perlen von einem auf den Schulterteil des Kleides genähten Riemen herabhingen - aufgrund des Fundmaterials alemannischer Frauengräber (LovÁsZ 1999, 259; s. noch MARTIN 1995, 654). Diese Situation unterschied ich in der Tabelle nicht von anderen, in der Körpermitte beobachteten Perlenanordnungen, weil ihre Einordnung und Trennung vorläufig unsicher ist.

${ }^{79}$ Dies ist offensichtlich eine Vereinfachung, aber es gibt wenige gut beobachtete oder leicht interpretierbare Fälle. Auch die niedrige Zahl der mit Perlen zusammen gefundenen Textil- oder Lederreste erschwert die Interpretation. Nicht immer ist es eindeutig, ob die wenigen Perlen auf dem unteren Brustkorbteil zum zuvor genannten „Brustschmuck“ oder eventuell zum Gürtel gehören. Des Weiteren wissen wir nicht, wie die Perlen eigentlich befestigt waren. Von den Ausgrabungsbeobachtungen und der Untersuchung der Abnutzungsspuren sind weitere Informationen zu erhoffen. 


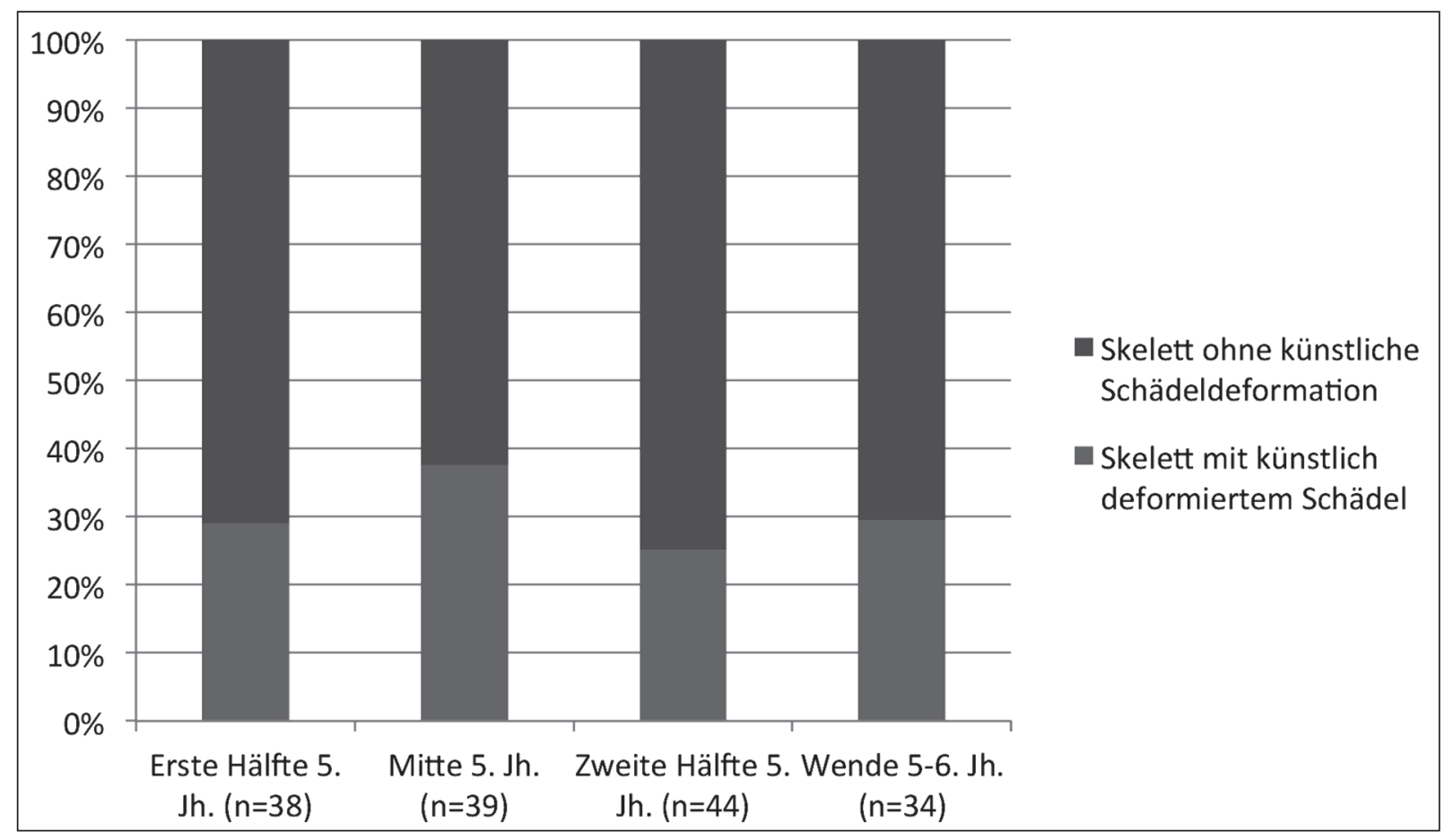

Abb. 7. Die Häufigkeitsverteilung der künstlich deformierten Schädel in den verschiedenen Phasen des 5. Jahrhunderts im Mitteldonaugebiet (aufgrund der beigabenführenden Frauengräber, Tabelle 1)

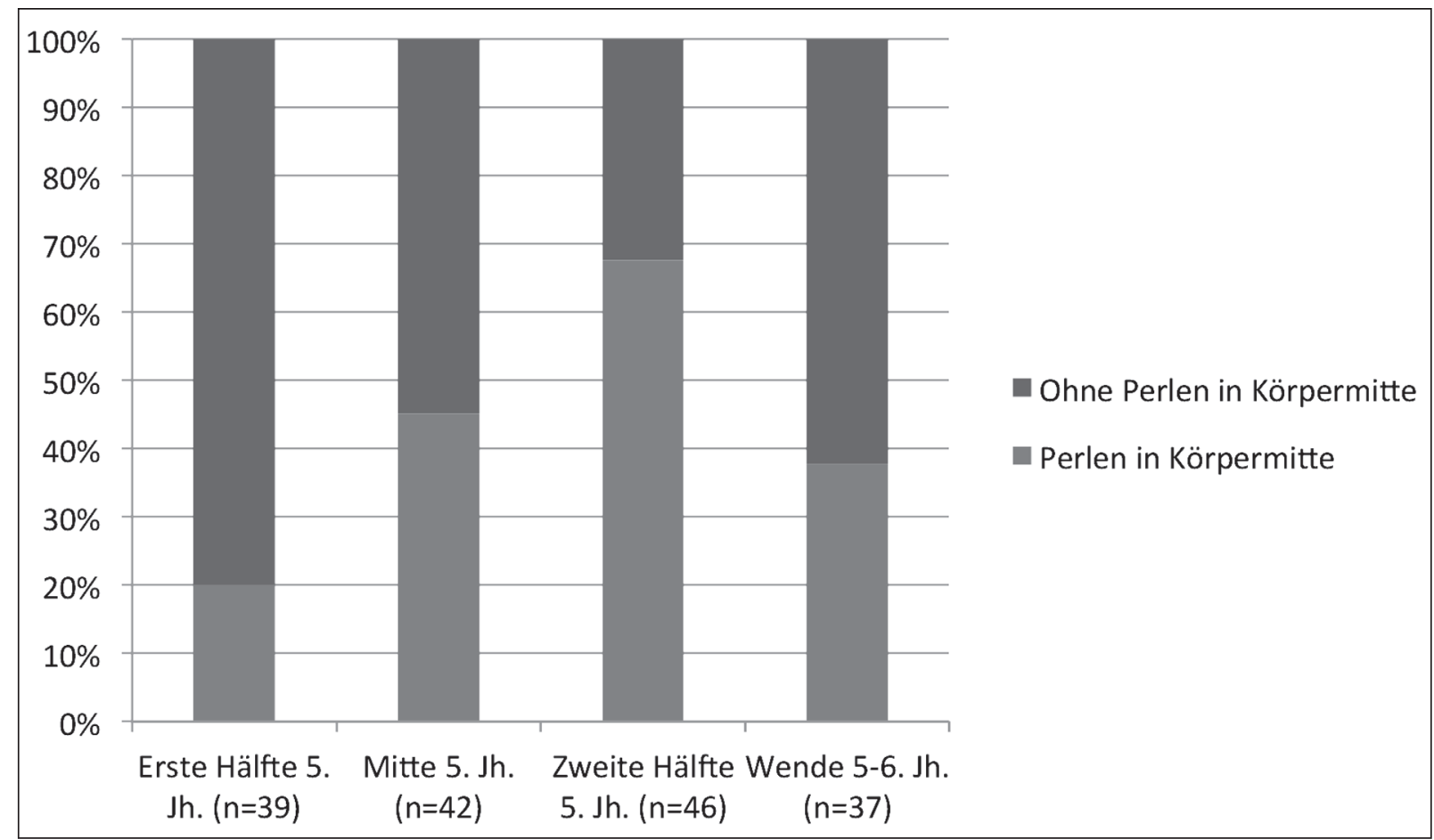

Abb. 8. Die Häufigkeitsverteilung der Perlen in der Körpermitte (Unterarm, Bauch, Becken, Schenkelknochen) in den verschiedenen Phasen des 5. Jahrhunderts im Mitteldonaugebiet (aufgrund der beigabenführenden Frauengräber, Tabelle 1) 
Tasche zierenden Perlen ist in der ersten Jahrhunderthälfte relativ niedrig (20\%), steigt aber in der Mitte und zweiten Hälfte des Jahrhunderts sprunghaft an (45\% und $61 \%)$. Sie werden zu einer der wichtigsten Modeerscheinungen, dann wird ihr Anteil wieder geringer (38\%) (Abb. 8). Die im mittleren Drittel des Körpers gefundenen Perlen kommen gleicherweise in Gräbern mit auf beiden Schultern, schräg oder mittig getragenen Fibeln oder (in Gräbern) ohne Fibeln vor ${ }^{80}$ Häufig ist zu beobachten, dass sich einige Perlen, meist 3-7 größere, innen am Arm, an der Hüfte oder auf dem Becken - entweder links- oder rechtsseitig - finden (z. B. mehrere Gräber von Viminacium-Burdelj, Tápé-Széntéglaégetö, Szentes-Kökényzug Grab 66). In den Gräbern von Tiszalök, Hács-Béndekpuszta (Grab 20), Hajdúnánás (Grab 829) und Balatonszemes (Grab 150) kann das von der Körpermitte nach unten oder entlang der Beine laufende, perlenbenähte Band - oder Schnur mit angereihten Perlen - verfolgt werden. Auch in diesen Gräbern sind unterschiedliche Fibelanordnungen zu beobachten: Die Perlenbänder wurden demnach nicht durch eine Fibel befestigt, sondern hingen eher vom Gürtel herab.

In vier Gräbern gibt es Beispiele der am Fuß liegenden Perlen; doch kann man in diesen Fällen nicht eindeutig entscheiden, ob es sich um ein mit Perlen benähtes Kleid oder eine dort abgelegte Schmuckbeigabe (z. B. ein Totengeschenk) handelt. ${ }^{81}$ Ebenfalls selten sind Bestattungen, bei denen das Tragen eines Armbandes beweisbar ist. Die am Schädel, nach dem Aufnehmen des Schädels in großen Mengen gefundenen kleinen Perlen deuten auf ein Haarnetz oder perlenbenähtes Kopftuch hin. ${ }^{82}$

Sowohl zur Halskette als auch zum Gürtel und Armband können Metallanhänger (axt- und halbmondförmige Anhänger, Schellen) und Tierzähne - verschiedene Gegenstände auch mit Amulettcharakter - gehören. Häufig sind die auf einen Drahtring gezogene größere Perle, Schelle, eventuell Hirschgrandel ${ }^{83}$ oder axtförmige Anhänger, vor allem in der Periode D2/D3, seltener in D3 ${ }^{84}$ Der Drahtring kann auch als Befestigung des Toilettenzubehörs gedient haben.

Einige gut beobachtete Funde mit reichem Perlenbestand sind besonders geeignet, die variable Erscheinung der Perlenmode darzustellen. Es gibt Bestattungen, in denen die Perlen an drei-vier verschiedenen Stellen beobachtet wurden: am Hals, in der Körpermitte, an den Unterschenkeln oder den Füßen. ${ }^{85}$ Herausragend reich ist das Perlenmaterial der Gräber von Hrtkovci-Vranja, Bački Monostor, Kapolcs und Smolin. Bei der Menge der Perlen zeigt sich ein großer Unterschied: In einzelnen Bestattungen kommen sogar mehrere Hundert Perlen vor (Hrtkovci-Vranja, Bački Monostor, Kapolcs 1, Hajdúnánás 441), anderswo gibt es nur ein oder zwei Perlen am Hals oder auf dem Becken.

Im Zusammenhang mit den Perlen halte ich es für wichtig, noch einmal hervorzuheben, dass die Kleidungsergänzungen in der Körpermitte, wahrscheinlich vor allem am Gürtel, in der Mitte und zweiten Hälfte des 5. Jahrhunderts sehr bedeutungsvoll wurden: Das zeigen die Perlen im mittleren Drittel des Körpers und die auf Metallringe gezogenen Anhänger gleicherweise. ${ }^{86}$

${ }^{80}$ Zwischen der Fibelanordnung und den Perlen der Körpermitte/Oberschenkel ist demnach kein solcher Zusammenhang festzustellen, wie er in der Forschung der Merowingerzeit erwogen wurde; vgl. MARTIN 1995, 654-655.

${ }^{81}$ Siehe Bodrogmonostorszeg 1898/6, 1901/1, Kapolcs Grab 1 sowie das nicht in die Tabelle aufgenommene Grab 20 von Mözs (SAlamon-Lengyel 1980, 98). In Bodrogmonostorszeg und Mözs fanden sich zusammen mit den Perlen durchbohrte Tierzähne und Schellen. Diese Gegenstände kommen anderswo am Hals oder an der Hüfte vor (z. B. Mártély-Szépfü: NAGY 2005d, 97).

${ }^{82}$ Siehe Szurdokpüspöki. In Szekszárd-Palánk Grab 217 gehörten angeblich auch Metallanhänger zum Kopfschmuck.

${ }^{83}$ RÁCZ-DARÓCZI-SZABÓ 2016.

${ }^{84}$ Nach Max Martins Feststellung kommen die auf Drahtringe gezogenen Gegenstände anfangs eher auf dem Brustkorb vor (,Gehänge des Brustschmucks“), später am von der Mitte herabhängenden Band (,mittlere Gehänge“) (MARTIN 1995, 670-673, 675, 678). Leider gibt es so wenige gut dokumentierte Fälle im Karpatenbecken, dass sich derartige Gesetzmäßigkeiten nicht beobachten lassen, aber die Lage auf dem Brustkorb ist tatsächlich eher für die früheren Gräber typisch. Beim Grab 32 von Smolin (D2/D3) werden die auf Draht gezogenen Perlen als „Kleiderschmuck“ erwähnt (TEJRAL 2005a, 162).

In Singidunum Grab 63 (D2/D3) lagen die Bernsteinperlen am Drahtring auf dem Brustkorb. In Viminacium-Više grobalja Grab 1461 (D2/ D3) hing die Schelle an einem längeren Draht vom Gürtel herab. In Bački Monostor Grab 1896/6 lagen an den Füßen, in Grab1901/1 am Becken und auch an den Füßen vom Ring herabhängende Schellen und Perlen (D2/D3). In Balatonszemes (Grab 268) waren auf dem Drahtring am Gürtel Schelle und Perle (D3) befestigt. Der Wechsel Brustkorb-Gürtel kann auch bei anderen Gegenständen, so bei Amuletten, Bullen, beobachtet werden: VIDA 1995, 258.

${ }^{85}$ Beispielsweise Hals, Körpermitte, Fuß: Bodrogmonostorszeg 1898/6 und Smolin; Oberkörper und Fuß: Kapolcs 1; Hals, Unterarm, Körpermitte, Knie: Hrtkovci-Vranja. Balatonszemes 268: Perlen am Hals, Gürtel und auch auf der Tasche.

${ }^{86}$ Darüber in weiterem Zusammenhang, über die kaiserzeitlichen und völkerwanderungszeitlichen Vorgänger des merowingerzeitlichen Frauengürtels: B. DÜBNER-MANTHEY: Die Gürtelgehänge als Träger von Kleingeräten, Amuletten und Anhängern symbolischer Bedeutung im Rahmen der frühmittelalterlichen Frauentracht. Archäologische Untersuchungen zu einem charakteristischen Bestandteil der weiblichen Tracht. Dissertation, Freie Universität Berlin. Berlin 1987, 129-136. 


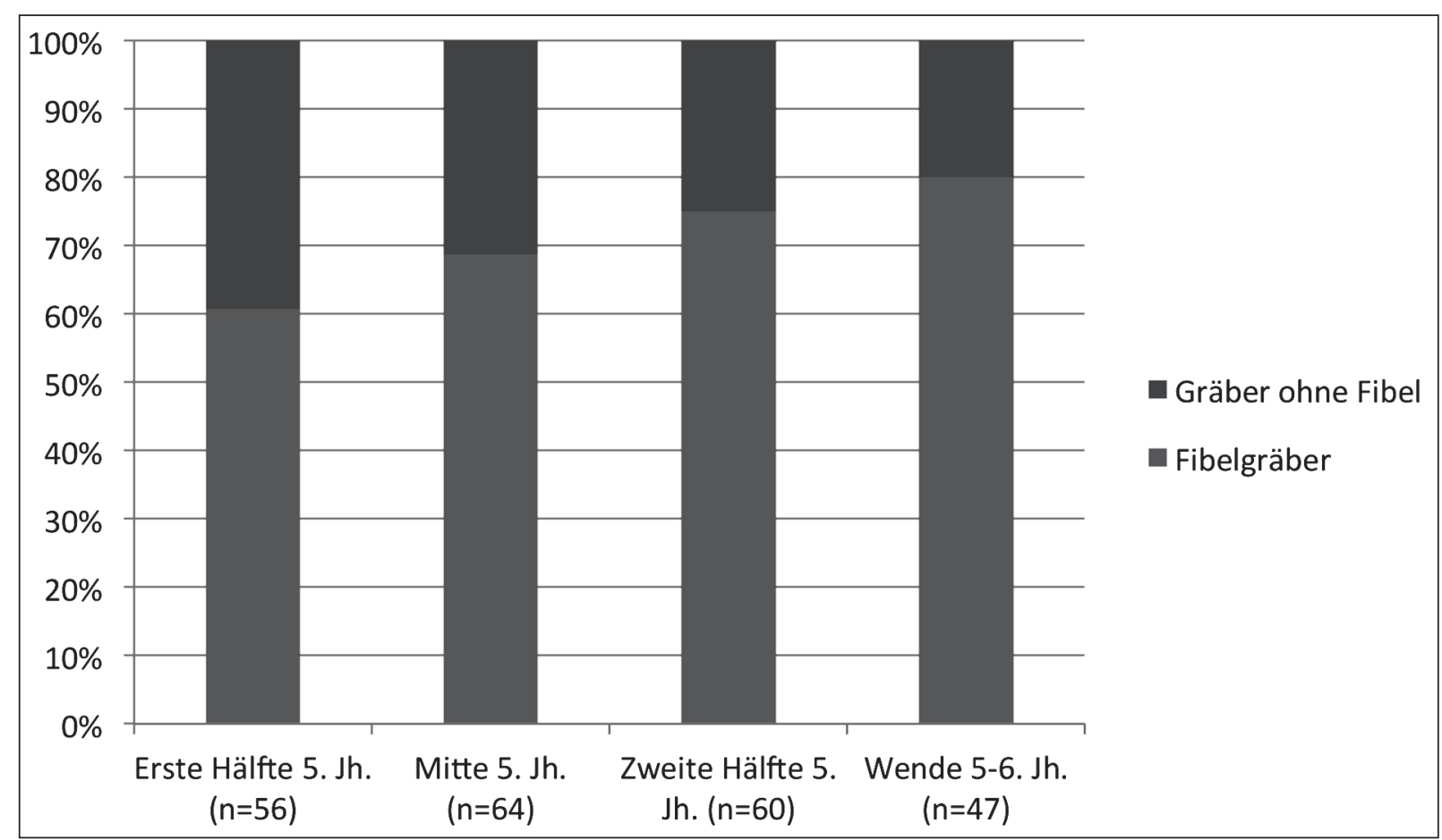

Abb. 9. Die Häufigkeitsverteilung der Fibelgräber in den verschiedenen Phasen des 5. Jahrhunderts im Mitteldonaugebiet (aufgrund der beigabenführenden Frauengräber, Tabelle 1)

Fibel, Kleidernadel. Die Fibel ist nach den Perlen das wichtigste Kleidungselement; sie ist bei ca. $70 \%$ der zumindest zwei Gegenstände enthaltenden Frauengräber des 5. Jahrhunderts - auch die nicht geschlossenen Fundkomplexe mitgerechnet - vorhanden (Abb. 9). Bei der Untersuchung der Anordnung der Fibeln/Kleidernadeln ${ }^{87}$ kann festgestellt werden, dass in der ersten Hälfte des 5. Jahrhunderts (65,2 \%) und in seiner Mitte (79,1\%) das auf beiden Schultern oder beiderseits am oberen Teil der Brust geheftete Kleid dominiert, das in der zweiten Hälfte und am Ende des Jahrhunderts immer seltener wird (41,9 \%, dann 20,7 \%). ${ }^{88}$ In der zweiten Hälfte des 5. Jahrhunderts erscheint ,schlagartig“ die im Bauchbereich getragene Fibel - an verschiedenen Orten des Karpatenbeckens,$-{ }^{89}$ die bis zur Jahrhundertwende die häufigste Art wird, die Kleidung zusammenzuhalten (32,3\% und später 44,8 \%). ${ }^{90}$ Außerdem ist auch das in der Mitte des Brustkorbs festgesteckte Kleid häufig: In der zweiten Hälfte bis ans Ende des 5. Jahrhunderts weist seine Verwendung einen leicht steigenden Anteil auf (17,4-24,1 \%). Diese Trageweise hat auch territorielle Bedeutung, denn sie wird vor allem in einstigen römischen (Viminacium, Singidunum) und in den gepidischen Gebieten verwendet. Die auf einer Schulter bzw. die am Oberteil des Brustkorbs schräg zusammengefasste Bekleidungen sind selten; Erstere gibt es in der ersten Hälfte der Epoche, Letztere in der zweiten. Leider ist der Anteil der unbekannten Fibelstellungen wegen der vielen gestörten Gräber bzw. der Gräber mit ungeklärten Fundumständen sehr hoch, sowohl der der paarweisen als auch der einzelnen Fibeltrageweise. (Abb. 10.)

${ }^{87}$ Über die Kleidernadeln - ihre Herkunft, Verwendungsweise, Verbreitung und chronologische Stellung - siehe ausführlich: QUAST 2005, 264-270.

${ }^{88}$ Möglicherweise bezeichnen diese zwei, etwas verschiedenen Fibelstellen unterschiedliche Kleidungsstücke (vielleicht Peplos, Mantel, Umhang oder vorne offenes Kleid). Ohne glückliche Textilfunde kann man in dieser Frage nicht weiterkommen. Zusammenfassend s. QUAST 2005, 281-284.

${ }^{89}$ Das früheste Auftreten ist beim Grab von Hrtkovci-Vranja (D2/D3) dokumentiert: Hier kam zusammen mit einer „Peplos-Fibel“ in der Körpermitte eine Eisenfibel vor. Leider ist jedoch nicht völlig eindeutig, ob sie in ihrer ursprünglichen Funktion oder als Teil der Tasche ins Grab gekommen war. Der Raumgewinn der neuen Mode ist eindeutig an den Beispielen von Balatonszemes, Hács, Szurdokpüspöki, Szolnok-Szanda und Tác (D3) zu verfolgen (s. Tabelle 1).

${ }^{90}$ Über die im Bauchbereich paarweise, parallel zueinander, schräg getragenen Fibeln um den Balaton und deren westeuropäische Beziehungen: StRaub 2008, 190-191. Möglicherweise müssen wir im Fall der in der Körpermitte getragenen Fibeln auch den etwas abweichenden Fibelstellungen Bedeutung beimessen, jedoch kann diese Frage wegen der fehlenden Textilreste nicht untersucht werden. 
Fibellage in der ersten Hälfte des 5. Jhs. $(n=34)$

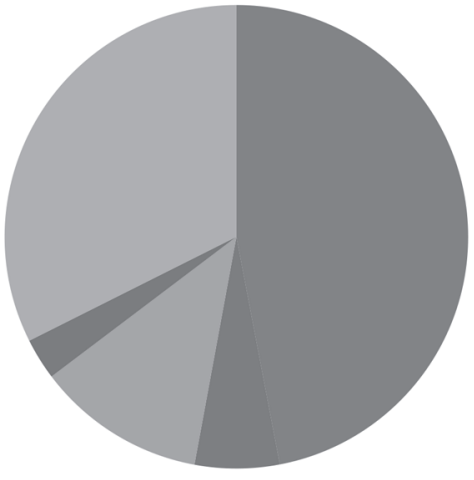

Fibellage in der Mitte des 5. Jhs. $(n=46)$

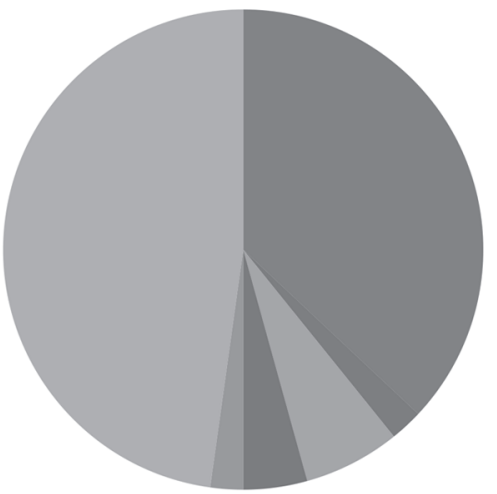

Fibellage in der zweiten Hälfte des 5. Jhs. $(n=45)$

Schulterfibel (paarig)

Wchulterfibel (einzel)

Wibel im Hals/auf der Brust

- 3 Fibel

E Fibel paarig schräg

Fibel auf dem Bauch

we eine Fibel im Hals und auf dem Bauch

unbekannte Fibellage

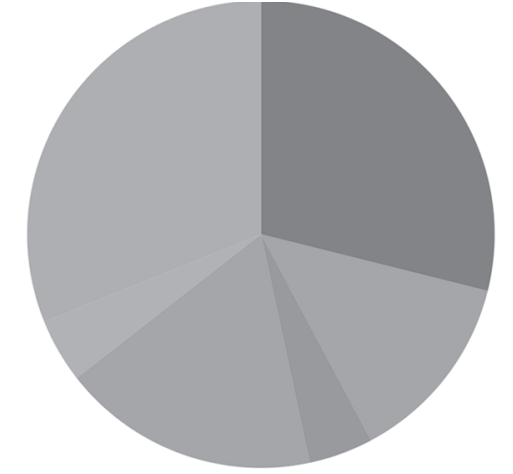

Fibellage um die Wende des 5.-6. Jhs. $(n=38)$

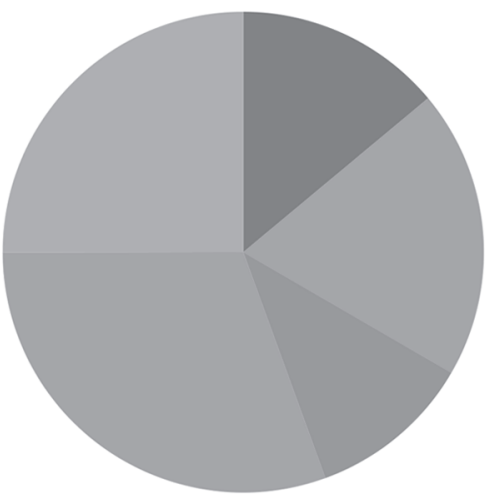

Abb. 10. Die Lage der Fibel in den verschiedenen Phasen des 5. Jahrhunderts im Mitteldonaugebiet (aufgrund der beigabenführenden Frauengräber, Tabelle 1)

Die Funktion der Nadeln in den Frauengräbern - Haarnadel, Schleiernadel, Kleidernadel - ist nur dort eindeutig, wo ihre Lage dokumentiert ist. Die auf beiden Schultern oder auf dem Brustkorb liegenden Exemplare sind die Fibelfunktion erfüllende Kleidernadeln (z. B. Bratei 1/1964, Kapolcs Grab 2, Nyíregyháza-Oros Grab 20, Ordacsehi-Csereföld Grab 510). Die nach spätantikem Muster zur Haartracht oder zum Kopftuch gehörende - an beiden Seiten des Kopfs, eventuell am Hals liegende - Nadel ist selten (Kapolcs Grab 1, Mezőkövesd-Nyárfa u.?). ${ }^{91}$

Die spektakulärste Ausstattung kann in den Bestattungen mit großen Blechfibeln oder Edelmetall-Kleidernadeln (D2 und vor allem D2/D3) und gegossen-kerbschnittverzierten Gegenständen (D2/D3 und D3) beobachtet werden $(A b b .11)$. Die Vielfältigkeit des Beigabenspektrums konnte durch die soziale Stellung, die materiellen und sozialen Möglichkeiten der Verstorbenen und ihrer Familie beeinflusst sein. Die am besten ausgestatteten Frauengräber enthalten 7-13 Gegenstände unterschiedlicher Funktion. Grab 1 von Untersiebenbrunn belegt mit seinen mindestens 15 Beigaben verschiedener Typen und wegen seines gehäuften Schmucks einen herausragenden Platz auch innerhalb dieser Gruppe. ${ }^{92}$ Die hier bestattete junge Frau und das Mädchen sind Vertreter der Gesellschaftsschicht, die eine Vorbildrolle für die Frauenkleidung und die Repräsentationsbräuche sowie zugleich für den Be-

${ }^{91}$ Detailliert: ProhásZKa 2006, 394-396; über die Nadeln mit Polyederende: QuAsT 2005, 264-268.

${ }^{92}$ Zur Gruppe der am reichsten ausgestatteten und die meisten Gegenstandstypen enthaltenden Gräber gehören die folgenden, gut beobachteten Gräber: aus dem frühen Material Maglód (ca. 10), Üllő (8), Regöly (9), Wien-Mödling (11), später Bratei 1/1964
(7), Hrtkovci-Vranja (11), Laa a. d. Thaya (9), Mezőkövesd-Mocsolyás (11), Smolin (12), Tiszalök (12), Mitterhof (7), Turda (7), SzekszárdPalánk 217 (12). Den in seiner Zusammensetzung dem Untersiebenbrunner Frauengrab am meisten ähnelnden Fund von Rábapordány nahm ich in meine Tabelle nicht auf, weil seine Interpretation als Frauengrab unsicher ist (BóNA 1993, 244). 
stattungsritus spielte. ${ }^{93}$ In ihrer Folge entstand bis zur Periode D2/D3 eine auffällig einheitliche, vor allem durch große Blechfibeln, spektakuläre Gürtelschnallen, Polyederknopf-Ohrringe und perlenreiche Mode (große Bernsteinperlen) charakterisierbare Elitegruppe. Zugleich ist das besagte Frauenset nicht nur für die Elitengräber typisch: In reduzierter Form kam es auch in ärmlicheren Bestattungen, in Gräberfeldern mit höherer Gräberzahl vor - im gesamten Karpatenbecken, in Pannonien und im Theißgebiet, in Sirmien und nördlich der Donau gleicherweise.

Wenn nicht die gesamte Kleidung, sondern nur einzelne Elemente der Frauenausstattung untersucht werden, kann man gleichfalls Zeuge der weiten geographischen Verbreitung sein: Beim Auftauchen der PolyederknopfOhrringe, der großen Bernsteinperlen, der seit der Mitte des 5. Jahrhunderts vorkommenden fassförmigen Goldperlen, der Kolbenarmringe, Spiegel, Kämme oder auch seltener getragenen Anhänger und Schellen kann kein regionales Muster beobachtet werden. ${ }^{94}$

Diese Homogenität bedeutet natürlich nicht, dass sämtliche Frauengräber „,ebenso aussehen“, aber es lässt sich ein sowohl horizontal (in weiter geographischer Region) als auch vertikal (in den verschiedenen Gesellschaftsschichten) in weitem Kreis bekanntes und verwendetes Frauenset rekonstruieren. Aus ihm konnten die einzelnen Gemeinschaften und Personen innerhalb ihrer materiellen und sozialen Möglichkeiten entsprechend ihrer Gewohnheiten ihre individuelle Ausstattung wählen. Die Menge und Qualität der Beigaben zeigt eine fortlaufende Skala von Bestattungen mit ein oder zwei einfachen Gegenständen bis zur oben genannten Elitegruppe.

Es lässt sich beobachten, dass in einzelnen Gräberfeldern, nahe beieinander, Kombinationen verschiedener Kleidungselemente auftreten (z. B. Páty Grab 560 und 564), ${ }^{95}$ aber es gibt auch Beispiele, dass die toten Frauen „uniformartig“ ähnliche Ausstattung bekamen (Viminacium-Burdelj). ${ }^{96}$ Der erstere Fall ist die eindeutige Widerlegung der Vorstellung, die die einzelnen Kleidungsbestandteile des 5. Jahrhunderts der Tracht gewisser Stammeseinheiten entsprechen lassen möchte (s. „,gotisches oder ostgermanisches Kleid“ mit Peplos und großer Gürtelschnalle und „Nomadenkleid“ ohne Fibel). ${ }^{97}$ Möglicherwiese hatten gewisse typische Bekleidungen eine Zeit lang auch „ethnische Bedeutung“: So war das mit vielen Perlen benähte Kleid im von den Sarmaten bewohnten Gebiet verbreitet und die auf beiden Schultern getragene Blechfibel besonders im Gebiet der Tschernjachow-MarosszentannaKultur beliebt. Im Laufe der Hunnenzeit änderten sich jedoch die Repräsentationsformen, die Kleidungselemente bekamen neue Qualität und Bedeutung: Unsere auf die Mitte des 5. Jahrhunderts bezüglichen Beobachtungen kann man nicht mit den (ethnischen oder kulturellen) Spezifiken des 4. Jahrhunderts erklären.

Die folgende Frage ist der Hauptbeweggrund für die Entstehung der neuen, aus spätantiken und barbarischen Traditonen gleicherweise stammenden, ${ }^{98}$ weiblichen Repräsentation, die die Modelle der späten Kaiserzeit ablöste und mehrere Jahrzehnte hindurch im Mitteldonaugebiet weiterlebte. Die wichtigste Rolle bei ihrem Zustandekommen spielte die neue Barbarenelite unterschiedlicher kultureller Herkunft. Ihre weitreichende geographische Ausstrahlung war teilweise den Ereignissen der „Hunnenbewegung“ und der ferne Gebiete verbindenden großen Völkerwanderungszeit und teilweise jener Erscheinung zu verdanken, dass einzelne Elemente der neuen Mode auch im Kreis der neuen Aristokratie des römischen Reiches Anhänger fanden. ${ }^{99}$ Für ihr Weiterbestehen im Mitteldonaugebiet mag jenes Repräsentationsmuster entscheidend gewesen sein, dem die Eliteschicht der hunnenzeitlichen und nachhunnenzeitlichen Staatsgebilde folgte. Weitere Untersuchungen verdienen die räumliche

${ }^{93}$ Detailliert über die Untersiebenbrunner Gräber, die Herkunft, Vorgeschichte und Rolle des Beigabenbrauchs und der Elemente der Bekleidung: ScHMAUdER 2002, 125-127, 150-155, 170-172; über die Kertscher sowie nord- und ostpontischen Vorgänger der sog. Donaugebiet-ostgermanischen Frauentracht und Bestattungspraxis: TEJRAL 1988, 237-238.

${ }^{94}$ Einige Verbreitungskarten: Spiegel - IstVÁNOVITSKUlCSÁR 1993, Abb. 2; tonnenförmige Goldperlen - Kiss 1995, 314 316.

${ }^{95}$ In dem frühvölkerwanderungszeitlichen Gräberfeld von Páty gab es 12 Bestattungen, darunter 4 Frauengräber, zwei mit Beigaben. Eines mit Nadel und Kamm und das andere mit Gürtelschnalle, Nadelbehälter und Kamm (OTTOMÁNYi 2001, 41-43).

${ }^{96}$ Fibelpaar und am Becken einige große Perlen: Zotović 1981; IVANIŠEVIĆ-KAZANSKY-MASTYKOVA 2006.
${ }^{97}$ WeRner 1956, 83. Zusammenfassend zur Forschungsgeschichte des Fragenkreises ,Stammestracht“: RUMMEL 2007, 35-48.

${ }^{98}$ In dieser Studie beschäftige ich mich nicht mit der Herkunft der Elemente der Bekleidung des 5. Jahrhunderts, der ,mode danubienne“. Darüber zusammenfassend: TeJRAL 2011; KAZANSKI 1990; HARHOIU 1997. Über einzelne Gegenstandstypen und die mit ihnen verbundenen Bestattungsbräuche siehe z. B. noch: Polyederknopf-Ohrring (HeINRICH 1990, 92-94; DoBOs 2012, 18), Spiegel und Bestattung mit Spiegel (IsTVÁNOVITS-KulCSÁR 1993; ANKE 1998, 18-31), zweireihiger Beinkamm und Bestattung mit Kamm (OTTOMÁNYi 2001, 50), Blechfibel (GAuss 2009), Schulterfibel (RUMMEL 2007, 276-294).

${ }^{99}$ Vgl. RuMMEL 2007, 394-406. 


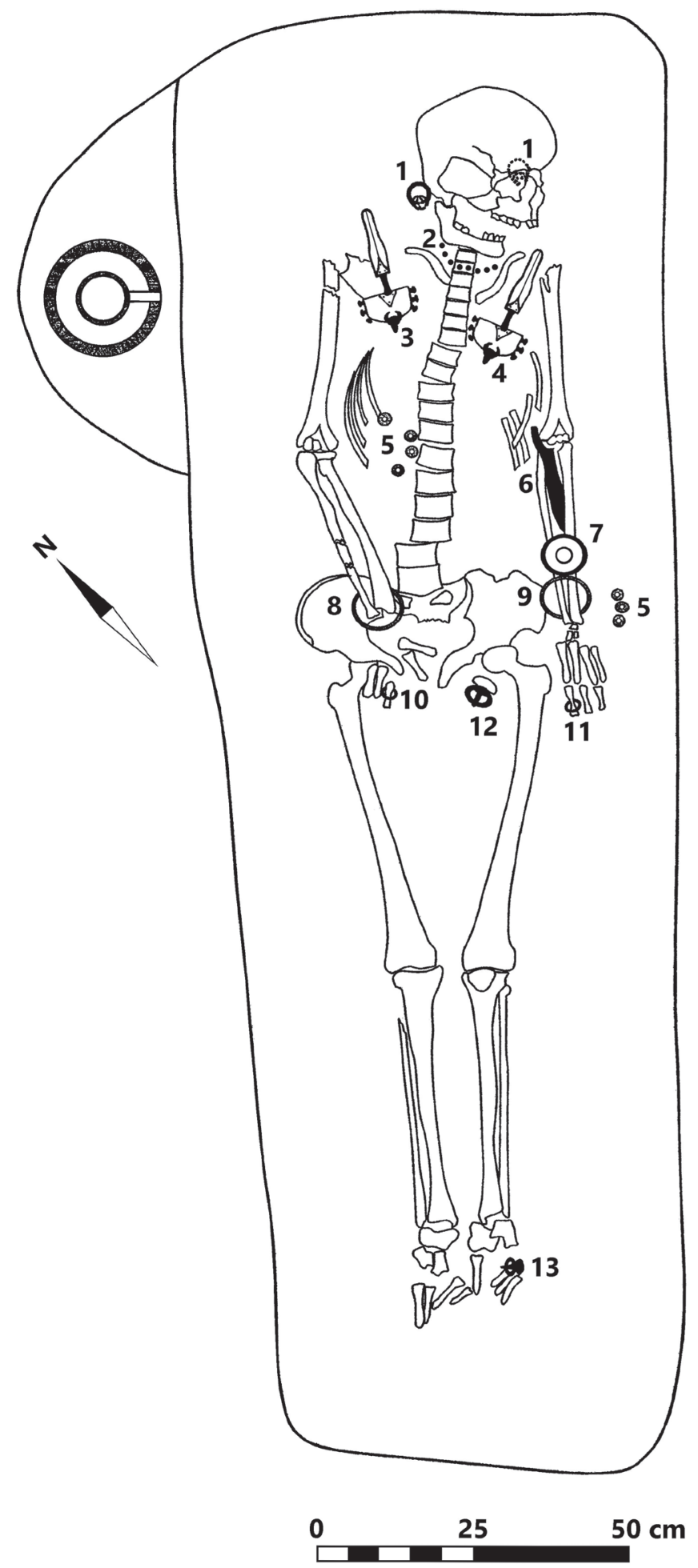

Abb. 11. Mezőkövesd-Mocsolyás, Grab 2 (in einer kleinen Gräbergruppe, Mitte des 5. Jahrhunderts): 1: Goldenes Ohrringpaar mit Polyederknopf, 2. kleine Glasperlen (nicht vorhanden), 3-4: silbernes Blechfibelpaar, 5: große Perlen (Glas, Bernstein), 6: Messer, 7: Spiegel, 8-9: silbernes Armringpaar, 10-11: silberne und bronzene Fingerringe, 12: silberne Gürtelschnalle, 13: silberne Schuhschnalle, 14. Henkelkrug (nach LovÁsz 1997) 
Ausdehnung der hier behandelten charakteristischen Kleidung und die Beleuchtung ihrer Zusammenhänge von der Krim bis nach Westeuropa.

Das sich bis zur Mitte des 5. Jahrhunderts herausgebildete typische Frauenset kann auch in den Phasen D3 und E, bis zum Beginn des 6. Jahrhunderts, verfolgt werden, von Niederösterreich bis nach Siebenbürgen. Veränderungen gab es bei den Gegenstandstypen, der Herstellungstechnik und Verzierung, aber das bedeutet nicht die Veränderung der Funktion der einzelnen Elemente und des „Gesamtbildes“ der Kleidung. ${ }^{100}$ Seit der Mitte des 5. Jahrhunderts ist die wichtigste Innovation bezüglich der Funktion der Gegenstände der Raumgewinn der Fibel in der Körpermitte, im Bauchbereich, gleichzeitig in verschiedenen Gebieten des Karpatenbeckens. Doch auch dieser Wechsel geschah stufenweise neben der jahrzentelangen Weiterexistenz der früheren Fibelmoden.

\section{Multivariante statistische Untersuchung der Frauengräber des 5. Jahrhunderts}

Durch die aufgrund identischer Gesichtspunkte vorgenommene tabellarische Sammlung eignet sich das Fundmaterial auch für multivariante statistische Analysen. Die Hauptfrage dieser Untersuchungen ist, ob sich irgendwelche - auf die Zeit, den Raum, eventuell auf gesellschaftliche Gruppen bezügliche - Gruppierungsmöglichkeiten innerhalb des Fundmaterials ergeben. Die wichtigste Erkenntnis aus der Hauptkomponentenanalyse unter Einbeziehung der ungestörten Bestattungen - die sich bereits auf den Diagrammen einzelner Elemente des Bestattungsritus und der Kleidung gezeigt hat - ist, dass der Ritus und die Ausstattung der Frauengräber des 5. Jahrhunderts ein einheitliches Bild zeigen bzw. die Kombinationen einzelner Elemente der Ausstattung dieses Frauensets keine abtrennbaren Gruppen bilden (Abb. 13).

Die vom „Verdichtungsgebiet“ weiter entfernten Orte (auf den Abbildungen nach oben) beziehen sich in erster Linie auf an den Anfang der untersuchten Periode (erste Hälfte 5. Jh.) datierbare Grabensembles (z. B. Budapest-Zalavár u., Ártánd-Nagyfarkasdomb, Gencs-Kápolnadomb, Untersiebenbrunn Grab 2). Diese sind stärker mit den verschiedenen früheren - sarmatischen, östlichen, spätantiken - Traditionen verbunden (und von diesem Gesichtspunkt aus Fortsetzer des mosaikartigen archäologischen Bildes der Periode D1). Ihre typischen Merkmale sind: N-S- und S-N-Orientierung, Gefäßbeigaben, Tierknochen, Schuh- und Gürtelschnallen. Einige weitere „abtrennbare Punkte" bilden die reichen Frauengräber der Phase D2/D3 und D3 (nach rechts), die ein sehr vielfältiges Beigabenspektrum aufweisen. Diese Ensembles repräsentieren den Höhepunkt der „mode danubienne“.

Mit der Analyse kann auch der - oben beschriebene - Prozess gut illustriert werden, wie in der ersten Hälfte des 5. Jahrhunderts durch Verschmelzung verschiedener kultureller Einflüsse ein neues, einheitliches Repräsentationsmuster entsteht, was in der Bekleidung wie im Bestattungsritus beobachtet werden kann.

\section{DIE FRÜHESTEN GRÄBER DER GEPIDENZEITLICHEN REIHENGRÄBERFELDER}

Seit der zweiten Hälfte des 5. Jahrhunderts erschienen in der Osthälfte des Karpatenbeckens wiederum die mehrere Jahrzehnte lang benutzten größeren Gräberfelder, ähnlich den westeuropäischen Tendenzen. Im folgenden Kapitel untersuche ich, welche Erscheinungen sich an diesen Fundorten - Bestattungsritus, Grabausstattung, Brauch der Schädeldeformation - an die vorige Epoche sowie die mit der Nutzung der großen Gräberfelder auch parallel beobachteten Einzelgräber und kleinen Gräbergruppen anschließen. Die frühen Bestattungen der neuen Gräberfelder können am häufigsten eben aufgrund der typischen Beigaben der Frauengräber festgestellt werden. ${ }^{101}$ Wie im vorigen

${ }^{100}$ Eine häufig analysierte, wichtige Veränderung ist z. B die Verbreitung gegossener Schnallen und Fibeln statt der Blechgegenstände (BIERBRAUER 1995). Um die Mitte des 5. Jahrhunderts erscheint die fassförmige gerippte Goldperle und ist in Phase D3 am beliebtesten.

${ }^{101}$ Die Beurteilung der frühen Männergräber in den Reihengräberfeldern ist wegen der Datierungsschwierigkeiten ihres Fundmaterials eine schwerere Aufgabe. Mit dieser Frage hat sich Attila Kiss P. in seiner Dissertation beschäftigt (A. KIss P.: „,... ut strenui viri...“. A gepidák Kárpát-medencei története [Geschichte der Gepi- den im Karpatenbecken]. Doktori disszertáció, SZTE. Szeged 2015); s. noch KISS P. 2016. Am besten weisen die auch für die Hunnenzeit typischen einschneidigen Waffen auf frühe Bestattungen hin: Szolnok-Szanda Grab 30 ist aufgrund der Gürtelschnalle und des Langsax mit schmaler Klinge ins letzte Drittel des 5. Jahrhunderts zu datieren (BÓNA 2002c, 206). Daneben sind auch die Schnallen mit Steineinlagen mediterraner Herkunft wichtig, die in die Zeit um die Jahrhundertwende datiert werden können: Szentes-Berekhát Grab 37, gleichfalls mit schmalem Langsax (CSALLÁNY 1961, 74-75). 

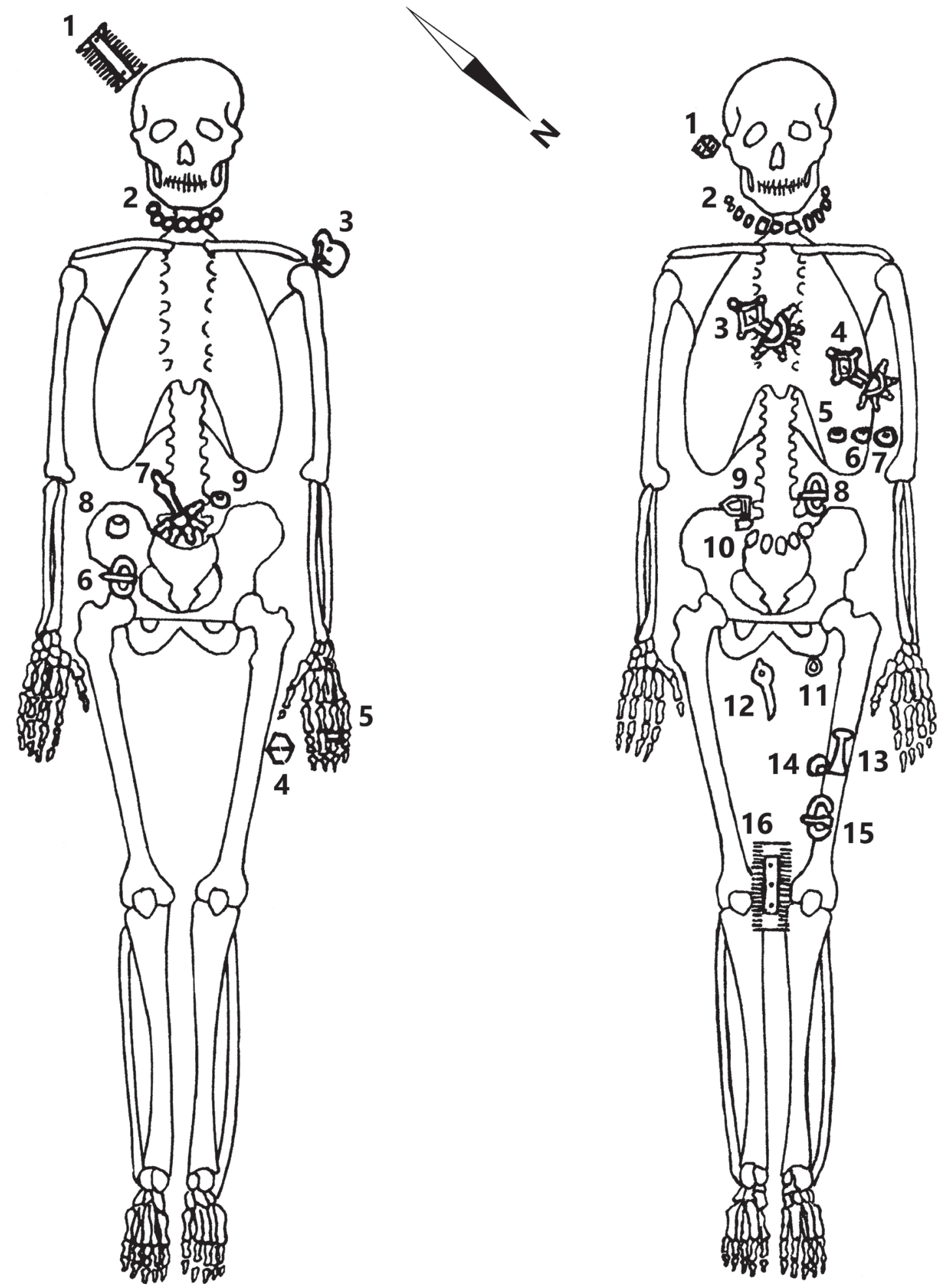

Abb. 12. Frauengräber der gepidenzeitlichen Gräberfelder von Szentes-Kökényzug. 1: Grab 49. 1. Knochenkamm, 2. kleine Glasperlen, 3. Feuerstein, 4. Spinnwirtel, 5. Silberring, 6. Eisenschnalle, 7. Bronzefibel, 8-9. große Perlen (Chalzedon und Glas);

2: Grab 81. 1. Ohrring mit Polyederknopf, 2. kleine Perlen (Glas, Bernstein), 3-4. Silberfibelpaar, 5-7. große Perlen (Glas, Bernstein),

8. Eisenschnalle, 9. Anhänger, 10. Bernsteinperlen, 11. Bronzering, 12-13. Toilettenbesteck (Löffel und Pinzette), 14. Bernsteinperle, 15. Schnalle, 16. Knochenkamm (nach CsALLÁNY 1961) 
Kapitel darauf hingewiesen wurde, ist die chronologische Einordnung der Bestattungen der Reihengräberfelder schwer. Eine belegungschronologische Analyse steht vorerst nur für Hódmezővásárhely-Kishomok und Szőreg-Téglagyár zur Verfügung. So finden sich in meiner Analyse nur jene Gräber, die gut datierbare Gegenstände enthielten. ${ }^{102}$

\section{Hunnenzeitliche Traditionen im Bestattungsritus der gepidenzeitlichen Gräberfelder}

Beim Überblicken der Charakteristiken der Frauengräber des 5. Jahrhunderts haben wir schon erfahren, dass ein großer Teil der gepidenzeitlichen Bestattungsbräuche (W-O-Orientierung, häufige Beigabe von Kämmen) ${ }^{103}$ ein Ergebnis der allgemeinen Entwicklung des 5. Jahrhunderts ist. Der Anteil der Gefäßbeigaben ist nach Berechnungen von Margit Nagy in den einzelnen gepidenzeitlichen Gräberfeldern sehr verschieden (6,3-19\%, HódmezővásárhelyKishomok mit dem herausragenden Wert von 27,4\%), ${ }^{104}$ entspricht aber insgesamt der allgemein beobachteten sinkenden Tendenz im 5. Jahrhundert - ebenso wie das fast völlige Verschwinden der Tierknochenbeigaben. Die Spindelbeigabe wird im Laufe des 5. Jahrhunderts immer häufiger; das in dieser Studie untersuchte Muster weist an der Wende des 5./6. Jahrhunderts einen herausragend hohen Wert (47 \%) auf. Bei sämtlichen Frauengräbern der gepidenzeitlichen Reihengräberfelder ist der Spindelanteil weit geringer (Hódmezővásárhely-Kishomok $21 \%$ ). ${ }^{105}$ Dieser Unterschied kann damit zusammenhängen, dass in die von mir analysierten, gut datierbaren Frauenbestattungen mit „reicheren“ Beigaben als ihre Umgebung auch eine Spindel öfter gelegt wurde als in ärmere Gräber.

Spuren eines speziellen, selten angewandten Ritenelements sind die in den Grabschacht eingetieften Nischen, die zusammengesetzten Grabformen. Die kleine Nische für die Gefäßbeigabe am Kopfende des Grabes taucht außer in den aus der ersten Hälfte und Mitte des 5. Jahrhunderts stammenden Fällen (z. B. Csővár, Mezőkövesd-Mocsolyás, Šarovce) auch in gepidischen Reihengräberfeldern auf (Hódmezővásárhely-Kishomok Grab 28, vielleicht Szőreg Grab 55). ${ }^{106}$ Das Grab von Hódmezővásárhely hat Margit Nagy in die früheste Phase des Gräberfeldes datiert, in die zweite Hälfte des 5. Jahrhunderts.

Für die Gräber mit langer Seitennische ${ }^{107}$ bieten sich sogar mehrere transdanubische Beispiele - nach spätrömischen, hunnenzeitlichen und nachhunnenzeitlichen Vorkommen - an. Der Fund von Tiszapalkonya ist der Beweis dafür, dass es diese Bestattungsform auch im Theißgebiet schon in der Hunnenzeit gab. ${ }^{108}$ Die Seitennische war auch an einigen gepidenzeitlichen Fundorten vorhanden; einzelne Gemeinschaften verwendeten sie regelmäßig bei der Gestaltung der Grabgrube (Szolnok-Zagyva-part-Alcsi, ${ }^{109}$ Tiszapüspöki $^{110}$ ).

\section{Das Erscheinen des Frauensets des 5. Jahrhunderts in gepidenzeitlichen Reihengräberfeldern}

In den frühen Bestattungen der gepidenzeitlichen Nekropolen sind das oben beschriebene Frauenset, die Elemente der „mode danubienne“, noch zu verfolgen. Das Gräberfeld von Hajdúnánás-Fürj-halom-dülö ${ }^{111}$ befindet

\footnotetext{
${ }^{102}$ Das bedeutet zugleich, dass nur Gräber aufgenommen wurden, die ,reicher“ waren als ihre Umgebung, was in gewisser Weise den Anteil des Vorkommens einzelner Beigaben und Kleidungselemente verzerrt.

${ }^{103}$ Vgl. BónA-NAGY 2002b, 171, Tabelle 18.

${ }^{104}$ BÓNA-NAGY 2002b, 94, 169, Tabelle 15.

${ }^{105}$ BÓNA-NAGY 2002b, 129.

${ }^{106}$ CSAllány 1961, 300-301; BÓNA-NAGY 2002b, 46. Zusammenfassend über die Erscheinung: NovoTNÝ 1976, 82-83.

${ }^{107} \mathrm{Zu}$ diesem Thema stehen uns mehrere Sammlungen, zusammenfassende Bewertungen zur Verfügung: SÁGI 1984, 85; STRAub 2014, 209, 211; G. LôRINCZY-P. STRAub: Az avar kori padmalyos temetkezésekről. Szempontok a Kárpát-medencei padmalyos temetkezések értékeléséhez (Über die awarenzeitlichen Nischengräber. Angaben zur Bewertung der Nischengräber des Karpatenbeckens). Arrabona 44/1 (2006) 277-314; P. PROHÁszKA: Gazdag padmalyos női temetkezés Brigetio/Komárom-Szőny Gerhát temetőjéből (Ein reiches römisches Frauengrab mit Nische aus
}

dem Gerhát-Gräberfeld von Brigetio). FA 52 (2005-2006 [2006]) 79-107.

${ }^{108}$ CSAllány 1958, 84.

${ }^{109}$ CSEH 2005a, 25-26.

${ }^{110}$ K. Hoppát-P. F. KovÁcs-Zs. MAsEK-E. HorvÁth-Zs. BENDŐ: Warriors of the wild. A germanic cemetery in Tiszapüspöki, Hungary. Poster bei der Konferenz „Kollaps - Neuordnung - Kontinuitäten. Das Theißgebiet nach dem Untergang des Hunnenreiches“ im Archäologischen Institut der Eötvös Loránd Universität (Budapest) am 14.-15. Dezember 2015.

${ }^{111}$ In der Nähe (Hajdúnánás-Fürj-halom-járás) wurde auch eine kleine Grabgruppe freigelegt: drei Gräber aus der zweiten Hälfte des 5. Jahrhunderts, ein Männer-, ein Altfrauen- und ein Kindergrab (Familiengrabstelle?) (RÁcz 2014). Die Frau lag dem Brauch der Epoche entsprechend in einem auf beiden Schultern gehefteten Kleid, mit zweireihigem Geweihkamm im Grab. Eine vollkommene Parallele der Fibel wurde in Slimnice nahe Sibiu gefunden, in einer Einzel-Frauenbestattung (GLODARIU 1974). 
sich am Nordrand des gepidischen Siedlungsgebiets. ${ }^{112}$ Das wahrscheinlich früheste Grab ist die Frauenbestattung 441/618: Gefunden wurden hier neben dem Kopf Geweihkamm, Polyederknopf-Ohrring, unter dem Schädel Perlen, zwischen den Wirbeln Eisenfragmente (Fibel?), am linken Unterarm am Gürtel oder auf der Tasche befestigte Glasund Bernsteinperlen und ein zylindrischer Silberblechgegenstand (Nadelbehälter?), ${ }^{113}$ am rechten Oberschenkel ein zerbrochener Spiegel (Abb. 14-16). Die anthropologischen Ergebnisse bereichern unser Bild von der Bestattung weiter: In dem Gründergrab lag eine Frau im Adultus-Alter mit stark deformiertem Schädel und rein mongoliden Schädelmerkmalen. ${ }^{114}$

Im Karpatenbecken sind mehrere ähnlich zusammengesetzte Grabensembles bekannt: Zu ihnen gehören das Einzelgrab aus Hódmezővásárhely-Sóshalom mit großen Blechfibeln (D2b oder D2/D3), Grab 217 der kleinen Gräbergruppe von Szekszárd-Palánk (D3) und der Fund von Bácsordas (terminus post quem-Datierungsangabe durch die im Grab gefundene Münze von Theodosius II.). Die Charakteristiken von Hajdúnánás Grab 441 spiegeln - obwohl hier die große Fibel und die Gürtelschnalle fehlen - eindeutig die in der Hunnenzeit entstandene und für die Mitte und zweite Hälfte des 5. Jahrhunderts typische Bekleidung und Identität. Die Datierung ist ungewiss, in Frage kommen Periode D2/D3 ebenso wie D3.

Auch das auf beiden Schultern oder beiden Seiten der Brust geheftete Kleid taucht in einzelnen späten, in die zweite Hälfte des 5. und an den Anfang des 6. Jahrhunderts datierbaren Fundensembles auf; Beispiele dafür sind Ártánd-Lencsésdomb Grab 1, Floreşti-Polus CX Grab 41B, Szolnok-Zagyvaufer Grab 16 sowie die Bestattungen 50, 59 und 66 von Szentes-Kökényzug. An den Fundorten Szolnok und Szentes ist festzustellen, dass gleichzeitig mehrere Arten von Bekleidung bei der das Gräberfeld nutzenden Bevölkerung Mode waren: Man trug neben dem „Peplos“ auch das „modernere“, am Bauch geheftete (Szentes-Kökényzug Grab 49) und das für die zweite Hälfte des 5. Jahrhunderts typische, schräg zusammengehaltene Kleid (Szentes-Kökényzug Grab 81, Szolnok-Zagyvapart Grab 18). In diesen Gräbern sind sonstige Elemente - so die Polyederknopf-Ohrringe, die großen Bernsteinperlen, die in der Körpermitte die Tasche oder den Gürtel schmückenden größeren Perlen bzw. die paarweise getragenen Armbänder (und auch die allgemein vorkommenden Kämme, Spinnwirtel und Gürtelschnallen) - Fortsetzungen der früheren Tradition. In Hódmezővásárhely-Kishomok Grab 105 gehört neben dem Dreiknopf-Fibeltyp mit geradem Fuß ${ }^{115}$ (wahrscheinlich in der Mitte, auf dem Brustkorb getragen) das Krug-Becher-Ensemble und auch die große Bernsteinperle am Oberschenkel in diese Reihe. Ein weiteres Beispiel für die „Gründer“ der gepidenzeitlichen Gräberfelder ist das früheste Grab am Fundort Egerlövő, das ebenfalls eine Frauenbestattung mit PolyederknopfOhrring war. ${ }^{116}$

Ich halte es für wichtig hervorzuheben, dass eines der wesentlichen Charakteristiken der Frauengräber des 5. Jahrhunderts, die variantenreiche Verwendung der Perlen - mit besonderer Berücksichtigung der im mittleren Körperdrittel gefundenen Perlen - auch in den Reihengräberfeldern zu finden ist. Beispiele dafür sind in Hajdúnánás das oben erwähnte Grab 441 sowie Grab 444 (Kindergrab mit deformiertem Schädel) und Grab 829, des Weiteren auch Szentes-Kökényzug Grab 81 ( $A b b$. 12.). Im letzteren Fall lagen am Hals kleinere, auf dem Brustkorb nahe der einen Fibel größere und in der Körpermitte in einer Reihe mittelgroße Perlen. ${ }^{117}$ Diese Anordnung entspricht in vollem Maße der perlenreichen Kleidung der Perioden D2/D3-D3.

An den oben genannten Fundorten lagen die die frühe Tradition bewahrenden Frauenbestattungen in allen Fällen in den Grabreihen-Grabgruppen der Gräberfelder, zwischen den übrigen Gräbern eingereiht. Es sind auch mehrere Fundorte bekannt, an denen die Bestattungen des 5. Jahrhunderts und die des 5.-6. oder 6-7. Jahrhunderts nahe beieinander lagen, die kontinuierliche Belegung aber nicht beweisbar ist. Zu ihnen gehören in Siebenbürgen die Fundorte Bratei (Baráthely) ${ }^{118}$ und Fântânele (Szászújős). ${ }^{119}$ Das einzigartige Beispiel für die Beziehung zwischen einem gepidenzeitlichen Gräberfeld und der Elite des 5. Jahrhunderts ist Floreşti (Szászfenes), wo das Grab

\footnotetext{
${ }^{112}$ Aufgrund der Bestattungsbräuche und des Fundmaterials fügt sich das Gräberfeld in die Reihe der Fundorte ähnlichen Alters im Theißgebiet ein. Es war stark beraubt und ist durch ärmliches Fundmaterial und wenige Gräber von Bewaffneten charakterisiert. Seine häufigsten Beigaben waren der zweireihige Geweihkamm und das Geramikgefäß neben dem Kopf. Radiokarbonuntersuchungen wurden am anthropologischen Material von 6 Gräbern vorgenommen; sie ergaben einheitlich das Intervall zwischen 430-540 und 440-550 (STADLER et al. 2008, Abb. 18-19).
}

${ }^{113}$ Der Fund ähnlicher Form aus Szekszárd-Palánk Grab 217 kam mit Eisennadeln zusammen ans Licht (KISS 1996, 55-57).

${ }^{114}$ Die anthropologische Untersuchung des Gräberfeldes haben im Rahmen der OTKA-Ausschreibung Nr. PD 104728 Tamás Hajdu, Tímea Balassa und Ildikó Pap durchgeführt.

${ }^{115}$ BÓNA-NAGY 2002b, 121.

${ }^{116}$ LOVÁSZ 1991, 58.

${ }^{117}$ CSALLÁNy 1961, 38.

${ }^{118}$ BARZU-HARHOIU 2008, 535, Abb. 2, 13, 15.

${ }^{119}$ Dobos 2012, 13, Pl. 55. 
PCA of the 5 th $c$. burials

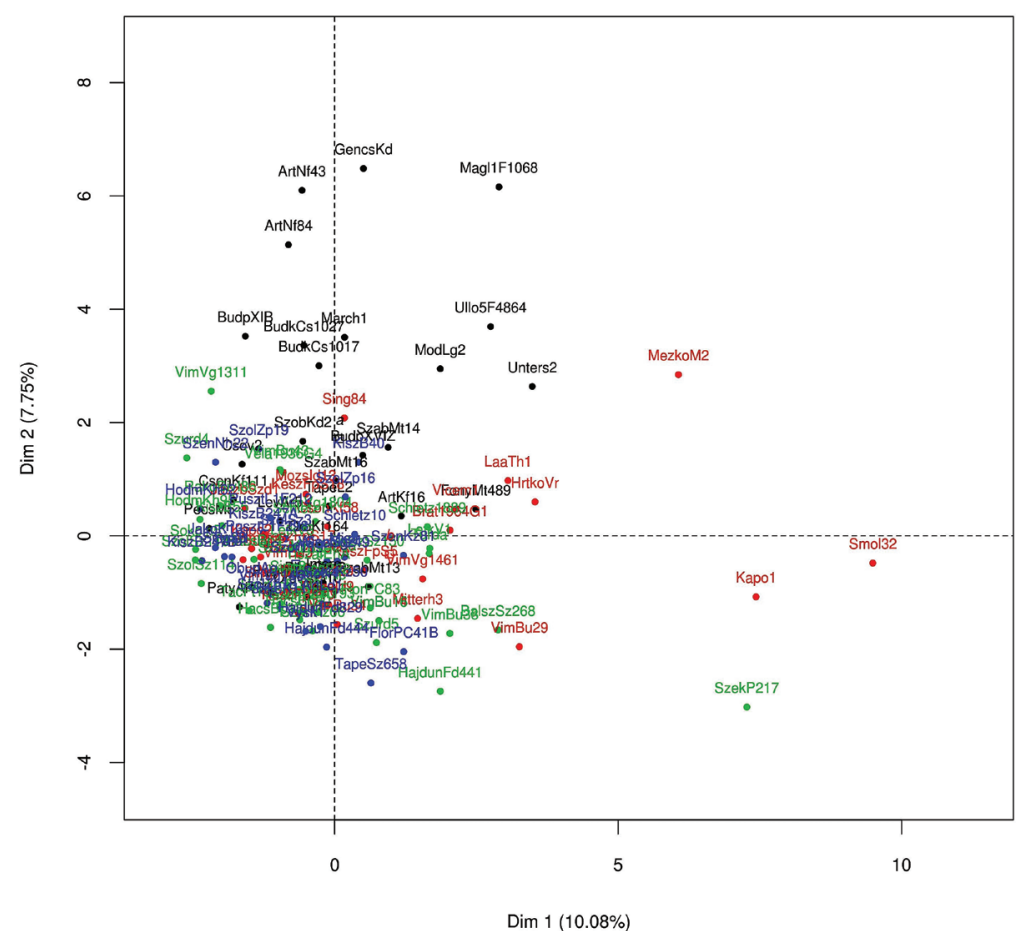

PCA of the 5th $\mathrm{c}$. burials

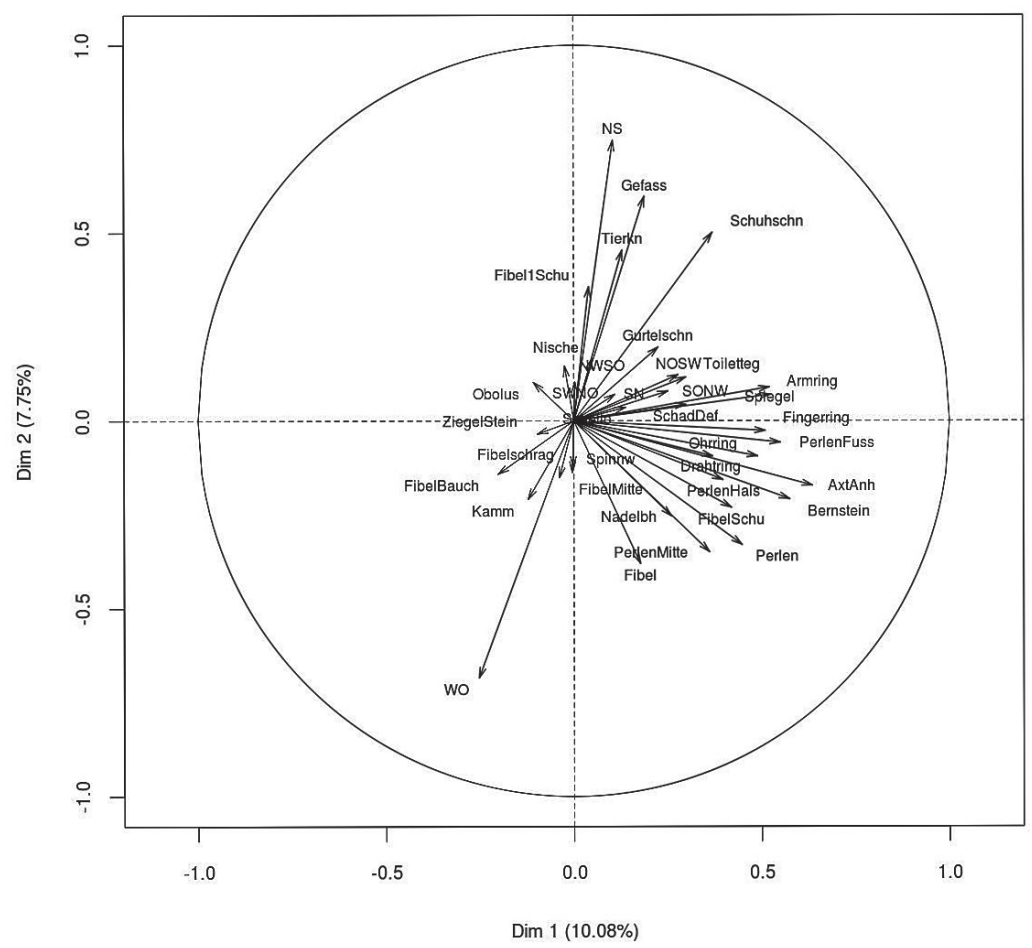

Abb. 13. Hauptkomponentenanalyse der ungestörten beigabenführenden Frauengräber aus dem Mitteldonaugebiet (vgl. Tabelle 2). Schwarz: erste Hälfte des 5. Jahrhunderts; rot: Mitte des 5. Jahrhunderts; grün: zweite Hälfte des 5. Jahrhunderts; blau: Ende des 5., Anfang des 6. Jahrhunderts. 

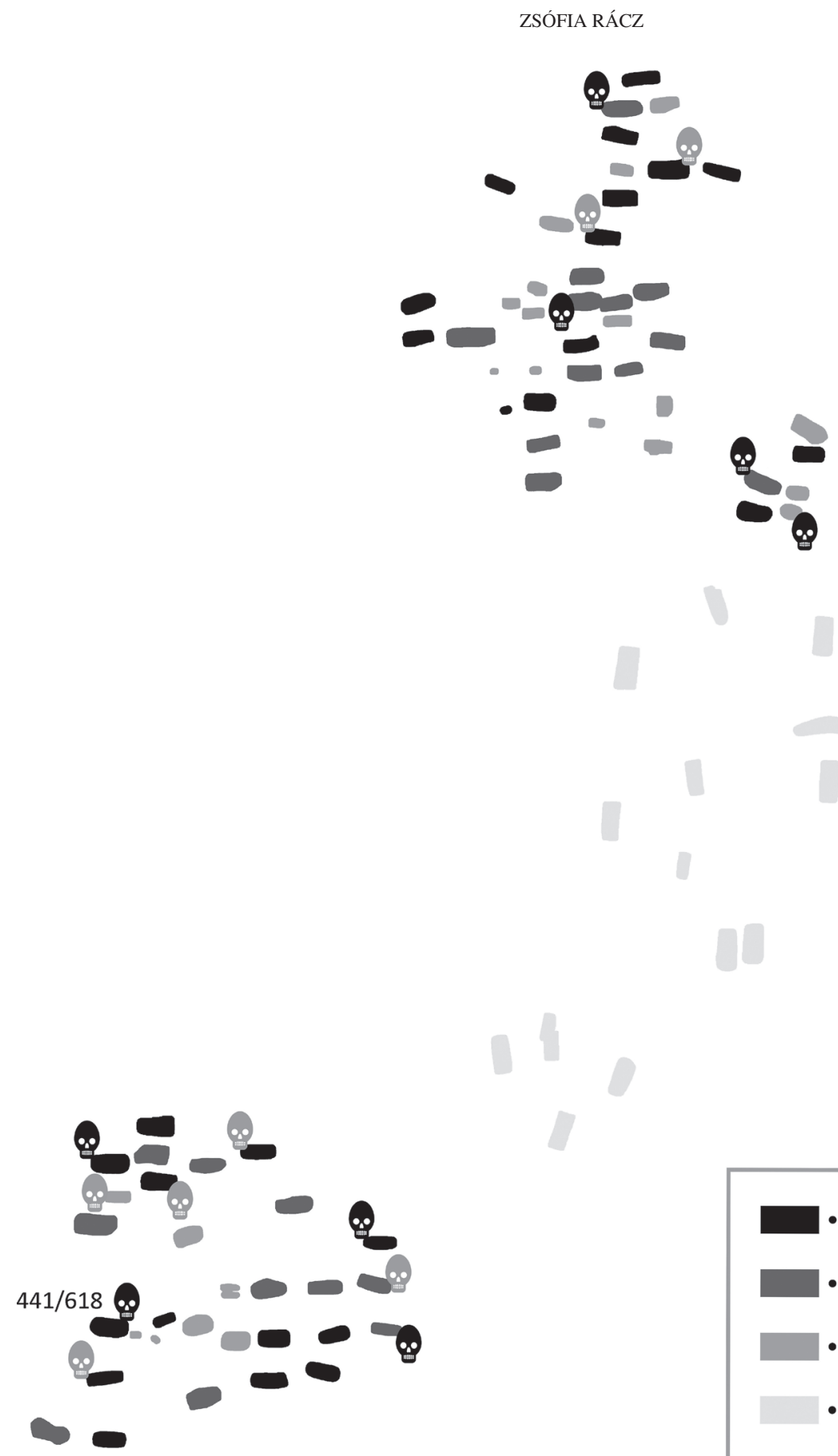

- Frauengrab

- Männegrab

- Kindergrab

- Sarmatenzeitliches Gräberfeld

- starke artifizielle Schädeldeformation 0. artifizielle Schädeldeformation

Abb. 14. Der Gräberfeldplan von Hajdúnánás-Fürj-halom-dủlő mit Markierung der Gräber mit künstlich deformiertem Schädel und des vermuteten „Gründergrabes“ (Grab 441/618) 
der „Fürstin“ in 20 Meter Entfernung von einem Gräberfeld mit 120 Gräbern - separiert - lag, in W-O-Orientierung, im „Peplos-Kleid“, und ihr Schädel die Spuren der künstlichen Schädeldeformation trug. ${ }^{120}$ Gute Parallelen dieses Grabes sind die Einzelbestattungen der weiblichen Elite von Turda und Gáva.

Von der Beobachtung der Zusammensetzung der Grabbeigaben und Bekleidungselemente kann auch weiterer Nutzen als der erhofft werden, dass wir Informationen über die Kontinuität zwischen Hunnen- und Gepidenepoche gewinnen. Mit dieser Methode können wir wahrscheinlich auch mehrere solche Bestattungen der Reihengräberfelder in die Frühphase der Belegung - in die zweite Hälfte des 5. und die Wende des 5./6. Jahrhunderts - einreihen, die ansonsten keine sehenswerten, gut datierbaren Gegenstände enthalten (z. B. HódmezővásárhelyKishomok Grab 74, Szentes-Berekhát Grab 32, Kiszombor Grab 149). ${ }^{121}$

\section{Frühe Gegenstandstypen in gepidischen Reihengräberfeldern}

Über die Zusammensetzung der Grabensembles und der typischen Kleidung hinaus können auch einzelne Gegenstandstypen eine Verbindungsklammer darstellen zwischen den gepidenzeitlichen Gräberfeldern und dem Fundmaterial der vorangegangenen Periode und zugleich den Einzelgräbern/Gräbergruppen und Reihengräberfeldern. Ein gutes Beispiel dafür ist die Kerbschnittfibel mit Rankenmuster von Szőreg-Téglagyár Grab 19, die im mittleren Drittel des 5. Jahrhunderts gefertigt worden war, einige Jahrzehnte später aber wahrscheinlich in stark abgenutztem Zustand ins Grab gelegt wurde. ${ }^{122}$ Auch die kleinen Dreiknopffibeln von Hódmezővásárhely-Kishomok Grab $105^{123}$ und Szolnok-Szanda Grab 114 sind frühe, in der Periode D3 aufkommende Gegenstandstypen. Mehrfach erwähnt wurden die Polyederknopf-Ohrringe und großen Bernsteinperlen, die schon seit Anfang des 5. Jarhunderts wichtige Teile des Frauenschmucks waren: Diese Gegenstandstypen können auch in den gepidenzeitlichen Gräberfeldern verfolgt werden (s. Tabelle 1). Die tonnenförmige Goldperle spätantiker Herkunft ist ein häufiger Begleiter der Elitengräber in der Mitte und der zweiten Hälfte des 5. Jahrhunderts, im gesamten Gebiet des Karpatenbeckens. ${ }^{124}$ In gepidenzeitlichen Gräberfeldern taucht sie in Tiszapüspöki ${ }^{125}$ und Szentes-Kökényzug Grab 29 auf. In leicht veränderter Variante gibt es sie auch noch im 6. Jahrhundert (Szentes-Nagyhegy Grab 9 und 84). ${ }^{126}$ Die Schnalle mit Kerbschnitt- und Tierkopfverzierung bzw. Almandineinlage von Szolnok-Szanda Grab 118 ist ebenfalls ein früher Gegenstandstyp ${ }^{127}$ (hier zusammen mit Fibel mit umgeschlagenem Fuß). Die Spiegelbeigabe, die in der ersten Hälfte des 5. Jahrhunderts sehr häufig war, in der Jahrhundertmitte und zweiten Hälfte nach und nach aber immer seltener wird, kommt in den Reihengräberfeldern nur in dem von Hajdúnánás vor (Grab 441).

Außer den spektakulären Frauenbestattungen - eventuell mit Fibeln, reichem Perlenmaterial oder deformiertem Schädel - können auch einfacher ausgestattete Gräber in den Reihengräberfeldern gefunden werden, in denen jeweils ein weniger auffälliger Gegenstand auf die frühere Periode verweist. Im oben erwähnten Gräberfeld von Hajdúnánás sind dies eine kleine nierenförmige, beinerne Taschenschnalle, ${ }^{128}$ ein Spiralfingerring aus Edelmetallband ${ }^{129}$ und eine auf einer Seite sehr stark verdickte, seit der späten Sarmatenzeit bekannte Schnallenform. ${ }^{130}$ Die

${ }^{120}$ Sz. NAGY: Das gepidische Fürstengrab von Floreşti/ Szászfenes, Siebenbürgen. Poster bei der Konferenz „Kollaps - Neuordnung - Kontinuitäten. Das Theißgebiet nach dem Untergang des Hunnenreiches“ im Archäologischen Institut der Eötvös Loránd Universität (Budapest) am 14.-15. Dezember 2015.

${ }^{121}$ BÓNA-NAGY 2002b, 63-64; Csallány 1961, 74, 181.

${ }^{122}$ NAGY 2005c, 181.

${ }^{123}$ BÓNA-NAGY 2002b, 121-122.

${ }^{124}$ KISs 1995, 314-316; KISs 2001, 126

${ }^{125}$ Siehe Anm. 94.

${ }^{126}$ CSALLÁNy 1961, 47, 59.

${ }^{127} \mathrm{Vgl}$. Ártánd-Kisfarkasdomb: IstvánOvits-KulCSÁR 1999, fig. 15/1 und 6; Fano: BIERBRAUER 1991, Abb. 22/2.

${ }^{128}$ Kleine nierenförmige Geweihschnalle (L: $\left.1,8 \mathrm{~cm}\right), \mathrm{Obj}$. 150. Aus frühvölkerwanderungs-hunnenzeitlichen Fundensembles kennen wir einige ähnliche Exemplare: Mártély-Szépfü (NAGY 2005d, 97, Abb. 4.1, Abb. 7.6), Csongrád-Kenderföldek Grab 28 (PÁrduCZ 1959, 312, Taf. VIII.3).
${ }^{129}$ Grab 247; vgl. Szécsény und Répcelak sowie Szekszárd-Palánk Grab 217 (D3) mit ihren Edelmetall-Spiralfingerringen (Tabelle 1).

${ }^{130}$ Grab 91, hohles Bronzegussstück (L: 3,9 cm). Die auf einer Seite sehr stark verdickte D-förmige oder ovale Form (kann länglicher oder gerundeter sein) findet sich in erster Linie in spätsarmatischen-hunnenzeitlichen Fundensembles, so z. B. in Tápé-Malajdok Gräberfeld A (PÁRdUCZ-KoREK 1948, 304), Csongrád-Kenderföldek (PÁRDUCZ 1959, 377) und Madaras-Halmok in mehreren Bestattungen (VÖRÖS-KÖHEGYI 2011, 24, 74, 286, Taf. 1.5, Taf. 44.10). Die Form gibt es auch noch an der Wende 5./6. Jahrhundert, wie Szolnok-Zagyvapart Grab 17 (CSEH 2005a, 21, Taf. 38.9) und MezőkeresztesCethalom Grab 13 mit dem Silberschnallenfund (SimONYI 2005, 206, Taf. 28.13) zeigen. In Egerlövő Grab 5 lag mit der Eisenfibel mit umgebogenem Fuß und dem einglättverzierten Becher zusammen eine ähnliche Schnalle (LovÁsz 1991, 59, Taf. IV.1). 
in Kinderbestattungen vorkommenden, zwischen die Halskettenperlen aufgefädelten Hirschgrandelamulette erscheinen auch an hunnen- und gepidenzeitlichen Fundorten, in Einzelgräbern, kleinen Grabgruppen und Reihengräberfeldern gleicherweise, in Transdanubien und auch im Theißgebiet. ${ }^{131}$

Die Menge und die Qualität der edelsteinbesetzten, polychrom verzierten Gegenstände haben sich in der Gepidenzeit gegenüber den hunnenzeitlichen Verhältnissen erheblich verringert. Ausnahmen sind die Gegenstände der in die zweite Hälfte des 5. Jahrhunderts datierbaren Elitengräber. ${ }^{132}$ Es gibt jedoch auch einige interessante Beispiele in Reihengräberfeldern, die auf die für gewisse Zeit noch wichtige Rolle der Granate hinweisen: In Hajdúnánás Grab 162, einem gestörten Grab mit deformiertem Schädel, lagen 15 Almandinplättchen auf einem Haufen. Die Steine waren teils aus anderen Gegenständen herausgebrochen worden und teils in halbfertigem Zustand. ${ }^{133}$ Auch Szentes-Berekhát Grab 61 enthielt einen ähnlichen Steinbestand, der leider nicht mehr vorhanden ist. ${ }^{134}$

\section{Künstliche Schädeldeformation am Skelettmaterial der gepidenzeitlichen Reihengräberfelder}

Die Beweise für eine direkte Verbindung zwischen Hunnen- und Gepidenzeit und zugleich der Kontinuität der Bevölkerung sind die Individuen mit deformiertem Schädel. ${ }^{135}$ Ihr Vorkommen weist an den einzelnen Fundorten unterschiedliche Anteile auf. ${ }^{136}$

Tiszagyenda: 22 Fälle ${ }^{137}$

Hajdúnánás-Fürj-halom-dülő: von 74 Skeletten/60 Schädeln 14 sowie ein unsicherer Fall ${ }^{138}$

Floreşti-Polus center: von 99 Skeletten 12 sowie 6 sehr schwach deformierte Fälle ${ }^{139}$

Kiszombor B: von 144 Skeletten 9 Fälle ${ }^{140}$

Szőreg: von 118 Skeletten 7 (?) Fälle ${ }^{141}$

Szolnok-Szanda: von 222 Gräbern 6 Fälle ${ }^{142}$

Hódmezővásárhely-Kishomok: von 107 Gräbern 2 Fälle ${ }^{143}$

In den Gräberfeldern von Szentes-Kökényzug, Szentes-Nagyhegy und Egerlövő wurde die Erscheinung nur in je einem Fall ${ }^{144}$ und in Szentes-Berekhát überhaupt nicht dokumentiert. In einigen Gräberfeldern mit kleinerer Gräberzahl und unveröffentlichtem archäologischem Material ist der Anteil der deformierten Schädel sehr hoch: Den Vorberichten nach hatten im ins 5. Jahrhundert datierten Gräberfeld von Ároktő von 20 Skeletten 7 (sowie 4 wegen einer speziellen Kopfschmuck?), ${ }^{145}$ in Rákóczifalva-Bivaly-tó von 8 Skeletten 5 Individuen deformierten Schädel. ${ }^{146}$

Wie schon im vorangegangenen Kapitel ausgeführt wurde, kann die Frage, ob in einer gegebenen Periode und an einem gegebenen Ort die Bevölkerung tatsächlich noch das Verfahren der Körpermodifizierung praktiziert hat oder vielleicht nur die älteren Individuen Träger des Brauchs der Schädelentstellung waren, durch die Untersuchung der Kinderskelette beantwortet werden. Der Anteil der bekannten Kinderskelette je eines Gräberfeldes kann

${ }^{131}$ RÁCZ-DARÓCZI-SZABó 2016. Siehe noch mit weiteren Amulett-Typen: B. Tо́тH 1994, 294-296.

${ }^{132}$ HORVÁth 2012, 204-206, 209-210.

${ }^{133}$ HORVÁTH-BENDŐ 2011.

${ }^{134}$ Csallány 1961, Taf. LXVIII.9-29.

${ }^{135}$ Wahrscheinlich können auch die mongoliden Individuen der Kontinuität zugeschrieben werden (BóNA-NAGY 2002, 146). NAGY 2008

${ }^{136}$ Zusammenfassend: CSEH 1990, 37-38; SZÉCSÉNYI-

${ }^{137}$ O. LÁsZló-T. HAJdu-Zs. Bernert: A comprehensive study of artificial cranial deformation in Gepidic populations from Hungary. In: M. Teschler-Nicola-W. Baumann (eds): Abstract book of the 18th European Meeting of the Paleopathology Association. Wien 2010, 147. Bezüglich der Gesamtgrabzahl habe ich keine Informationen.

${ }^{138}$ Im Rahmen der OTKA-Ausschreibung Nr. PD 104728 haben Tamás Hajdu, Tímea Balassa und Ildikó Pap die Untersuchungen durchgeführt. Im Idealfall kann der Anteil der entstellten Schädel im Gräberfeld nicht an der Gräberzahl, sondern der Zahl der vorhan- denen Schädel ausgerechnet werden. Diese Zahl steht mir nur beim Gräberfeld von Hajdúnánás zur Verfügung.

${ }^{139}$ Freundliche schriftliche Mitteilung von Szilárd Gál, der das anthropologische Material von Szászfenes aufgearbeitet hat.

${ }^{140}$ In Kiszombor Gräberfeld B hatten nach Lajos Bartucz 21 Individuen einen entstellten Schädel, nach neueren Untersuchungen jedoch nur 9 (LITÁK-MARCSIK 1977).

${ }^{141}$ Margit Nagy erwähnt in ihrer archäologischen Publikation von Szőreg nur 3 Schädel als entstellt (NAGY 2005c, 195); aufgrund der anthropologischen Literatur sind 7 als solche zu betrachten. Zusammenfassend: SZÉCSÉNYI-NAGY 2008, 105-107.

142 BÓNA 2002c, 236

${ }^{143}$ BÓNA-NAGY 2002b, 73, 75.

${ }^{144}$ BERECZKI-MARCSIK 2006; CSALLÁNY 1961, 36-37, 52-53.

${ }^{145}$ KŐVÁRI-SZATMÁRI 2003.

${ }^{146}$ Rákóczifalva-Bivalytó Rokkant-föld I.: HAJDUBERNERT 2007 


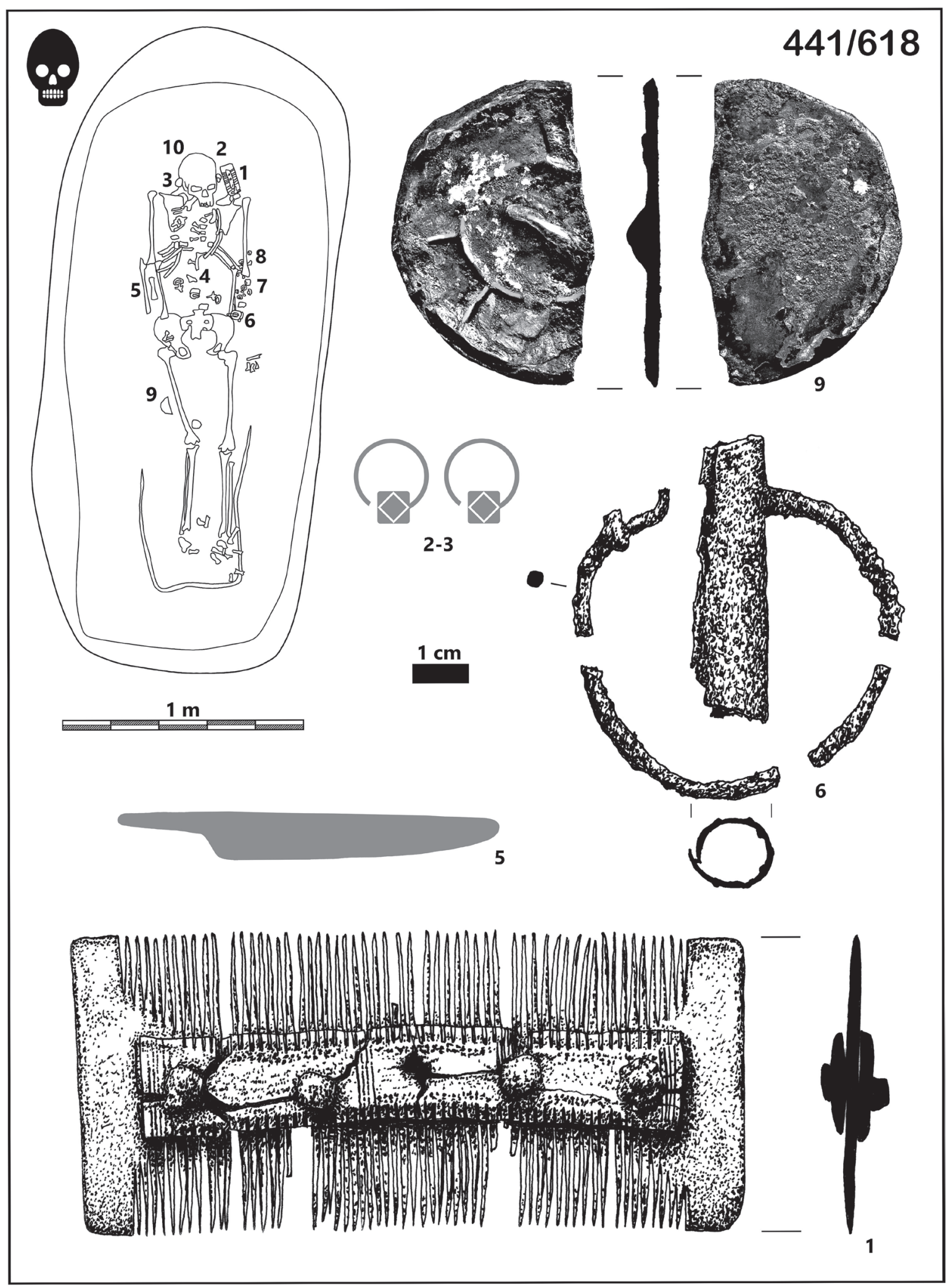

Abb. 15. Hajdúnánás-Fürj-halom-dülő, Grab 441/618 (,Gründergrab“) 
unsere Beobachtungen beeinflussen: ${ }^{147}$ Ist er sehr klein, müssen wir damit rechnen, dass die Ergebnisse zugunsten der Erwachsenen geändert werden.

Am Fundort Hajdúnánás-Fürj-halom-dűlő kann aufgrund der anthropologischen Untersuchungen festgestellt werden, dass von den insgesamt 15 deformierten Schädeln 8 die Spuren einer ausgesprochen starken Verformung aufwiesen $(A b b .14)$. Von ihnen waren 5 Individuen Erwachsene im Maturus-Alter (3 Männer und 2 Frauen), ein Mann im fortgeschrittenen Adultus-Alter (30-39 Jahre), eine Frau im etwas jüngeren Adultus-Alter (25-34 Jahre) sowie ein 1-2-jähriges Kind. Die junge Frau (mit Bensteinperlen und Spiegel) ist gerade die als Gründergrab des Gräberfeldes bestimmte Bestattung. Das Grab des Kleinkindes kann nicht genauer datiert werden: Es enthielt nur Kamm und Eisenschnalle. Die übrigen 7 Bestattungen mit mäßig oder schwach deformierten Schädeln gehörten zu Skeletten von 5 Frauen im Adultus- und einer im Maturus-Alter sowie zu einem Kleinkind von 3,5-4,5 Jahren. Das letztere Grab ist für die Datierung besonders wichtig: Das Fundmaterial mit zahlreichen Perlen und mit Vogelfibel kann an die Wende des 5./6. Jahrhunderts datiert werden. ${ }^{148}$ Das Kleinkindergrab beweist eindeutig, dass die hier bestattende Gemeinschaft - an der Wende des 5./6. Jahrhunderts noch ganz sicher - das in der Säuglingszeit vorzunehmende Körpermodifizierungsverfahren geübt hat, wenn auch nicht in seiner stärksten Form. Das Gründergrab und das hohe Lebensalter des Individuums mit stark verformtem Schädel zeigen zugleich, dass der Brauch eher in der frühen Phase der Belegung typisch war. In keinem einzigen der Gräber mit späteren Gegenstandstypen lag ein Skelett mit deformiertem Schädel. Nach einer vorläufigen anthropologischen Mitteilung über den Fundort Tiszagyenda gab es auch in diesem Gräberfeld ein Kleinkind mit deformiertem Schädel. ${ }^{149}$

Ausgehend von Anna Szécsényi-Nagys Sammlung in ihrer Diplomarbeit kann festgestellt werden, dass in den übrigen gepidenzeitlichen Reihengräberfeldern weder Individuen mit deformiertem Schädel im Infans- noch im Juvenis-Alter bestattet worden waren. ${ }^{150}$ In Hódmezővásárhely-Kishomok, Kiszombor und Szöreg ist diese Erscheinung vor allem an Erwachsenen im Maturus- und Adultus-Alter (mehrheitlich an Männern) zu verfolgen. ${ }^{151}$ Vom Fundort Szolnok-Szanda liegt keine anthropologische Analyse vor. In der archäologischen Publikation sind 6 Individuen als deformiert bestimmt, sie sind jedoch alle Erwachsene. ${ }^{152}$ In Ártánd-Lencsésdomb und Hódmezővásárhely-Gorzsa hatten je eine senile bzw. ältere Frau deformierte Schädel. ${ }^{153}$ Wichtige Funde sind noch die kleinen Gräberfelder von Mezőkeresztes-Cethalom und Szolnok-Zagyvapart mit je einem gut datierbaren Frauengrab: In den Bestattungen vom Ende des 5. Jahrhunderts lagen Frauen im Adultus-Alter, die wahrscheinlich etwa in der Jahrhundertmitte, eventuell im dritten Viertel, geboren wurden. ${ }^{154}$

Insgesamt ist festzustellen, dass die gepidenzeitlichen Bestattungen mit deformiertem Schädel eher Beweise für die in der Hunnenzeit, Mitte des 5. Jahrhunderts, geborenen Individuen sind als für das intensive „Weiterleben" des Brauchs. Einige Gemeinschaften mögen aber noch einige Jahrzehnte nach der Jahrhundertmitte die Körpermodifizierungspraxis weiter gepflegt haben (Hajdúnánás).

${ }^{147}$ Bezüglich des Anteils und des genauen Alters der Kinder verfüge ich über ausführliche Angaben nur aus dem Gräberfeld von Hajdúnánás (s. Anm. 137): Die noch nicht Erwachsenen machten ca. $32 \%$ der Bevölkerung aus. (Selbst noch bei den urzeitlichen Populationen ist eine Bevölkerung bekannt, bei der dieser Anteil über 50 $\%$ beträgt. Berücksichtigt man aber die Serien der untersuchten Epoche, gelten auch schon diese $32 \%$ als hoher Wert.) Die Neugeborenen und Juvenis-Altrigen (15-19-Jährigen) fehlen jedoch fast völlig im Fundmaterial. Demgegenüber nähert sich die Zahl der in die 1-9-jährigen Altersgruppen gerechneten Individuen den vorweg erwarteten Werten an.

$$
{ }^{148} \text { RÁCZ } 2011 .
$$

${ }^{149}$ Die Publizierung der anthropologischen Analyse dieser Gräberfelder wird wegen der hohen Fallzahl besonders wichtig für die Beurteilung der gepidenzeitlichen Schädeldeformation; s. Anm. 134.
${ }^{150}$ SZÉCSÉNYI-NAGY 2008.

${ }^{151}$ SZÉCSÉNYI-NAGY 2008.

152 BÓNA 2002c, 236.

153 Ártánd-Lencsésdomb Grab 6 (MESTERHÁzY 2005, 55); Hódmezővásárhely-Gorzsa Grab 93 (CsAlláNY 1961, 129).

${ }^{154}$ CSEH 2005a, 22; SiMONYI 2005, 206. Ein großer Teil der Bestattungen mit entstelltem Schädel enthielt leider kein gut datierbares Fundmaterial. Diesbezüglich wäre die Kenntnis der Sterbealterangaben von Szolnok-Szanda Grab 1 wichtig, des an die Wende 5./6. Jahrhundert oder Anfang 6. Jahrhundert datierbaren Frauengrabes mit Fibel, bzw. auch die Information, ob der männliche Tote im MaturusAlter im auf die Wende 5./6. Jahrhundert datierten Szőreger Grab 10 tatsächlich einen entstellten Schädel hatte. Diesbezüglich sind die Angaben in der Fachliteratur widersprüchlich; s. SzÉCSÉNYI-NAGY 2008 . 


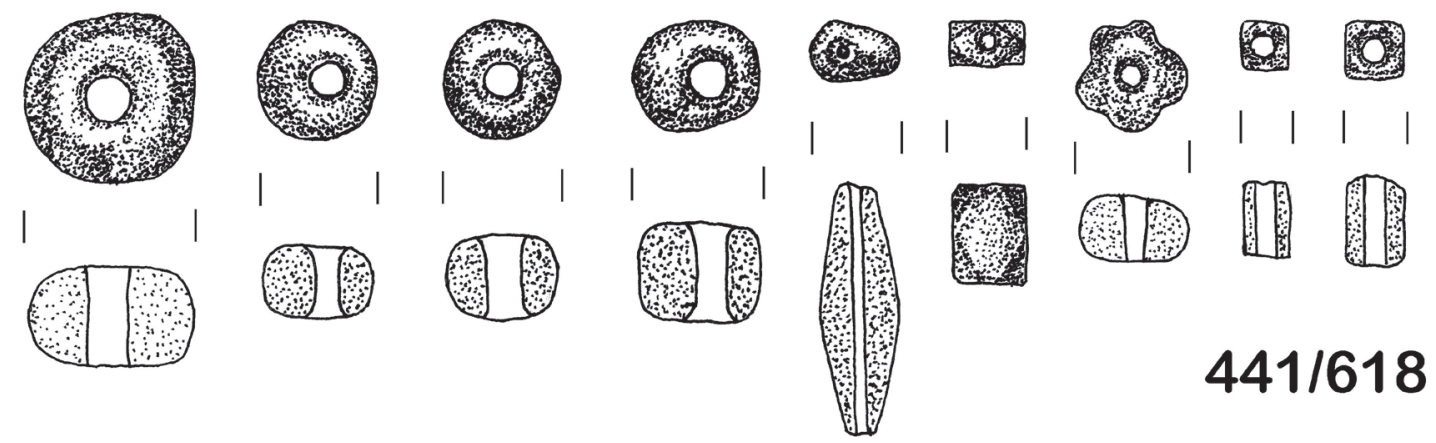

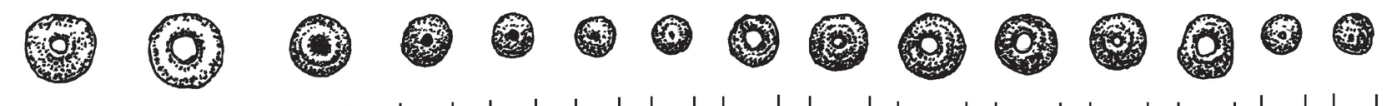

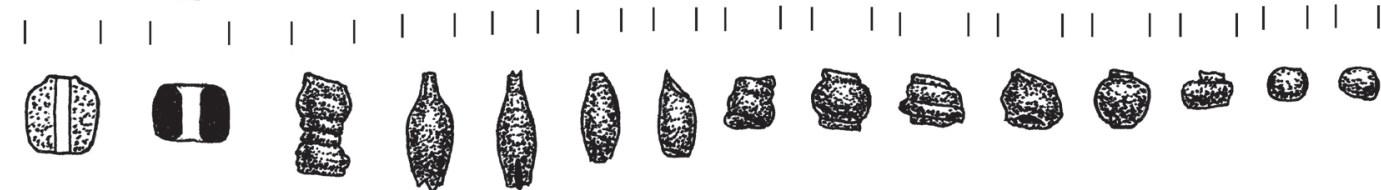

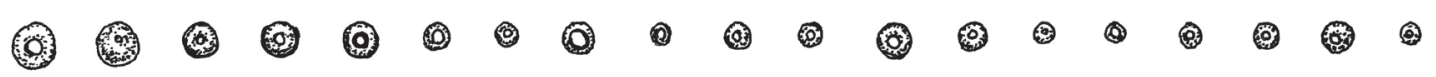

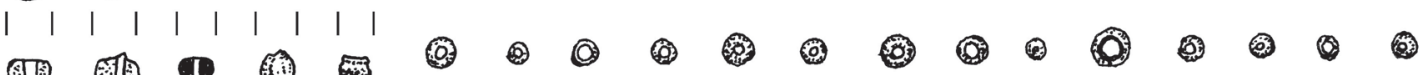

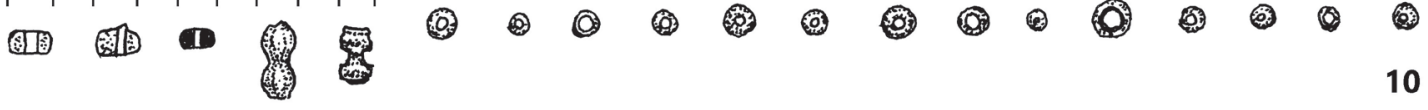
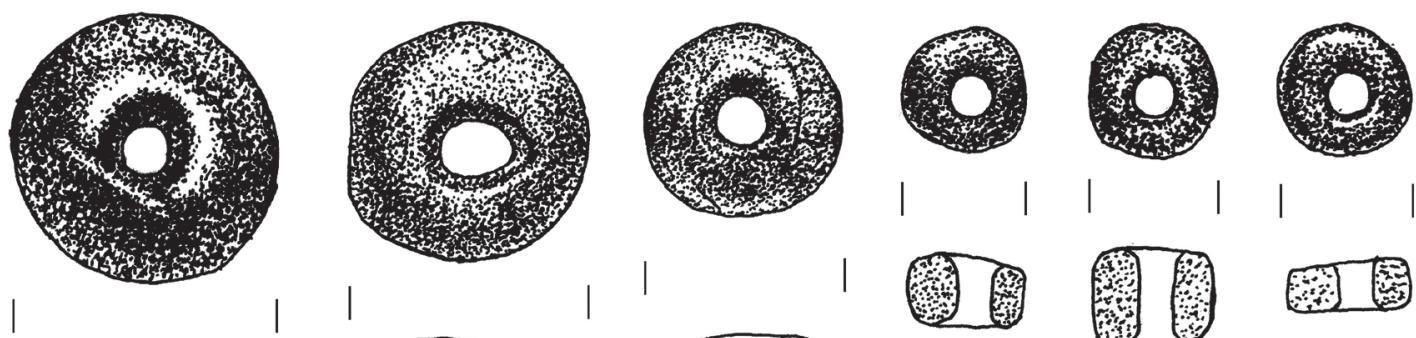
|
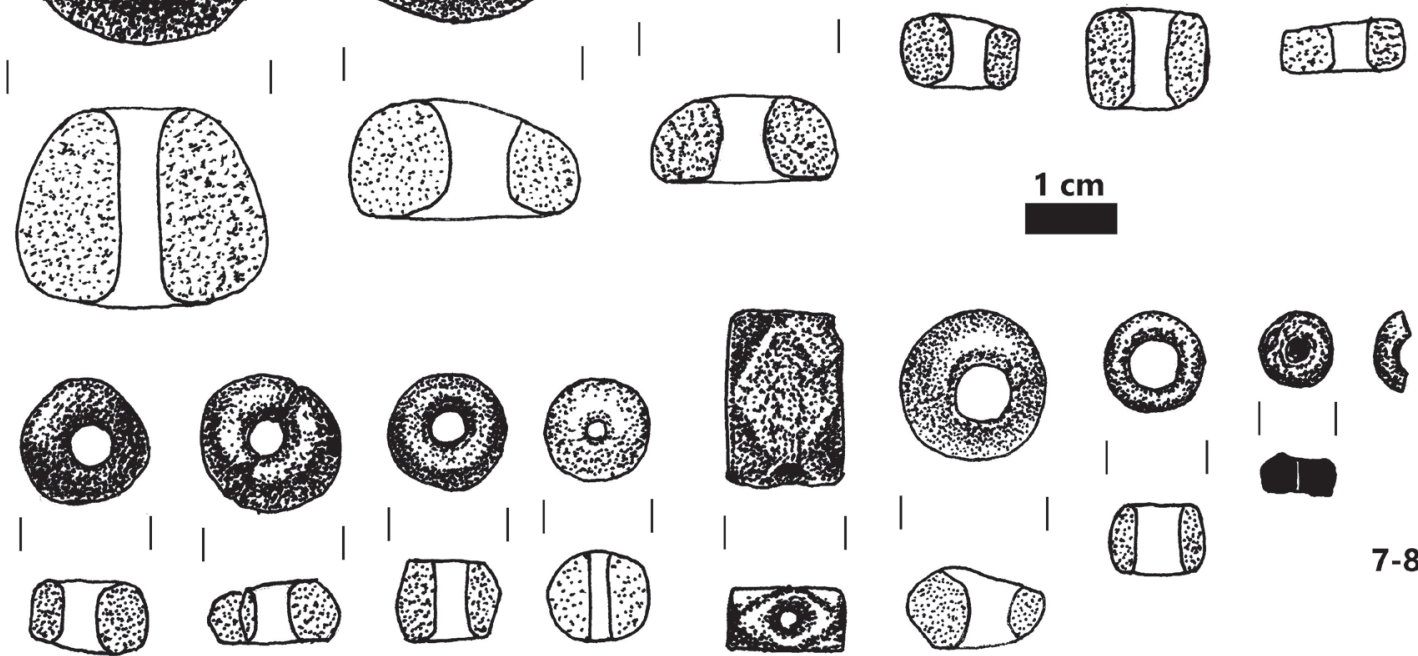

闵图

Abb. 16. Hajdúnánás-Fürj-halom-dülő, Grab 441/618 („Gründergrab“) 


\section{ZUSAMMENFASSUNG}

Die Untersuchung des Bestattungsritus, der Zusammensetzung und der Elemente der Frauenkleidung und der Bestattungen mit deformierten Schädeln hat übereinstimmend gezeigt, dass es zwischen den Gräberfeldern, kleinen Grabgruppen und Einzelbestattungen des 5. Jahrhunderts und den frühen Gräbern der gepidischen Reihengräberfelder des 5.-6. Jahrhunderts eindeutige Zusammenhänge und Parallelitäten gibt. Von diesen Aspekten her betrachtet wird man Zeuge einer kontinuierlichen Umgestaltung zwischen der Hunnen- und Gepidenzeit. Dieser Prozess kann auch mit den Ergebnissen statistischer Untersuchungen illustriert werden. All das deutet darauf hin, dass der Beginn der neuen Gräberfelder mit hoher Gräberzahl keine scharfe kulturelle Grenzlinie bedeutet. Die Machtstruktur hatte sich geändert, im politischen Sinne handelt es sich seit der zweiten Hälfte des 5. Jahrhunderts im Theißgebiet und in Siebenbürgen um Gebiete unter gepidischer Herrschaft, aber das war nicht verbunden mit dem Verschwinden der von der früheren Struktur geschaffenen Charakteristiken, mit der plötzlichen, radikalen Veränderung der materiellen Kultur oder der Bestattungsbräuche. Die Entstehung von Gräberfeldern mit hoher Gräberzahl spiegelt eher - darüber hinaus, dass sie in dieser Epoche der allgemeinen Tendenz entspricht - die mit der Entstehung des gepidischen Königtums stufenweise politische Konsolidierung des Gebiets.

An der Wende des 4./5. Jahrhunderts erschien im Kreis der weiblichen Mitglieder der Barbarenelite - auf barbarischen und antiken Grundlagen - ein Repräsentationsmuster, das bis in die Mitte des 5. Jahrhunderts in einer weiten geographischen Region und bei breiten Schichten der Bevölkerung Nachfolger fand. Die Vervollständigung der Mode und ihr Höhepunkt kann auf die Mitte und zweite Hälfte des 5. Jahrhunderts gelegt werden - das zeigt das unterschiedliche Accessoire: die große Zahl der Ohrringe, die perlenreiche Kleidung, die Blechfibeln, Kleidernadeln, kerbschnittverzierten Gegenstände und auch der hohe Anteil von Schädeldeformation. Die neue Mode kann weder ethnisch noch gesellschaftlich einer engeren Gruppe zugeeignet werden. Die wichtigste Rolle bei der Verbreitung der Kleidung im Mitteldonaugebiet wird die Elitenschicht der Hunnenherrschaft und der diese ablösenden barbarischen Staatsgebilde gespielt haben. Das spezielle Frauenset kann im gesamten Karpatenbecken auch noch in der zweiten Hälfte des 5. Jahrhunderts verfolgt werden, was - ungeachtet der politischen Zergliedertheit - auch weiterhin auf die kulturelle Einheit des Gebiets hinweist. Mit der Beschreibung der im Laufe des 5. Jahrhunderts beobachteten Veränderungen (beispielsweise der wachsenden Bedeutung der in der Körpermitte getragenen Perlen und der auf dem Bauch angesteckten Fibel) können wir die Veränderung der Mode, nicht aber die Siedlungsgebiete verschiedener Gentes rekonstruieren.

Die Beurteilung dessen, ob die in der zweiten Hälfte des 5. Jahrhunderts und auch später, um die Wende des 5./6. Jahrhunderts verfolgte typische Frauenkleidung ein gewisses bewusstes Festhalten, einen Rückgriff auf die Repräsentationsbräuche der Hunnenepoche zum Ausdruck brachte, ist eine schwerere Frage. ${ }^{155}$ Ich halte es für möglich, dass im Kreis jener Elite, die in reichen Gräbern bestattet wurde, die in die zweite Hälfte bis ans Ende des Jahrhunderts datiert werden können, auch dieser Gedanke eine Rolle gespielt haben kann. ${ }^{156}$

\section{LITERATUR}

ALMÁSsY et al. 2005

AMENT 2003

ANKE 1998

\footnotetext{
= K. Almássy-C. Astaloș-A. Babolcsi-B. Gergely-E. Istvánovits-C. Virag: NyíregyházaRozsrétszőlő, Nevelős-homokbányától D-re (Varga-tábla) (Nyíregyháza-Rozsrétszőlő, south from the sand mine Nevelős, Varga-tábla). RégKut 2005. Budapest 2006, 291-292.

= H. H. AMENT: Reihengräberfriedhöfe. In: RGA 24. Berlin-New York 2003, 362-365.

= B. ANKE: Studien zur reiternomadischen Kultur des 4. bis 5. Jahrhunderts. Weißbach 1998
}

${ }^{155}$ Darauf verweist eine interessante Erscheinung, mit der ich mich im Rahmen dieser Studie nicht beschäftigte: In Einzelfällen ist zu beobachten, dass die Prestigegegenstände sehr in Ehren gehalten, sehr lange gebraucht werden und abgenutzt-repariert (z. B. Turda; BĂRBULESCU 2008) oder gar pars pro toto ins Grab gelegt werden (Singidunum 63: IVANIŠEVIĆ-KAZANSKI 2002, 134).
${ }^{156}$ Die Studie konnte mit Hilfe der OTKA-Ausschreibung Nr. PD 104728 und des János Bolyai-Forschungsstipendiums (BO/00468/13) verwirklicht werden.

Ich möchte mich für die vielen Gespräche und Ratschläge bei meinen Kollegen, Adrienn Blay, Zsuzsanna Siklósi, Péter Tomka, Tivadar Vida, István Koncz, Levente Samu und für die Hilfe bei der Hauptkomponentanalyse bei Péter Csippán herzlich bedanken. 
BÁCSMEGI-GUBA 2007

BĂRBULESCU 2008

BARKÓCZI-SALAMON 1976

BARTUCZ 1936

BĂRZU 1986

BĂRZU-HARHOIU 2008

BENINGER 1929

BENINGER 1931

BENINGER 1934

BENINGER 1937

BENINGER-FREISING 1933

BERECZKI-MARCSIK 2006

BIERBRAUER 1995

BIERBRAUER 1998

BIERBRAUER 2006

BíRÓ-TOMKA im Druck

BoNDÁR-HoNTI-KISs 2000

BONDÁR et al. 2007

BÓNA 1960

BÓNA 1971

BÓNA 1993

BÓNA 2002a

BÓNA 2002b

BÓNA 2002c

BÓNA et al. 1993

BÓNA-NAGY 2002a

BÓNA-NAGY 2002b

BRATHER 2002
= G. BÁCSMEGI-Sz. GuBA: Letűnt korok emlékezete. Szurdokpüspöki régmúltja a legújabb régészeti kutatások tükrében [Erinnerung an vergangene Zeiten. Die frühe Vergangenheit von Szurdokpüspöki im Spiegel der neuesten archäologischen Forschungen]. Szurdokpüspöki 2007.

= M. BĂRBULESCU: Mormântul princiar germanic de la Turda (Das germanische Fürstengrab von Turda). Cluj-Napoca 2008.

= L. BARKÓCZI-Á. SALAMON: Das Gräberfeld von Szabadbattyán aus dem 5. Jahrhundert. MittArchInst $5(1974 / 75$ [1976]) 89-111.

= L. BARTUCZ: A kiszombori temető gepida koponyái (Die Gepiden-Schädel des Gräberfeldes von Kiszombor). Dolg 12 (1936) 178-204.

= L. BĂRZU: Monumente germanice descoperite la Bratei, jud. Sibiu (Monuments germaniques découverts à Bratei dép. de Sibiu). SCIVA 37 (1986) 89-101.

= L. BĂRZU-R. HARHOIU: Gepiden als Nachbarn der Langobarden und das Gräberfeld von Bratei. In: J. Bemmann-M. Schmauder (Hrsg.): Kulturwandel in Mitteleuropa. Langobarden - Awaren - Slawen. Bonn 2008, 513-578.

= E. BENINGER: Germanengräber von Laa an der Thaya (N.-Ö.). Eiszeit und Urgeschichte 6 (1929) 143-155.

= E. BENINGER: Der westgotisch-alanische Zug nach Mitteleuropa. Mannusbibliothek 51. Leipzig 1931.

= E. BENINGER: Die Germanen in Niederösterreich - von Marbod bis zu den Babenbergern. Wien 1934.

= E. BENINGER: Die germanischen Bodenfunde in der Slowakei. Reichenberg-Leipzig 1937.

= E. BenINGER-H. Freising: Die germanischen Bodenfunde in Mähren. Reichenberg 1933.

= Zs. BERECZKI-A. MARCSIK: Artificial cranial deformation in Hungary. In: M. B. Mednikova (ed.): Iskusstvennaja deformacija golovy čeloveka v proslom Evrazii (Artificial deformation of human head is Eurasian past). OPUS. Meždisciplinarnye issledovanija v archeologii 5. Moskva 2006, 96-114.

= V. BIERBRAUER: Das Frauengrab von Castelbolognese in der Romagna (Italien). Zur chronologischen, ethnischen und historischen Auswertbarkeit des ostgermanischen Fundstoffs des 5. Jahrhunderts in Südosteuropa und Italien. JRGZM 1991 (1995) 541-592.

= V. Bierbrauer: Gepiden in der Wielbark-Kultur (1.-4. Jahrhundert n. Chr.)? Eine Spurensuche. In: A. Wessb (Hrsg.): Studien zur Archäologie des Ostseeraumes. Von der Eisenzeit bis zum Mittelalter. Festschrift für Michael Müller-Wille. Neumünster 1998, 389-403.

= V. BIERBRAUER: Gepiden im 5. Jahrhundert. Eine Spurensuche. In: V. Mihailescu-Bîrliba-C. HribanL. Munteanu (eds): Miscellanea romano-barbarica. In honorem septagenarii magistri Ion Ioniță oblata. București 2006.

= Sz. BíRÓ-P.TOMKA: Über die mysteriöse „schwarze Schicht“ und das sog. „hunnenzeitliche Gräberfeld“ von Győr-Széchenyi-Platz. In: Festschrift für den 80. Geburtstag von Jaroslav Tejral. Brno. Im Druck.

= M. BondÁR-Sz. HonTI-V. KISS: A tervezett M7-es autópálya Somogy megyei szakaszának megelőző régészeti feltárása (1992-1999). Előzetes jelentés I. (The preceding archeological excavation of the planing M7 highway in County Somogy (1992-1999). Preliminary report I). SMK 14 (2000) 93-114.

= M. BondÁR-Sz. Honti-G. MÁRKus-P. G. NÉMETH: Balatonszemes-Szemesi-berek. In: K. Belényesy-Sz. Honti-V. Kiss (eds): Gördülő idő. Régészeti feltárások az M7-es autópálya Somogy megyei szakaszán Zamárdi és Ordacsehi között (Rolling time. Excavation on the M7 motorway in County Somogy between Zamárdi and Ordacsehi). Kaposvár 2007, 123-133.

= I. BóNA: A soponyai germán temető (Das germanische Gräberfeld von Soponya). Alba Regia 1 (1960) 165-166

= I. BóNA: Fejér megye története. 1. Fejér megye története az őskortól a honfoglalásig. 5. A népvándorlás kora Fejér megyében. [Geschichte des Kom. Fejér. 1. Geschichte des Kom. Fejér von der Urzeit bis zur Landnahme. 5. Die Völkerwanderungszeit im Kom. Fejér]. Székesfehérvár 1971.

= I. BóNA: A hunok és nagykirályaik [Die Hunnen und ihre Großkönige]. Budapest 1993.

= I. BóNA: Barabás-Bagolyvár. In: BóNA-NAGY 2002a, 17-21.

= I. BÓNA: Domoszló-Víztároló. In: BóNA-NAGY 2002a, 27-28.

= I. BóNA: Szolnok-Szanda. In: BóNA-NAGY 2002a, 197-237.

= I. BÓNA-J. CSEH-M. NAGY-P. TOMKA-Á. TÓTH: Hunok-Gepidák-Langobardok. Történeti régészeti tézisek és címszavak [Hunnen - Gepiden - Langobarden. Historische archäologische Thesen und Stichwörter]. Magyar őstörténeti könyvtár. Szeged 1993.

= I. BÓNA-M. NAGY: Die Gräberfelder der Gepiden am Theißgebiet I. MonGermArchHung 1. Budapest 2002

= I. BóNA-M. NAGY: Hódmezővásárhely-Kishomok. In: BóNA-NAGY 2002a, 34-189.

$=\mathrm{S}$. BRATHER: Ethnische Interpretationen in der frühgeschichtlichen Archäologie. Ergänzungsbände zum RGA 42. Berlin-New York 2002. 
BRUNŠMID 1905

BUDINSKÝ-KRIČKA 1950

BuGARSKI 2012

CSALlÁNy 1958

Csallány 1961

\section{CSEH 1990}

CSEH 2005a

CSEH 2005b

CSEH et al. 2005

DARNAY 1901

DAUTOVA-RuŠEVLJAN 1981

Cs. DAX 1980

DIACONU-DÖRNER 1967

DimitRIJEVIĆ 1964

Dobos 2012

DOMBAY 1956

FEHR 2008

FERENCZ-NAGY-LĂZĂRESCU 2009

FITZ-LÁNYI-BÁNKI 1975

GÁBOR 1998

GALLINA 2005

GARAM-VADAY 1990

GAUss 2009

GiNDELE et al. 2004

GLODARIU 1974

GRÓF 1992

GubITZA 1899

GuBITZA 1902

HAJDU-BERNERT 2007

HAKENBECK 2009
= J. BRUNŠMID: Starine ranijega srednjega vijeka iz hrvatske i Slavonije I. VHAD 8 (1905) 208-220. $=\mathrm{V}$. BUDINSKÝ-KRIČKA: Prehistorické a ranodejinné nálezy v Leviciach (Trouvailles préhistoriques et protohistoriques de Levice en Slovaquie). AR 2 (1950) 153-158.

= I. BUGARSKI: Occupation of the south Pannonian soil during Late Antiquity and the Migration period: Šajkaška revisited. In: V. Ivanišević-M. Kazanski (eds): The Pontic-Danubian Realm in the Period of the Great Migration. Paris-Beograd 2012, 11-34.

= D. CSALLÁNY: Hamvasztásos és csontvázas hun temetkezések a Felső-Tisza vidékén (Die hunnenzeitlichen Brand- und Skelettgräber in den Gebieten am oberen Lauf der Theiß). HOMÉ 2 (1958) 83-99.

= D. CsallánY: Archäologische Denkmäler der Gepiden im Mitteldonaubecken (454-568 u. Z.). ArchHung 38. Budapest 1961

= J. CsEH: Adatok az V-VII. századi gepida emlékanyag egységéhez [Angaben zur Einheit des gepidischen Fundmaterials im 5.-7. Jh.]. SzMMÉ 7 (1990) 29-80.

= J. CSEH: Szolnok-Zagyva-part, Alcsi. In: CSEH et al. 2005, 18-33.

= J. CSEH: Tiszaföldvár-Érhalom, Patkós tanya. In: CSEH et al. 2005, 34-36.

= J. Cseh-E. Istvánovits-E. Lovász-K. Mesterházy-M. Nagy-I. M. NepPer-E. Simonyi: Gepidische Gräberfelder im Theißgebiet II. MonGermArchHung 2. Budapest 2005.

= K. DARNAY: Sümeghvidéki emlékek a régibb középkorból [Funde der Gegend um Sümeg aus dem früheren Mittelalter]. ArchÉrt 21 (1901) 176-182.

= V. DAutova-RuŠEVLJAn: Ein germanisches Grab auf dem Fundort Vranja bei Hrtkovci in Syrmien. AI 20-21 (1980-1981 [1981]) 146-153.

= M. Cs. DAX: Keleti germán női sírok Kapolcson (Ostgermanische Frauengräber in Kapolcs). VMMK 15 (1980) 97-106.

= GH. DiACONU-E. DöRnER: Zwei ostgotische Fibeln im Arader Museum. Dacia 11 (1967) 349-354.

= D. DimitriJević: Le cimitière gépide à „Kormadin“ près de Jakovo en Srem, Serbie. Inventaria Archaeologica 7 (1964).

= A. Dobos: Migration Period and Early Medieval Cemeteries at Fântânele (Bistriţa-Năsăud County). Cluj-Napoca 2012.

= J. DombaY: Der gotische Grabfund von Domolospuszta. JPMÉ 1 (1956) 104-129.

$=$ H. FEHR: Germanische Einwanderung oder kulturelle Neuorientierung? Zu den Anfängen des Reihengräberhorizontes. In: S. Brather (Hrsg.): Zwischen Spätantike und Frühmittelalter. Berlin-New York 2008, 67-102.

= SZ. FERENCZ-SZ. NAGY-V. LĂZĂRESCU: Necropola din secolul al VI-lea p. Chr. (The sixth century A.D. necropolis). In: S. Mustaţă-F. Gogâltan-S. Cociş-A. Usuţiu (eds): Cercetări arheologice preventive la Floreşti-Polus center, jud. Cluj (2007) (Rescue excavations at Floreşti-Polus center, Cluj County, 2007). Cluj-Napoca 2009.

= J. FITZ-V. LÁNYI-Zs. BÁNKI: Kutatások Gorsiumban 1973-ban (Forschungen in Gorsium im Jahre 1973). Alba Regia 14 (1975) 289-333.

= O. GÁBoR: 5. századi sírok Kővágószőlős határában (Fifth century Cemetery from Kövágószőlős, County Baranya, South Hungary). JPMÉ 43 (1998 [1999]) 131-140.

= Zs. GALLINA: 5. századi sírok Ordacsehi-Csereföldön [Gräber aus dem 5. Jahrhundert in OrdacsehiCsereföld]. ZalaiMúz 14 (2005) 129-135.

= É. GARAM-A. H. VADAY: Sarmatische Siedlung und Begräbnisstätte in Tiszavalk. ComArchHung (1990) 171-219.

= F. GAUSS: Völkerwanderungszeitliche „Blechfibeln“: Typologie, Chronologie, Interpretation. Ergänzungsbände zum RGA 67. Berlin-New York 2009.

= L. Marta-C. Astalos-Z. KÁdas-C. VIRAG-D. SANA: Nyíregyháza-Oros, Úr-Csere. In: RégKut 2004. Budapest 2005, 256-257.

= I. GlodARIU: Ein Grab aus dem 5. Jahrhundert in Slimnic (Rumänien). Germania 52/2 (1974) 483-489.

= P. GRÓF: Népvándorláskori vonatkozások egy késő római erőd és temető feltárásának kapcsán (Völkerwanderungszeitliche Bezüge im Zusammenhang mit der Erschließung einer spätrömischen Festung und eines Gräberfeldes). JAMÉ 30-32 (1987-1989 [1992]) 129-144.

= K. GUBITZA: A bodrogh-monostorszegi leletekről [Über die Funde von Bodrogmonostorszeg]. ArchÉrt 19 (1899) 264-268.

= K. GuBITZA: A bodrogh-monostorszegi sírleletekről [Über die Grabfunde von Bodrogmonostorszeg]. ArchÉrt 22 (1902) 338-342.

$=$ T. HAJDU-Zs. BERNERT: Embertani adatok a Tisza-vidék szarmata és gepida korához (Anthropological data to Sarmatian and Gepid Age of the Tisza region). Tisicum 16 (2007) 327-344.

= S. E. HAKENBECK: 'Hunnic' modified skulls: Physical appearance, identity and the transformative nature of migrations. In: H. Williams-D. Sayer (eds): Mortuary Practices and Social Identities in the Middle Ages. Essays in Honour of Heinrich Härke. Exeter 2009, 64-80. 
HALSALL 2010

HAMPEL 1871

HAMPEL 1891

HAMPEL 1911

HARHOIU 1997

HARHOIU-GáLL-LAKATOS 2009

HEINRICH 1990

HeInRICH-TAMÁSKA-STRaub 2015

HORVÁTH 2012

HORVÁTH-BENDŐ 2011

IsTVÁNOVITS 1993

ISTVÁNOVITS 1996

IsTVÁNOVITS 1998

ISTVÁNOVITS 2000

ISTVÁNOVITS-KULCSÁR 1993

ISTVÁNOVITS-KULCSÁR 1999

ISTVÁNOVITS-MESTERHÁZY-NEPPER 1996 = E. IstVÁNOVITS-K. MESERHÁZY-I. M. NEPPER: Hunnenzeitliche Gräber von Ártánd. In: Hunnen + IVANIŠEVIĆ-KAZANSKI 2002

= V. IvanišEvić-M. KAZANSKi: La nécropole de l'époque des Grandes Migrations à Singidunum. Singidunum 3 (2002) 101-158.

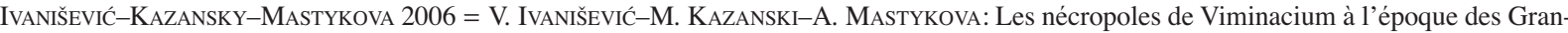
des Migrations. Collége de France - CNRS Centre de Recherche d'Histoire et Civilisation de Byzance. Monographies 22. Paris 2006.

Kat. Germanen

Kat. Ori antichi

KAZANSKI 1990

KAZANSKI-MASTYKOVA 2003

H. KeLEMEN 2008

eology, 1992-2009. Brill's Series on the Early Middle Ages 18. Leiden-Boston 2010.

$=$ J. HAMPEL: A szabolcsmegyei muzeum II. [Das Museum vom Kom. Szabolcs II]. ArchÉrt 5 (1871) $77-86$.

= J. HAMPEL: Népvándorláskori kincs Szabolcsmegyében [Ein völkerwanderungszeitlicher Schatzfund im Kom. Szabolcs]. ArchÉrt 11 (1891) 91-92.

. HAMPEL: A gávai sírlelet (Szabolcs m.) [Der Grabfund von Gáva, Kom. Szaboles]. ArchErr 31 $35-147$

ARHOIU: Die frühe Völkerwanderungszeit in Rumänien. Archaeologia Romanica 1. Bukarest

R. HaRholu-E. GálL-A. LaKatos: Gräberfeldsteile von Oradea-Salca Gheţărie aus dem 5. und 10.-11. Jahrhundert. ArchÉrt 134 (2009) 217-258 ArchA 74 (1990) 85-104.

= O. HeINRICH-TAMÁSKA-P. STRAUB: Zur Datierung und Deutung der Gräber und Gräberfelder des 5 . Jahrhunderts n. Chr. in Pannonia Prima und Valeria. In: T. Vida (ed.): Romania Gothica II. The

E. HORVÁTH: Ékkö- es üvegberakásos ötvöstárgyak a Kärpat-medence hun kori és kora Meroving Hunnic and Early Merovingian Periods). Doktori disszertáció, ELTE BTK. Budapest 2012.

E. HoRVÁtH-Zs. BENDö: Provenance study on a collection of loose garnets from a Gepidic period AMühely 2011, 17-32.

= E. IsTVÁNOviTS: Das Gräberfeld aus dem 4.-5. Jahrhundert von Tiszadob-Sziget. ActaArchHung 45 (1993) 91-146.

Reitervölker aus dem Osten. Ausstellungskatalog Schloß Halbturn. Eisenstadt 1996, 104-105. Ende des 4. und Anfang des 5. Jahrhunderts). MFMÉ-StudArch 4 (1998) 309-324.

= E. IsTVÁNovits: Völker im nördlichen Theißtal am Vorabend der Hunnenzeit. In: J. Bouzek-H. Friesinger-K. Pieta-B. Komoróczy (Hrsg.): Gentes, Reges und Rom. Auseinandersetzung - AnerČR Brno 16. Brno 2000, 197-208.

= E. ISTVÁNOVITS-V. KULCSÁR: Tükrök a császárkori és a kora népvándorlás kori barbár népeknél a Kárpát-medencében (Die Spiegel der kaiser- und frühvölkerwanderungszeitlichen Barbarenvölker m Karpatenbecken. Зеркала варварских народов Карпатского Бассейна в римское время и раннюю эпоху переселения народов). НОМЕ 30-31/2 (1993) 9-58.

E. IsTVÁNOVITS-V. KulCSÁR: Sarmatian and Germanic people at the Upper Tisza Region and South Alföld at the beginning of the Migration Period. In: J. Tejral-Ch. Pilet-M. Kazanski (red.): L'Occident romain et l'Europe centrale au debut d l'époque des Grandes Migrations. Brno 1999, 67-94

= W. Menghin-T. SpRINGER-E. Wamers (Hg.): Germanen, Hunnen und Awaren. Schätze der Völkerwanderungszeit. Ausstellungskatalog des Germanischen Nationalmuseums. Nürnberg 1987.

= E. OBERLÄNDER-TÂRNOVEANU-L. UngaRo (a cura di): Ori Antichi della Romania prima e dopo Traiano. Milano 2010.

= M. KAZANSKI: La diffusion de la mode danubienne en Gaule (fin du $\mathrm{IV}^{\mathrm{e}}$ siècle - début du VI ${ }^{\mathrm{e}}$ siècle): Essai d'interpretation Historique. AntNat 21 (1989 [1990]) 59-73.

= M. KAZANSKI-A. MASTYKova: Les origines du costume ,princier“ féminin des Barbares à l'époque des Grandes Migrations. In: F. Chausson-H. Inglebert (éd.): Costume et société dans l'Antiquité et le haut Moyen Age. Paris 2003, 107-120.

= M. H. KeLEMEN: Solva. Esztergom késő római temetői (Die spätrömischen Gräberfelder von Esztergom). Budapest 2008. 
KISS 1980

KISS 1981

KISS 1983

KIss 1995a

KISS $1995 b$

KISS 1996

KISS 2001

KIss P. 2016

KNUDSON-STOJANOWSKI 2008

KovÁCs 2004

KOVRIG 1951

KOVRIG 1959

KOVRIG 1985

KÖHEGYI-VÖRÖs 2011

KÖVÁRI-SZATMÁRI 2003

KULCSÁR 1998

KULCSÁR 2007

KULCSÁR et al. 2003

LÁNYI 1972

LÁNYI 1981

LEHÓCZKY 1908

LIPPERT 1968

LIPTÁK-MARCSIK 1977

LovÁsz 1986

LovÁsz 1991

LovÁsz 1999

LOVÁSZ 2005

LŐRINCZY-RÁCZ 2015

MAROSI 1937
= A. KISS: Germanische Grabfunde von Szabadbattyán aus dem 5. Jahrhundert. Alba Regia 18 (1980) 105-132.

= A. KISS: Germanischer Grabfund der Völkerwanderungszeit in Jobbágyi (Zur Siedlungsgeschichte des Karpatenbeckens in den Jahren 454-568). Alba Regia 19 (1981) 167-185.

= A. KIss: Die Skiren im Karpatenbecken, ihre Wohnsitze und ihre materielle Hinterlassenschaft. ActaArchHung 55 (1983) 95-131.

= A. KIss: Das germanische Gräberfeld von Hács-Béndekpuszta (Westungarn) aus dem 5.-6. Jahrhundert. ActaAntHung 36 (1995) 275-342.

= A. KIss: Die Werkstätten der Gräberfunde des Gepidenkönigs Omharus von Apahida (Siebenbürgen). ActaArchHung 47 (1995) 305-318.

= A. KIss: Das Gräberfeld von Szekszárd-Palánk aus der zweiten Hälfte des 5. Jh. und der ostgotische Fundstoff in Pannonien. ZalaiMúz 6 (1996) 53-86.

= A. Kiss: Das germanische Frauengrab von Répcelak (Westungarn) aus der zweiten Hälfte des 5. Jahrhunderts. ActaArchHung 52 (2001) 120-144.

= P. KISS: „... ut strenui viri...” A gepidák Kárpát-medencei története [Die Geschichte der Gepiden im Karpatenbecken]. Szeged 2015.

$=$ K. KNUDSON-C. STOJANOWSKI: New directions in bioarchaeology: Recent contributions to the study of human social identities. Journal of Archaeological Research 16/4 (2008) 397-432.

= P. KovÁcs: Hun kori sír Százhalombattán (A grave from the Hun period at Százhalombatta). ComArchHung 2004, 123-150.

= I. KovRIG: A tiszalöki és a mádi lelet [Die Funde von Tiszalök und Mád]. ArchÉrt 78 (1951) 113-120.

= I. KovRIG: Nouvelles trouvailles du V ${ }^{\mathrm{e}}$ siècle découvertes en Hongrie. ActaArchHung 10 (19571959 [1959]) 209-225.

= I. Kovrig: Das Diadem von Csorna. FolArch 36 (1985) 107-148.

= M. KÖHEGYI-G. VÖRÖs: Madaras-Halmok. Kr. u. 2-5. századi szarmata temető [Madaras-Halmok. Ein sarmatisches Gräberfeld aus dem 2.-5. Jh.]. Monográfiák a Szegedi Tudományegyetem Régészeti Tanszékéröl 1. Szeged 2011.

= I. KÖVÁRI-L. SzATMÁRI: A továbbélés megítélése az Ároktő, Csík-gát lelőhelyen feltárt 5-9. századi csontvázleletek alapján (Assessment of surviving relying upon the $5^{\text {th }}-9^{\text {th }}$ century skeletal findings dug up at the location of Ároktő, Csík-gát). HOMÉ 42 (2003) 135-163.

= V. KULCSÁR: A Kárpát-medencei szarmaták temetkezési szokásai (The burial rite of the Sarmatians of the Carpathian basin). Aszód 1998.

= G. KulcsÁr: Ordacsehi-Kistöltés. In: K. Belényesy-Sz. Honti-V. Kiss (eds): Gördülő idő. Régészeti feltárások az M7-es autópálya Somogy megyei szakaszán Zamárdi és Ordacsehi között (Rolling time. Excavation on the M7 motorway in County Somogy between Zamárdi and Ordacsehi). Budapest 2007, 185-192.

= V. Kulcsár-A. NAgY-R. PATAY-T. RÁCZ: Üllő, 5. számú lelőhely (Üllő, Site No. 5). In: RégKut 2003. Budapest 2004, 306-307.

= V. LÁNYI: Die spätantiken Gräberfelder von Pannonien. ActaArchHung 24 (1972) 53-213.

= V. LÁNYI: Das spätrömische Gräberfeld. In: A. Mócsy (Hrsg.): Die spätrömische Festung und das Gräberfeld von Tokod. Budapest 1981.

= T. LEHÓCZKY: Lévai és nagysárói leletekről [Über die Funde von Léva und Nagysáró]. ArchÉrt 28 (1908) 422-424.

= A. LIPPERT: Völkerwanderungszeitliche Grabfunde aus Schletz und Sigmundsherberg in Niederösterreich. Germania 1968, 325-333.

= P. LIPTÁK-A. MARCSIK: Kora-népvándorláskori embertani leletek Kelet-Magyarországon (Anthropologische Funde in Ostungarn aus der Frühvölkerwanderungszeit). DMÉ 1976 (1977) 35-48.

= E. LovÁsz: A tiszakarádi germán temetőről (Über den germanischen Friedhof in Tiszakarád). HOMK 24 (1986) 10-14.

= E. LovÁsz: Újabb adatok Borsod-Abaúj-Zemplén megye 5-6. századi történetéhez. Az egerlövői temető (Beiträge zur Geschichte des Komitates Borsod-Abaúj-Zemplén im 5.-6. Jahrhundert). MFMÉ 1984-85/2 (1991) 55-72.

= E. LovÁsz: Hun és germán jellegű leletek Borsod megyében (Hunnische und germanische Funde im Komitat Borsod). HOMÉ 37 (1999) 237-265.

= E. LovÁsZ: Mezőkövesd-Mocsolyás. In: CsEH et al. 2005, 50-53.

= G. LÕRINCZY-Zs. RÁCZ: Szabolcs-Szatmár-Bereg megye avar sírleletei II. Tiszavasvári-Kashalomdűlő kora avar kori temetkezései (Avarian Finds from Szabolcs-Szatmár-Bereg County II. Early Avarian Graves from Tiszavasvári-Kashalom-dülő). JAMÉ 56 (2014 [2015]) 141-217.

= A. MArosi: A soponyai germán sírlelet [Der germanische Grabfund von Soponya]. Székesfehérvári Szemle 7 (1937) 66-67. 
MARTIN 1995

MESTERHÁZY 1989

MESTERHÁZy 2005

MESTERHÁZy 2009

MÉSZÁRos 1970

MÜLLER 2010

NÁDORFI 1996

NAGY 1993

NAGY 1994

NAGY 1997

NAGY 2005a

NAGY 2005 b

NAGY 2005 c

NAGY $2005 d$

NAGY 2006

NAGY-B. Tóth 1998

NEMESKÉRI 1945

NÉMETI 1967

NÉMETI 1969

NEUMANN 1965

NOVOTNÝ 1976

ÓDOR 2001

OTTOMÁNYI 2001

OTTOMÁNYI 2008

PAPP-SALAMON 1980

PÁRDUCZ 1938

PÁRDUCZ 1959

PÁRDUCZ 1963

PÁRDUCZ-KOREK 1948

PINTYE 2014

Pittioni-Weninger 1944

POHL 1980
= M. MARTiN: Tradition und Wandel der fibelgeschmückten frühmittelalterlichen Frauenkleidung. JRGZM 1991/2, 629-680.

$=\mathrm{K}$. MesterházY: Ethnische und Handelsbeziehungen zwischen der Weichselmündung und der ungarischen Tiefebene in der römischen Kaiserzeit. In: J. Kmieciński (red.): Peregrinatio gothica. Archaeologia Baltica 8. Łódz 1989, 185-202.

= K. Mesterházy: Ártánd-Lencsésdomb. In: CsEH et al. 2005, 54-56.

= K. Mesterházy: Eine Gräbergruppe mit nordsüdlicher Grablegung im gepidischen Gräberfeld von Biharkeresztes-Ártánd-Nagyfarkasdomb. ActaArchHung 60 (2009) 73-95.

= Gy. MÉszÁRos: A regölyi korai népvándorláskori fejedelmi sír (Das Fürstengrab von Regöly aus der Frühvölkerwanderungszeit). ArchÉrt 97 (1970) 66-93.

= R. MÜLlER: Die Gräberfelder vor der Südmauer der Befestigung von Keszthely-Fenékpuszta. Castellum Pannonicum Pelsonense 1. Budapest-Leipzig-Keszthely-Rahden 2010.

= G. NÁDORFI: Gräber der Hunnenzeit in Csákvár. In: Hunnen + Awaren. Reitervölker aus dem Osten. Ausstellungskatalog Schloß Halbturn. Eisenstadt 1996, 96-99.

= M. NAGY: Gepida temetkezés és vallási élet [Bestattung und religiöses Leben der Gepiden]. In: I. Bóna-J. Cseh-M. Nagy-P. Tomka-Á. Tóth: Hunok - Gepidák - Langobardok. Történeti régészeti tézisek és címszavak. Magyar Ôstörténeti Könyvtár. Szeged 1993, 60-61.

= E. NAGY: V. századi népvándorláskori sírok Pécs-Málom lelöhelyen (Graves from the 5th century in Pécs-Málom). JPMÉ 38 (1993 [1994]) 95-102.

= M. NAGY: Szentes és környéke az 1-6. században. Történeti vázlat és régészeti lelőhelykataszter (Szentes und seine Umgebung vom 1. bis 6. Jahrhundert. Eine geschichtliche Skizze und ein archäologischer Fundortkataster). MFMÉ-StudArch 3 (1997) 39-95.

= M. NAGY: Gyulavári. In: CSEH et al. 2005, 64-79.

= M. NAGY: Hódmezővásárhely-Sóshalom. In: CSEH et al. 2005, 80-95.

= M. NAGY: Szőreg-Téglagyár. In: CsEH et al. 2005, 120-202.

= M. NAGY: Kora népvándorlás kori gyermeksír amulettekkel Mártélyról, Csongrád megye $\left(5^{\text {th }}\right.$ century child grave with amulets and iron bell from Mártély, Csongrád County). ZalaiMúz 14 (2005) 97-127.

= M. NAGY: Kora népvándorlás kori sírleletek Budapest területéről (Grabfunde aus der frühen Völkerwanderungszeit im Gebiet von Budapest). BudRég 40 (2006) 95-155.

= M. NAGY-Á. B. Tóth: Gepiden. Archäologisches. In: RGA 11. Berlin-New York 1998, 118-131.

= J. NEMESKÉRI: A gyöngyösapáti hunkori sír torzított koponyájának antropológiai vizsgálata (Anthropological examination of the deformed skull from Gyöngyösapáti, Hun period). ArchÉrt 5-6 (1944-1945 [1945]) 303-311.

= I. NÉMETI: Descoperiri funerare din sec. V. e.n. lîngă Carei (Grabfunde des 5. Jhs. u. Z. aus der Umgebung der Stadt Carei). ActaMusN 4 (1967) 499-507.

= I. NÉMETI: Un mormînt din secolul V descoperit la satul Ghenci, comuna Căuaş (Grabfund des 5. Jhs. u. Z. aus Ghenci). Satu Mare 1969, 121-124.

= A. NeumanN: Spital und Bad des Legionslagers Vindobona. JRGZM 1965, 99-114.

= B. NovotnÝ: Šarovce. Bratislava 1976.

= J. G. ÓdoR: 5. századi temető Sióagárdon (Das Gräberfeld von Sióagárd aus dem 5. Jh.). WMMÉ 2001 (23) 39-50

= K. OTTOMÁNYI: Hunkori sírok a pátyi temetőben („Hunnenzeitliche“ Gräber im Gräberfeld von Páty). ArchÉrt 126 (2001) 35-74.

= K. OtтомánYI: Hunnenzeitliche Gräber in Budakalász und Páty. ComArchHung (2008) 231-263.

= L. PAPP-Á. SALAMON: Gräber aus dem 5. Jh. in Letkés. MittArchInst 8-9 (1978-1979 [1980]) 85-92, 343-348.

= M. PÁRDUCZ: Der gotische Fund von Csongrád. Dolg 14 (1938) 124-138.

= M. PÁRDUCZ: Archäologische Beiträge zur Geschichte der Hunnenzeit in Ungarn. ActaArchHung 11 (1959) 309-398.

= M. PÁRDUCZ: Die ethnischen Probleme der Hunnenzeit in Ungarn. StudArch 1. Budapest 1963.

= M. PÁRDUCZ-J. KoREK: Germán befolyás a Maros-Tisza-Körös-szög késő szarmata emlékanyagában (Les éléments germaniques dans l'civilisation sarmatique récente de la région limitiée per les fleuves Maros, Tisza et Körös). ArchÉrt 7-9 (1946-1948 [1948]) 291-312.

= G. PINTYE: Hun Age single graves at the track of motorway M3. Ephemeris Napocensis 24 (2014) 277-298.

= R. Pittioni-J. Weninger: Zwei gotische Gräber aus Marchegg, Lkr. Gänfendorf, Niederdonau. Natur und Kultur 29. Wien-Leipzig 1944.

= W. PoHL: Die Gepiden und die gentes an der mittleren Donau nach dem Zerfall des Attilareiches. In: H. Wolfram-F. Daim (Hrsg.): Die Völker an der mittleren und unteren Donau im fünften und sechsten Jahrhundert. Wien 1980, 239-305. 
POHL 1998

PROHÁSZKA 2003

ProhÁSZKa 2006

Protase 1960

QUAST 2005

RÁCZ 2006

RÁCZ 2011

RÁCZ 2014

RÁCZ-DARÓCZI-SZABÓ 2016

RUMMEL 2007

SÁGI 1984

SALAMON-LENGYEL 1980

SCHILLING in Vorbereitung

SCHMAUDER 2002

Seoba naroda 1962

SIMON 2006

SIMONYI 2005

STADLER et al. 2008

STRAUB 2008

STRAUB 2011

STRAUB 2014

SZABÓ 1969

SZÉCSÉNYI-NAGY 2008
=W. PoHL: Gepiden. Historisches. In: RGA 11. Berlin-New York 1998, 118-131.

= P. ProhászKa: A perjámosi sír (1885) és helye az 5. századi lemezfibulás női temetkezések között (Das Grab von Perjámos (1885) und seine Stellung innerhalb der Frauenbestattungen mit Blechfibeln aus dem 5. Jahrhundert). ArchÉrt 128 (2003) 71-93.

= P. PROHÁsZKA: A wien-atzgersdorfi hunkori női sír-észrevételek a poliédervégű tűk viseléséhez (Das hunnenzeitliche Frauengrab von Wien-Atzgersdorf - Bemerkungen zur Tracht der Nadeln mit Polyederknopf). Arrabona 44/1. Ünnepi kötet a 65 éves Tomka Péter tiszteletére. Győr 2006, 391-410.

= D. Protase: Ein Grab aus dem V. Jahrhundert aus Cepari (Transsilvanien). Dacia 4 (1960) 569-576.

= D. QuAST: Völkerwanderungszeitliche Frauengräber aus Hippo Regius (Annaba/Bône) in Algerien. JRGZM 52 (2005) 237-315.

= T. Á. RÁCZ: Maglód, 1. sz. lelőhely (Maglód, Site No. 1). RégKut 2005. Budapest 2006, 227-228.

= Zs. RÁcZ: Madárfibulák a gepida korból (Vogelfibeln aus gepidischer Zeit). ArchÉrt 136 (2011) 165-179.

= Zs. RÁCZ: 5. századi sírok Hajdúnánás-Fürj-halom-dűlő (M3-41/A) lelőhelyről (Gräber aus dem 5. Jahrhundert von Nordost-Ungarn. Fundort Hajdúnánás-Fürj-halom-járás). In: A. Anders.-Cs. Balogh-A. Türk (Hrsg.): Avarok pusztái. Régészeti tanulmányok Lőrinczy Gábor 60. születésnapjára (Avarum solitudines. Archaeological studies presented to Gábor Lőrinczy on his sixtieth birthday). Opitz Archaeologica 6. Budapest 2014, 203-212.

= Zs. RÁCZ-M. DARÓCZI-SzABó: Szarvasszemfog-csüngők kora népvándorlás kori sírokban (Deer canine pendants from Early Migration Period burials). In: Á. Bollók-K. Gergely-B. Kolozsi-L. Kovács-L. Révész-G. Szenthe (Hrsg.): Népek és kultúrák a kora középkori Kárpát-medencében. Tanulmányok Mesterházy Károly tiszteletére. Budapest-Debrecen-Szeged 2016, 177-182.

$=$ PH. vON RuMmel: Habitus barbarus. Kleidung und Repräsentation spätantiker Eliten im 4. und 5. Jahrhundert. Ergänzungsbände zum RGA 55. Berlin 2007.

= K. SÁGI: Az ötvöspusztai V. századi sír (Das Grab von Ötvöspuszta aus dem 5. Jahrhundert). VMMK 17 (1984) 81-91.

= Á. SALAMON-I. LENGYEL: Kinship interrelations in a fifth-century 'Pannonian' cemetery: An archaeological and paleobiological sketch of the population fragment buried in the Mözs cemetery, Hungary. WA 12 (1980) 93-104.

= L. Schilling: Tác/Gorsium a római kor végétől az avar kor végéig [Tác/Gorsium vom Ende der Römerzeit bis zum Ende der Awarenzeit]. PhD-Dissertation, Manuskript. ELTE BTK, Budapest. In Vorbereitung.

= M. SCHMAUDER: Oberschichtgräber und Verwahrfunde in Süsosteuropa im 4. und 5. Jahrhundert I-II. Archaeologia Romanica 3. Bukarest 2002.

= D. DimitriJević-J. KovAČEvić-Z. VinSKi: Seoba naroda: arheološki nalazi jugoslovenskog Podunavlja [Völkerwanderungszeit: archäologische Funde in Jugoslawien]. Zemun 1962.

= L. SIMON (Hrsg.): Régészeti kutatások másfél millió négyzetméteren [Archäologische Forschungen auf anderthalb Millionen Quadratmetern]. Szentendre 2006.

= E. SimONYI: Mezőkeresztes-Cethalom. In: CSEH et al. 2005, 205-208.

= P. Stadler-H. Friesinger-W. Kutschera-E. Lauermann-Zs. RÁCZ-J. TejRal-E.-M Wild-T. ZEMAN: Kann man die Zuordnung zu den verschiedenen (ethnischen) Gruppen der Völkerwanderungszeit mittels naturwissenschaftlicher Datierungsmethoden verbessern? In: Hunnen zwischen Asien und Europa. Aktuelle Forschungen zur Archäologie und Kultur der Hunnen. Hg. vom Historischen Museum der Pfalz Speyer. Speyer 2008, 157-183.

= P. STRAuB: Adalékok a Balaton környéki 5. századi temetők Felső-Duna-vidéki kapcsolatához (Angaben zu den Beziehungen zwischen den Nekropolen des 5. Jahrhunderts in der Balaton-Region und im oberen Donaugebiet). ZalaiMúz 17 (2008) 189-207.

$=$ P. STRAuB: Angaben zum hunnenzeitlichen ostgermanischen Fundhorizont in Südtransdanubien Ausgehend von der Nekropole in Keszthely-Fenékpuszta (Contributions to the East-Germanic find horizon of the Hun Age in South-Transdanubia). In: O. Heinrich-Tamáska (Hrsg.): Keszthely-Fenékpuszta in Kontext spätantiker Kontinuitätsforschung zwischen Noricum und Moesia. CPP 2. Budapest-Leipzig-Keszthely-Rahden/Westf. 2011, 325-345.

= P. STRAub: Hunnenzeitliche Gräbergruppen in der Gemarkung von Fonyód, Kom. Somogy (Burial groups of the Hun period in the district of Fonyód, County Somogy). In: O. Heinrich-Tamáska (Hrsg.): Mensch, Siedlung und Landschaft im Wechsel der Jahrtausende am Balaton (People, Settlement and Landscape on Lake Balaton over the Millennia). CPP 4. Budapest-Leipzig-KeszthelyRahden/Westf. 2014, 207-222.

= J. Gy. SzABó: Heves megye régészeti emlékei II. [Die archäologischen Denkmäler im Kom. Heves II]. In: D. Dercsényi-P. Voit (Hrsg.): Heves megye müemlékei. Budapest 1969, 41-63.

= A. SzÉCSÉNYI-NAGY: A koponyatorzítás szokása a Kárpát-medencében az V-VI. században, régészeti és antropológiai adatok alapján [Der Brauch der Schädeldeformation im Karpatenbecken im 
SZENDREY 1928

SZŐKE 1996

TEJRAL 1973

TEJRAL 1974

TEJRAL 1982

TEJRAL 1988

TEJRAL 1999

TeJRAL 2005a

TEJRAL 2005b

TEJRAL 2007

TEJRAL 2012

TEJRAL-MARTEREROVÁ 2011

TOBIAS-WITTSCHKE-SCHROTIA-BINDER

TOČIK 1962

TOMKA 1967

TOMKA 2001

TOMKA 2005

TOMKA 2015

В. То́тн 1994

B. ТóTH 2005

B. То́тH 2006

VADAY 1975

B. VÁGÓ-BÓNA 1976

VIDA 1995

VIDA 2011

VISY 1981

WERNER 1956

WERNER 1959
5.-6. Jahrhundert aufgrund von archäologischen und anthropologischen Angaben]. Doktori disszertáció, ELTE BTK. Budapest 2008

= Á. SzENDREY: A miszlai gót sírlelet [Der gotische Grabfund von Miszla]. ArchÉrt 42 (1928) 222-225.

= B. M. SzŐKE: Das völkerwanderungszeitliche Gräberfeld von Kilimán-Felsőmajor. ZalaiMúz 6 (1996) 35- 45.

= J. TeJRAL: Mähren im 5. Jahrhundert. Die Stellung des Grabes 32 aus Smolin im Rahmen der donauländischen Entwicklung zu Beginn der Völkerwanderungszeit. Praha 1973.

= J. TEJRAL: Völkerwanderungszeitliches Gräberfeld bei Vyškov (Mähren). Praha 1974

= J. TEJRAL: Morava na sklonku antiky (Mähren an der Neige der Antike). Praha 1982.

$=$ J. TEJRAL: Zur Chronologie der frühen Völkerwanderungszeit im mittleren Donauraum. ArchA 72 (1988) 223-304

= J. TEJRAL: Die spätantiken militärischen Eliten beiderseits der norisch-pannonischen Grenze aus der Sicht der Grabfunde. In: Th. Fischer-G. Precht-J. Tejral (Hrsg.): Germanen beiderseits des spätantiken Limes. Köln-Brno 1999, 217-292.

= J. TEJRAL: Smolin. In: RGA 29. Berlin-New York 2005, 160-162.

= J. TEJRAL: Zur Unterscheidung des vorlangobardischen und elbgermanisch-langobardischen Nachlasses. In: W. Pohl-P. Erhart (Hrsg.): Die Langobarden. Herrschaft und Identität. Forschungen zur Geschichte des Mittelalters 9. Wien 2005, 103-200.

= J. TEJRAL: Das Hunnenreich und die Identitätsfragen der barbarischen ,gentes“ im Mitteldonauraum aus der Sicht der Archäologie. In: J. Tejral (Hrsg.): Barbaren im Wandel. Beiträge zur Kultur- und Identitätsumbildung in der Völkerwanderungszeit. Brno 2007, 55-120.

$=$ J. TEJRAL: Cultural or ethnic changes? Continuity and discontinuity on the Middle Danube ca. AD. 500. In: V. Ivanišević-M. Kazanski (eds): The Pontic-Danubian Realm in the Period of the Great Migration. Paris-Beograd 2012, 115-188.

= J. TeJral-V. Martererová: Einheimische und Fremde. Das norddanubische Gebiet zur Zeit der Völkerwanderung. Spisy Arch. Ústavu AV CR Brno 33. Brno 2011.

B. Tobias-K. Wiltschke-Schrotta-M. Binder: Das langobardzeitliche Gräberfeld von WienMariahilfer Gürtel. Mit einem Beitrag zur künstlichen Schädeldeformation im westlichen Karpatenbecken. JRGZM 57 (2010) 279-337.

= A. TočIK: Nové nálezy z doby st’ahovania národov na juhozápodnom Slovensku (Neue Funde aus der Völkerwanderungszeit in der Südwestslowakei). ŠtZ 9 (1962) 187-218.

= P. TomKA: Későrómai sírok a Hátulsó utcában (Spätrömische Gräber in der Hintergasse). Soproni Szemle 21 (1967) 245-253.

= P. TomKA: Az árpási 5. századi sír (Grab in Árpás aus dem 5. Jahrhundert). Arrabona 39 (2001) $161-188$.

= P. ToMKA: Korai avar sírok Börcs-Nagydombon, Győr-Moson-Sopron megye (Frühawarenzeitliche Gräber in Börcs-Nagydomb, Kom. Győr-Moson-Sopron). ArchÉrt 130 (2005) 137-180.

= P. TomKA: Eine römische Stadt und ihre barbarische Peripherie: Scarbantia. In: T. Vida (ed.): Romania Gothica II. The Frontier World. Romans, Barbarians and Military Culture. Budapest 2015, 587-615.

= Á. B. Tóтн: Kora népvándorlás kori sírok Tápé-Széntéglaégetőn (Gräber aus der frühen Völkerwanderungszeit in Tápé-Széntéglaégető). In: G. Lőrinczy (Hrsg.): A kőkortól a középkorig. Tanulmányok Trogmayer Ottó 60. születésnapjára. Szeged 1994, 285-309.

= Á. B. Tо́тн: Korai népvándorlás kori sír Aquincumban [Ein frühvölkerwanderungszeitliches Grab in Aquincum]. WMMÉ 27 (2005) 11-41.

= Á. B. Tо́тн: Gepidische Siedlungen im Theißgebiet. Monumenta Germanorum Archeologica Hungariae 4. Budapest 2006.

= A. VADAY: Ein „,barbarisches“ Skelettgrab von Zagyvarékas (Komitat Szolnok). MittArchInst 5 (1974-75 [1975]) 81-88.

= E. B. VÁGÓ-I. BóNA: Der spätrömische Südostfriedhof. Die Gräberfelder von Intercisa I. Budapest 1976.

= T. VIDA: Frühmittelalterliche scheiben- und kugelförmige Amulettkapsel zwischen Kaukasus, Kastilien und Picardie. BRGK 76 (1995) 221-292.

= T. VIDA: Die Zeit zwischen dem 4. und dem 6. Jahrhundert im mittleren Donauraum aus archäologischer Sicht. In: M. Konrad-Chr. Witschel (Hrsg.): Römische Legionslager in den Rhein- und Donauprovinzen - Nuclei spätantik-frühmittelalterlichen Lebens? München 2011, 615-650.

= Zs. VISY: V. századi sír Intercisában (Ein Grab aus dem 5. Jahrhundert in Intercisa). ArchÉrt 108 (1981) 211-217.

= J. WERnER: Beiträge zur Archäologie des Attila-Reiches. München 1956

= J. WERNER: Studien zu Grabfunden des 5. Jahrhunderts aus der Slowakei und der Karpatenukraine. S1A 7/2 (1959) 422-438. 
WINDL 1997a

WINDL 1997b

Zotović 1981

ZSIDI 1987
$=$ H. WINDL: Ein frühmerowingerzeitliches Frauengrab aus Ladendorf, VB Mistelbach, NÖ. In: J. Tejral-H. Friesinger-M. Kazanski (Hrsg.): Neue Beiträge zur Erforschung der Spätantike im mittleren Donauraum. Brno 1997, 67-76.

$=\mathrm{H}$. WINDL: Weitere völkerwanderungszeitliche Gräber aus Schletz, MG Asparn an der Zaya, VB Mistelbach, Niederösterreich. FÖ 35 (1996 [1997]) 377-387.

= L. Zotović: Nekropola iz vremena seobe naroda sa uže gradske teritorije Viminacija (Necropole du territoriale municipial de Viminacium de la periode des migrations des peuples). Starinar 31 (1980 [1981]) 96-115.

= P. ZsIDI: A Budapest XI. kerületi Gazdagréten feltárt 4-5. századi temető (Das auf dem Gazdagrét (Budapest XI. Bez.) freigelegte Gräberfeld aus dem 4.-5. Jahrhundert). ComArchHung 1987, 45-72. 


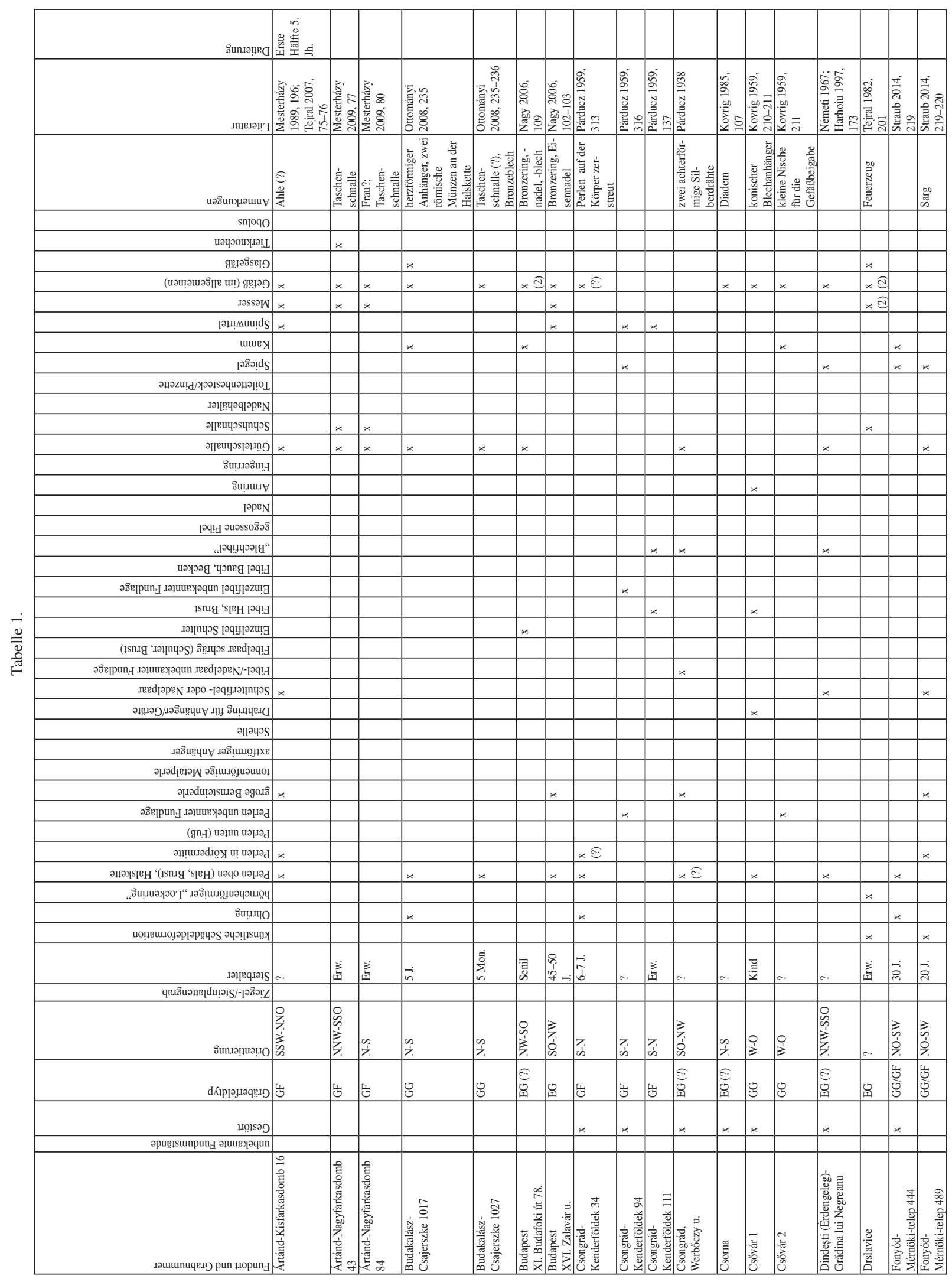




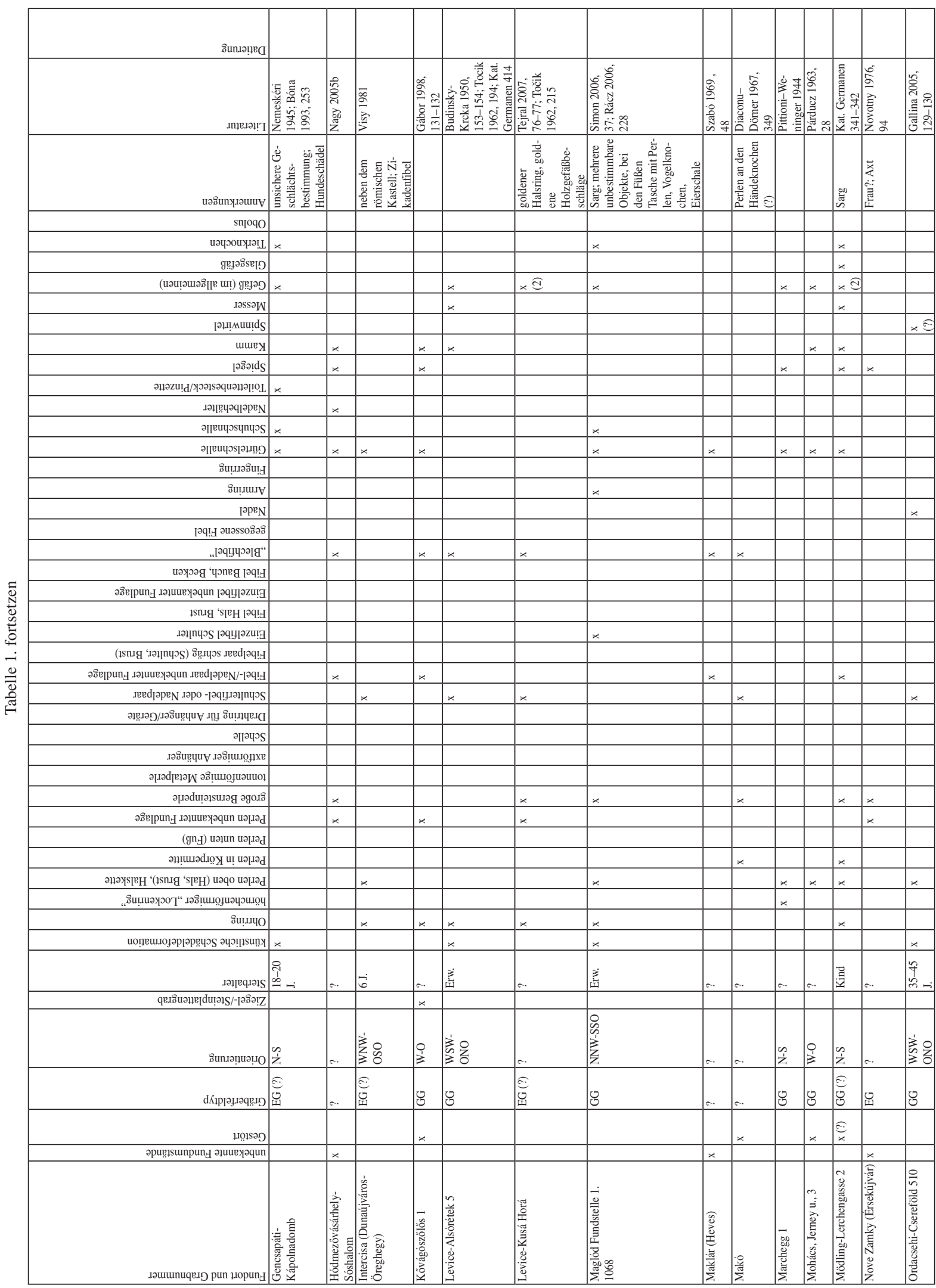




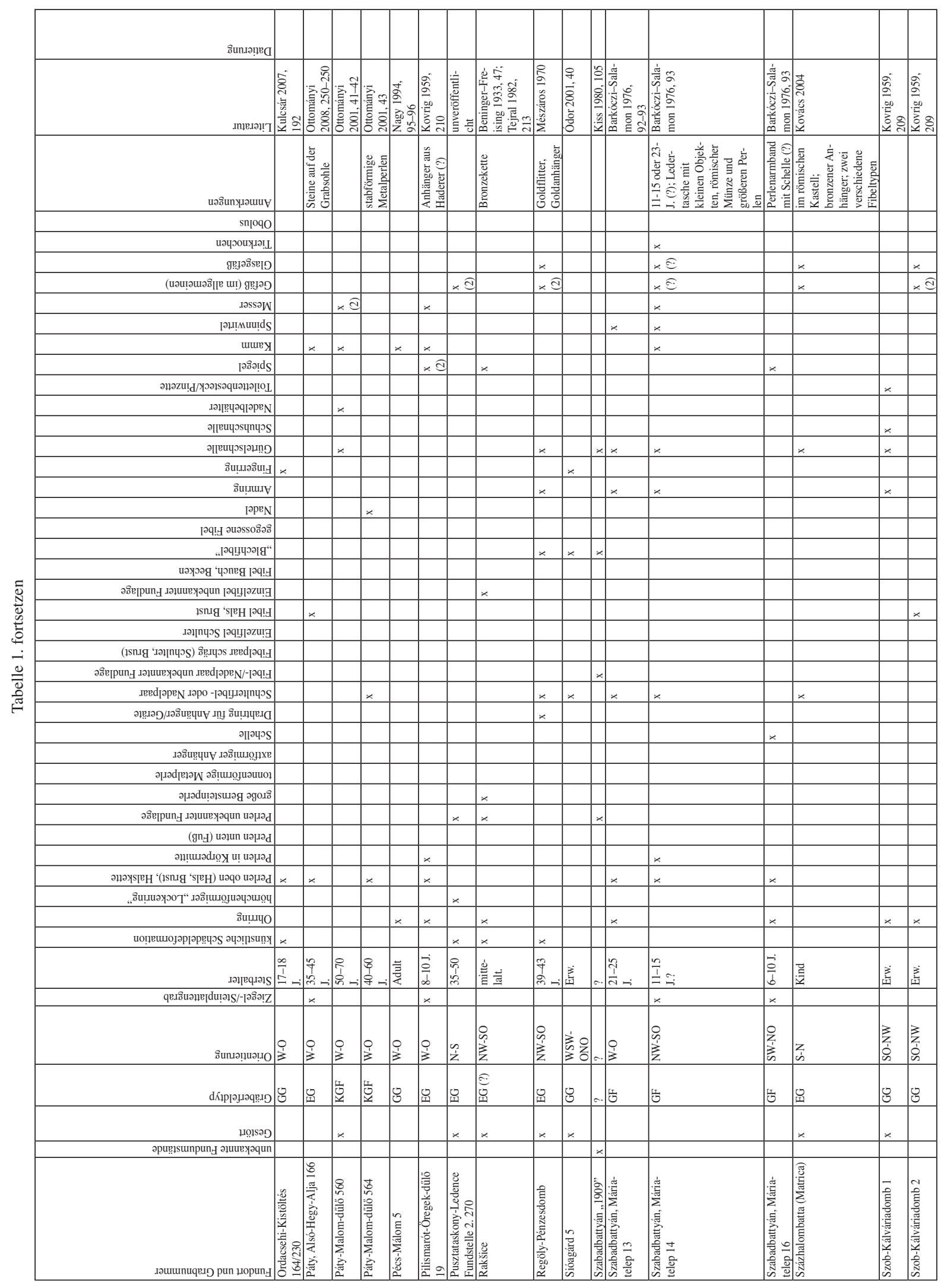




\begin{tabular}{|c|c|c|c|c|c|c|c|c|}
\hline Sิun.əฺ̣pa & & & & & & & & 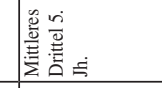 \\
\hline 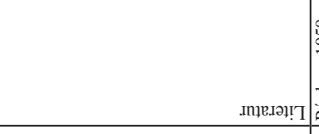 & 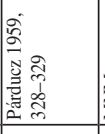 & 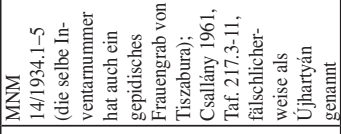 & 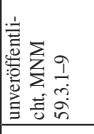 & 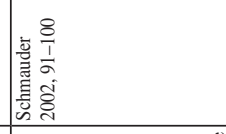 & 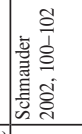 & 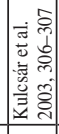 & 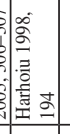 & 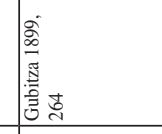 \\
\hline 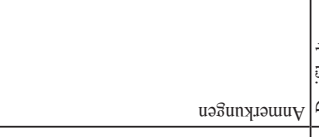 & 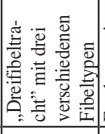 & 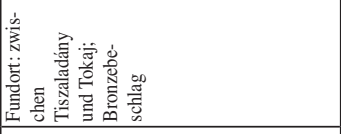 & 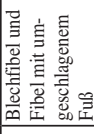 & 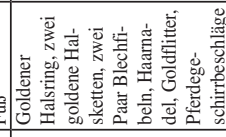 & 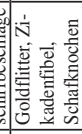 & 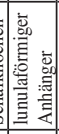 & & 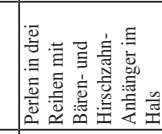 \\
\hline snioqo & & & & & 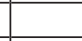 & & & \\
\hline иәчәоих.ю!. & & & & & $x$ & & & \\
\hline 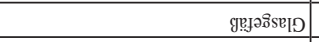 & & & & $\times \sqrt{a}$ & $\times \widetilde{I}$ & & & \\
\hline 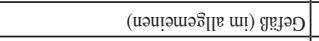 & $x$ & & & $\times \widehat{C}$ & $\times$ 王 & & & \\
\hline Iassey & $\times$ & & & $x$ & $\times$ & & & 工 \\
\hline 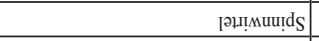 & $x$ & & & & & 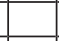 & $\times$ & \\
\hline шише प्र & & & & 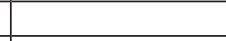 & $x$ & & & \\
\hline 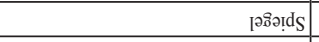 & & & $x$ & $x$ & $x$ & $x$ & & \\
\hline 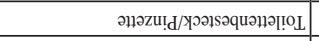 & & & & $x$ & $\times$ & & 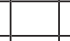 & \\
\hline 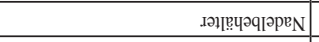 & & & & & & 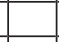 & & \\
\hline ә[एеицэципџр & & & & $x$ & 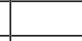 & $x$ & 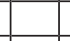 & \\
\hline 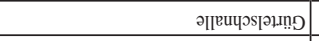 & & $x$ & $x$ & & - & $x$ & $x$ & \\
\hline รินแนวริแ! & & & & $\times \widehat{d}$ & & $x$ & & \\
\hline sิu!..... & & $x$ & $x$ & $x$ & & & 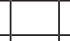 & \\
\hline Iәрер & & & & & & & 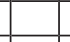 & \\
\hline 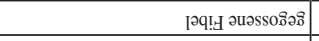 & $x$ & & & 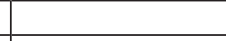 & & & - & \\
\hline 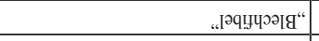 & & & $x$ & $x$ & & & $x$ & \\
\hline 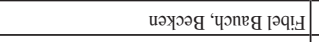 & & & & & & & & \\
\hline 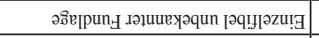 & & $x \odot$ & & & & & 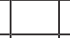 & \\
\hline 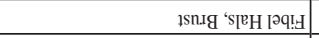 & $\star$ & & & & 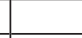 & & - & \\
\hline 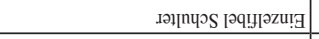 & & & & & & & & \\
\hline 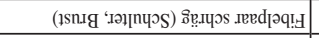 & & & & & & & - & \\
\hline 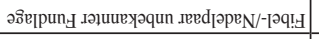 & & & $x €$ & $\times$ 过 & & & 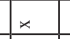 & \\
\hline 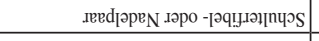 & $x$ & & & & $x$ & & & \\
\hline 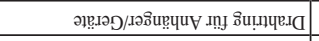 & & & & & $x$ & & & \\
\hline ӘाГभР & & & & & & *a & & \\
\hline 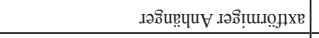 & & & & & & & & \\
\hline 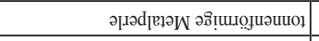 & & & & & & & & \\
\hline 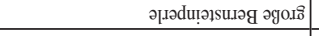 & & & $\times$ & $\star x$ & * & $x$ & $\times$ & * \\
\hline 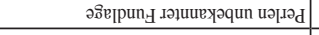 & & $\times$ & $\times$ & $\times$ & & 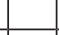 & $\times$ & \\
\hline 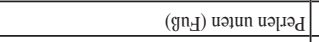 & & & & & & & & \\
\hline 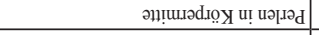 & & & & & $x$ & a. & & \\
\hline 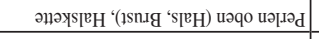 & 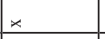 & & & $x$ & $x$ & $x$ 业 & & $x$ \\
\hline 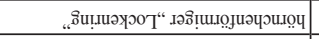 & & & & & & & & \\
\hline вищ.џо & & & & $\times$ & & $x$ & $\times$ & $\star$ \\
\hline 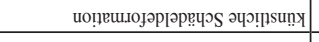 & & & & & & $x$ & & \\
\hline 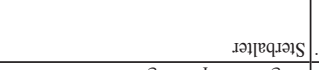 & $\begin{array}{l}\text { 总 } \\
\text { 窇 }\end{array}$ & - & $\therefore$ & 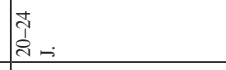 & $\stackrel{i}{2}$ & in & . & 言 \\
\hline 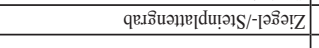 & & & & & & & & \\
\hline 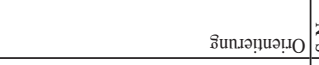 & $z_{i}$ & -. & $\therefore$ & $\hat{z}$ & $\hat{z}$ & $\tilde{z}_{z}$ & 。. & $\frac{1}{3}$ \\
\hline 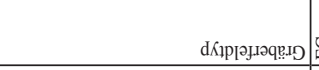 & 画 & -. & . & U & לי্ট & . & 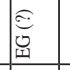 & 步 \\
\hline 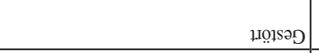 & & & & $\times$ & & & & \\
\hline 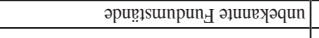 & & $x$ & $x$ & & & - & $x$ & \\
\hline гәшипичрег, рип цории & 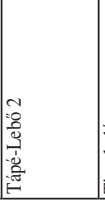 & 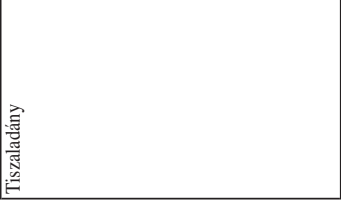 & 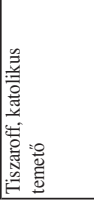 & 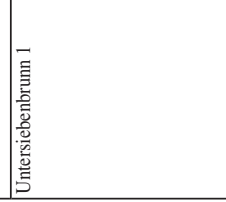 & 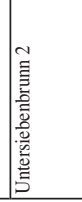 & 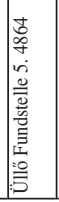 & $\frac{5}{2}$ & 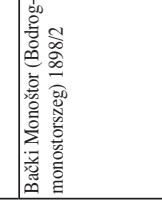 \\
\hline
\end{tabular}




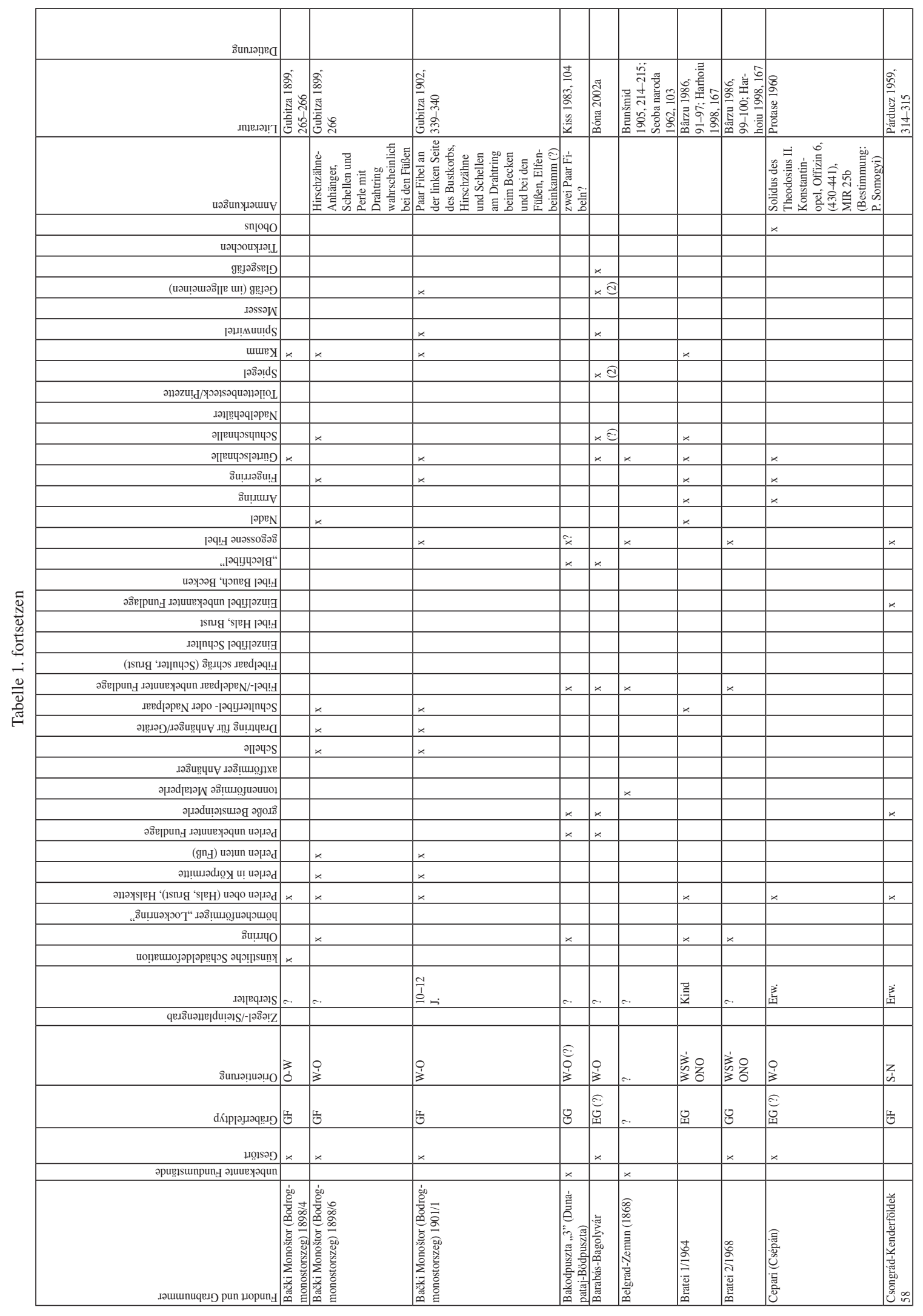




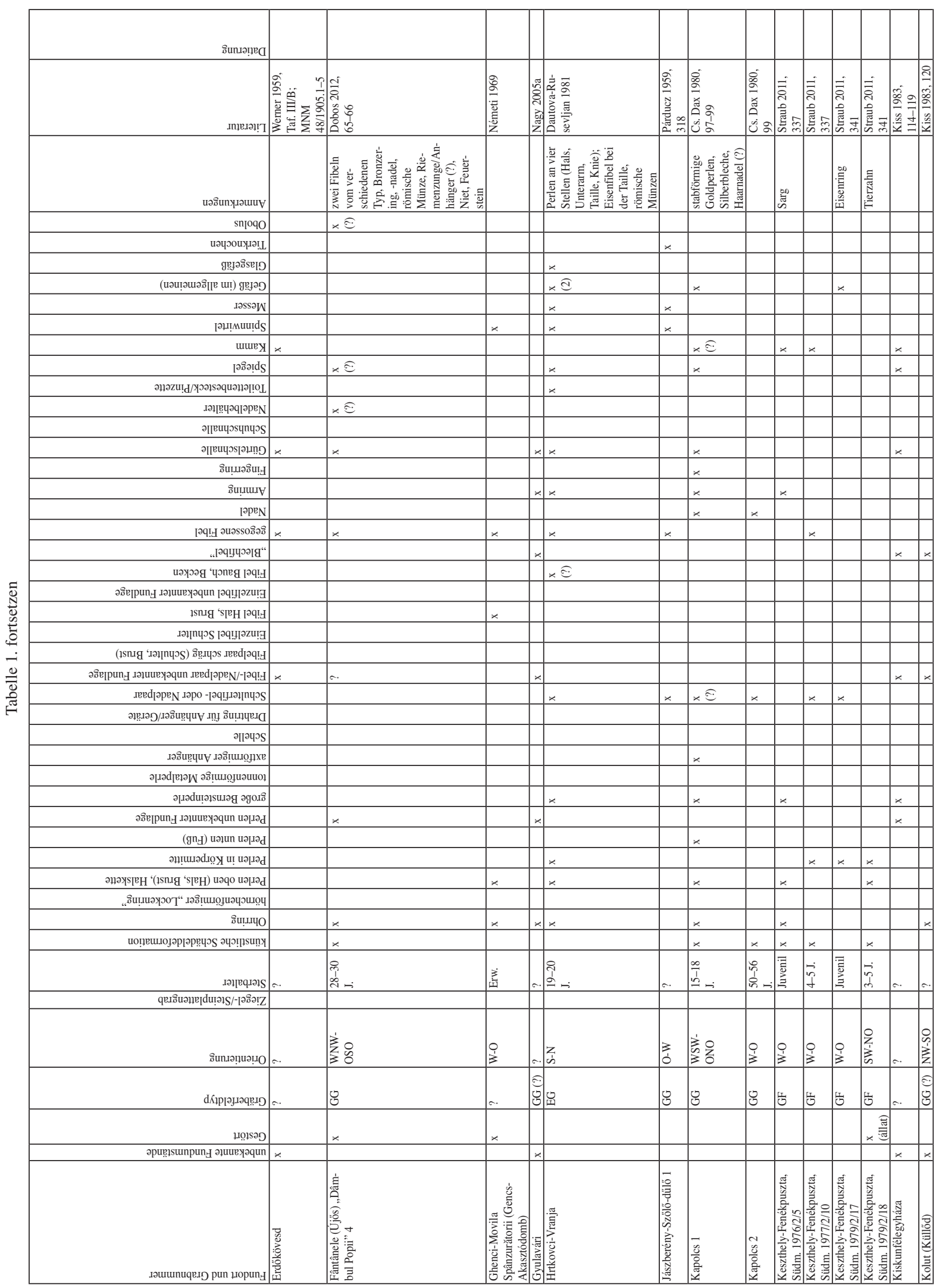




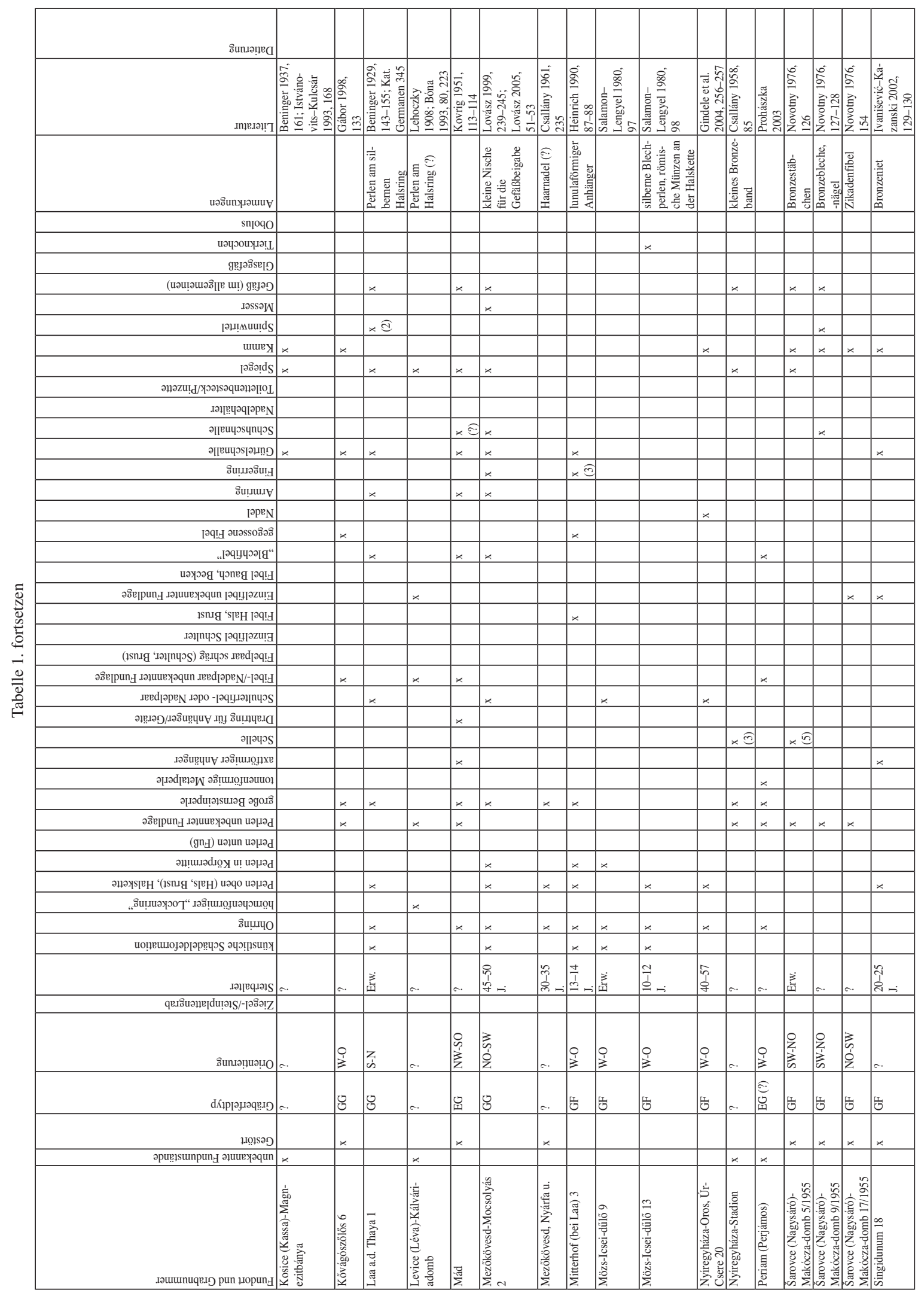




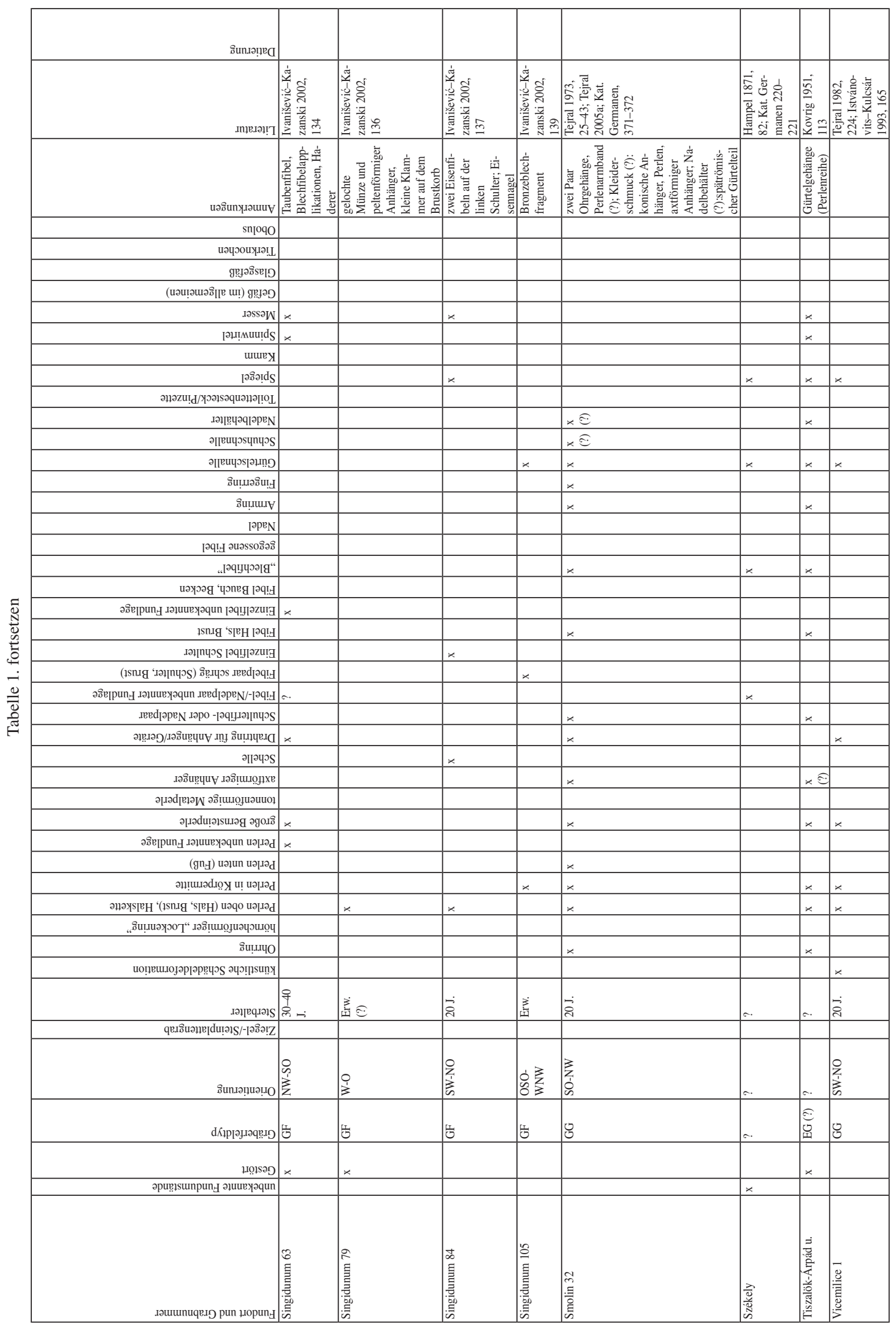




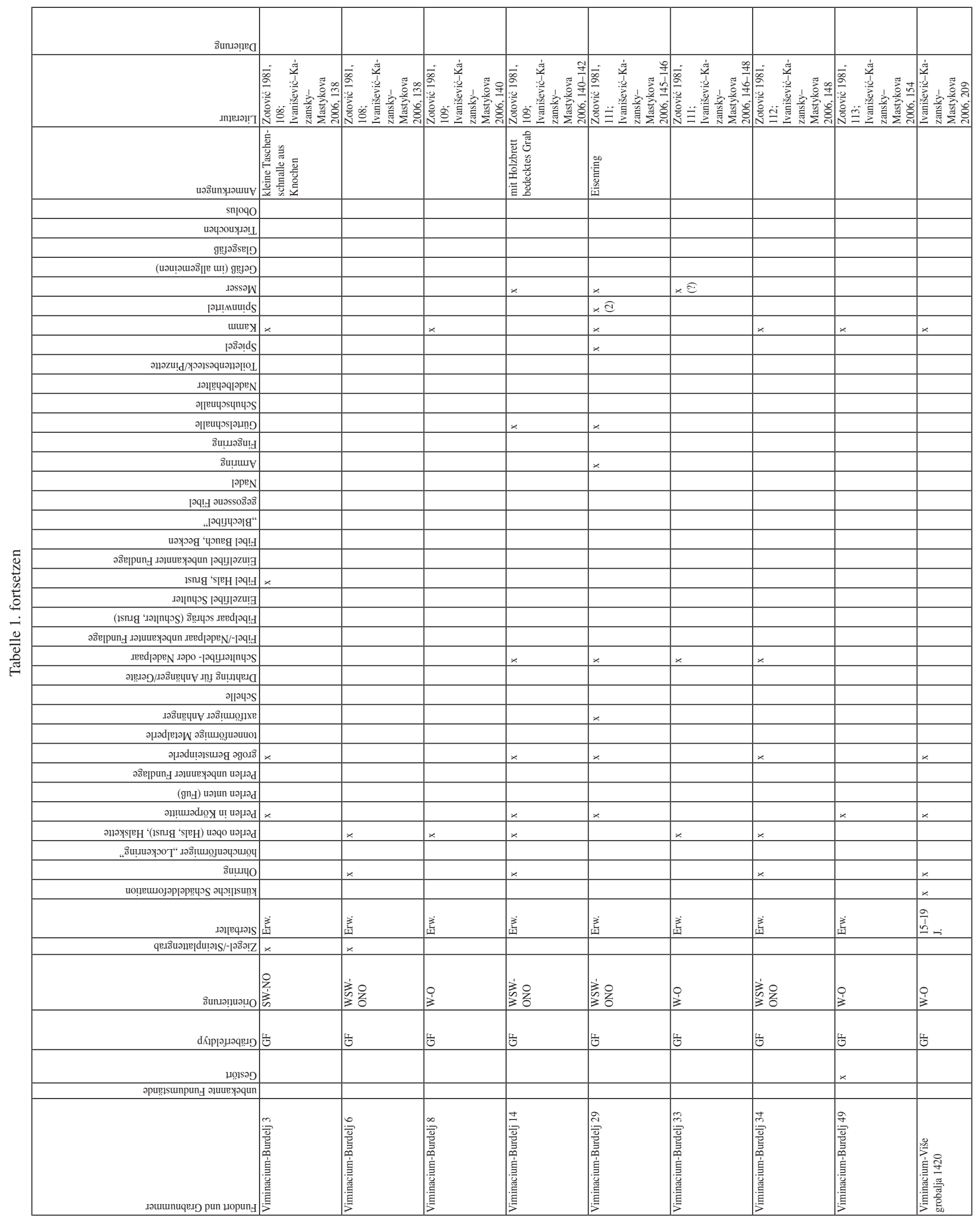




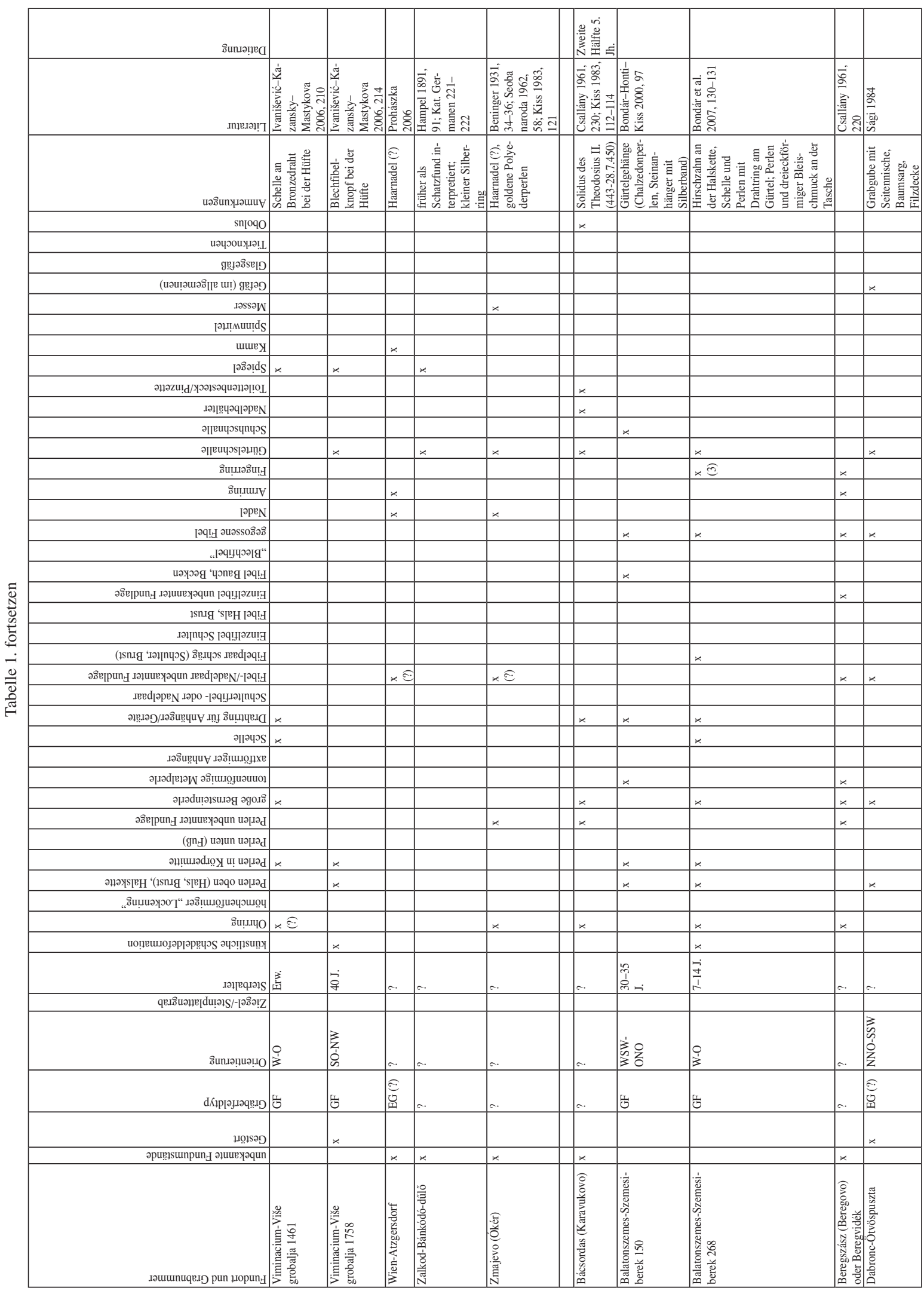




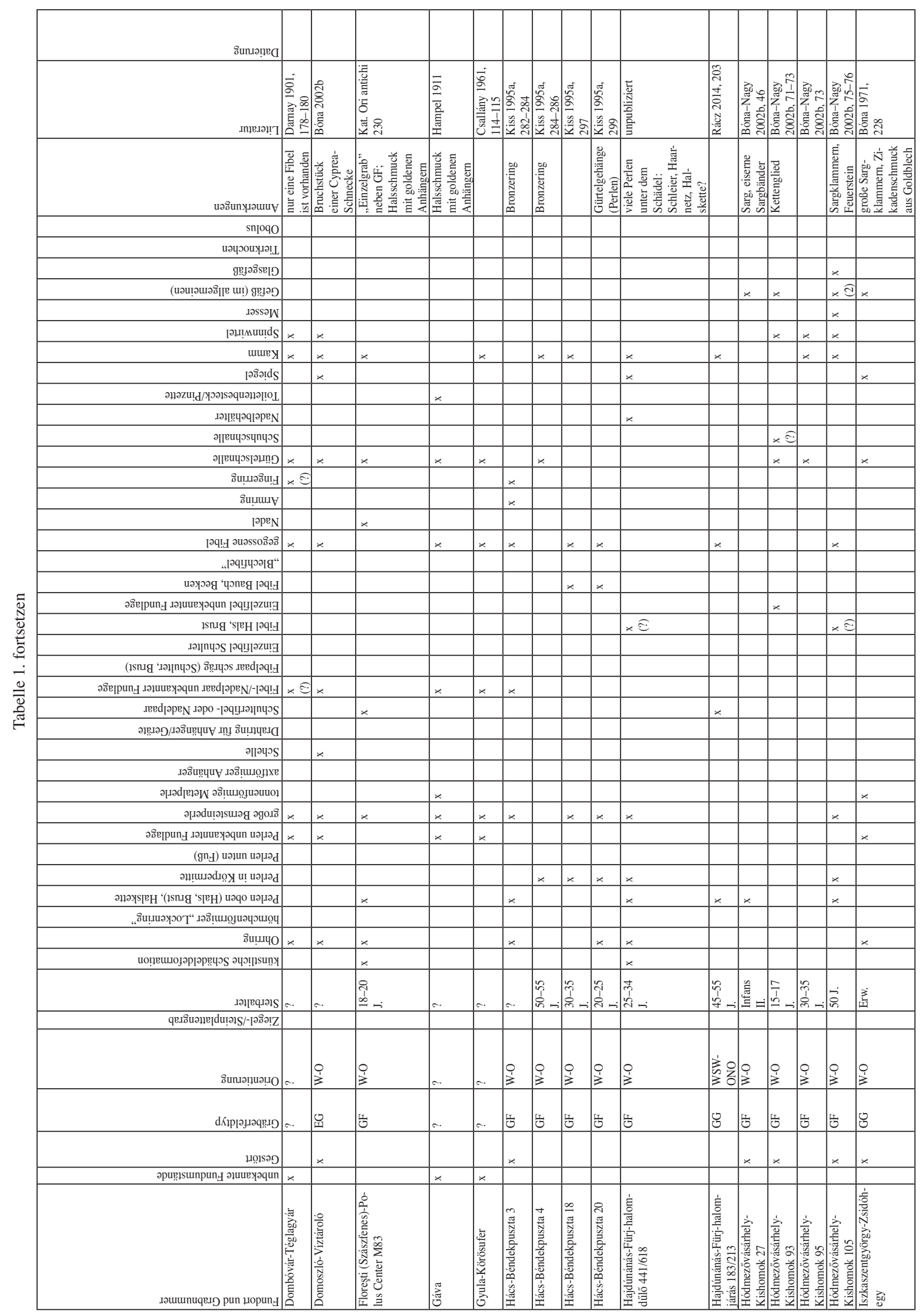




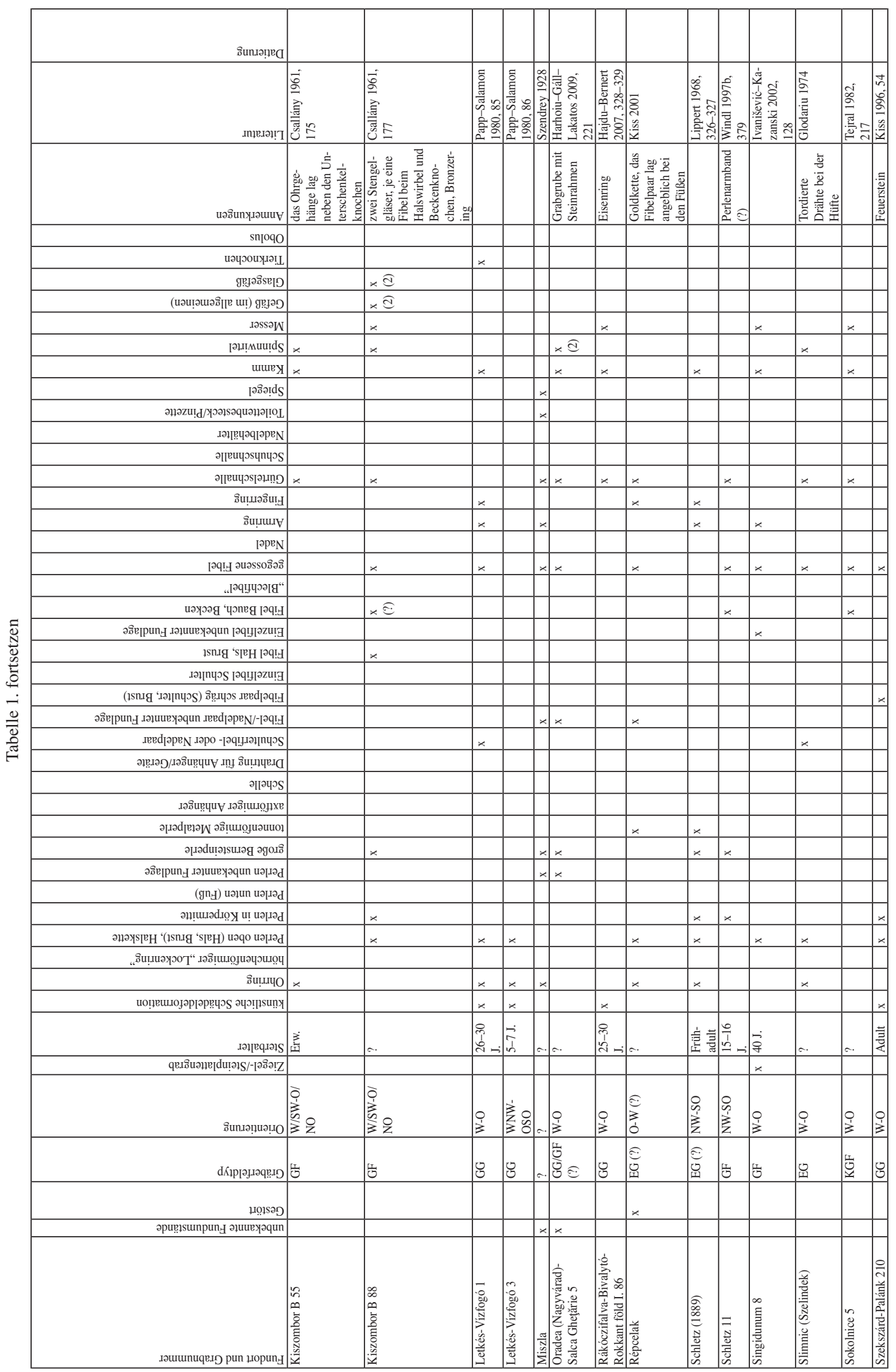




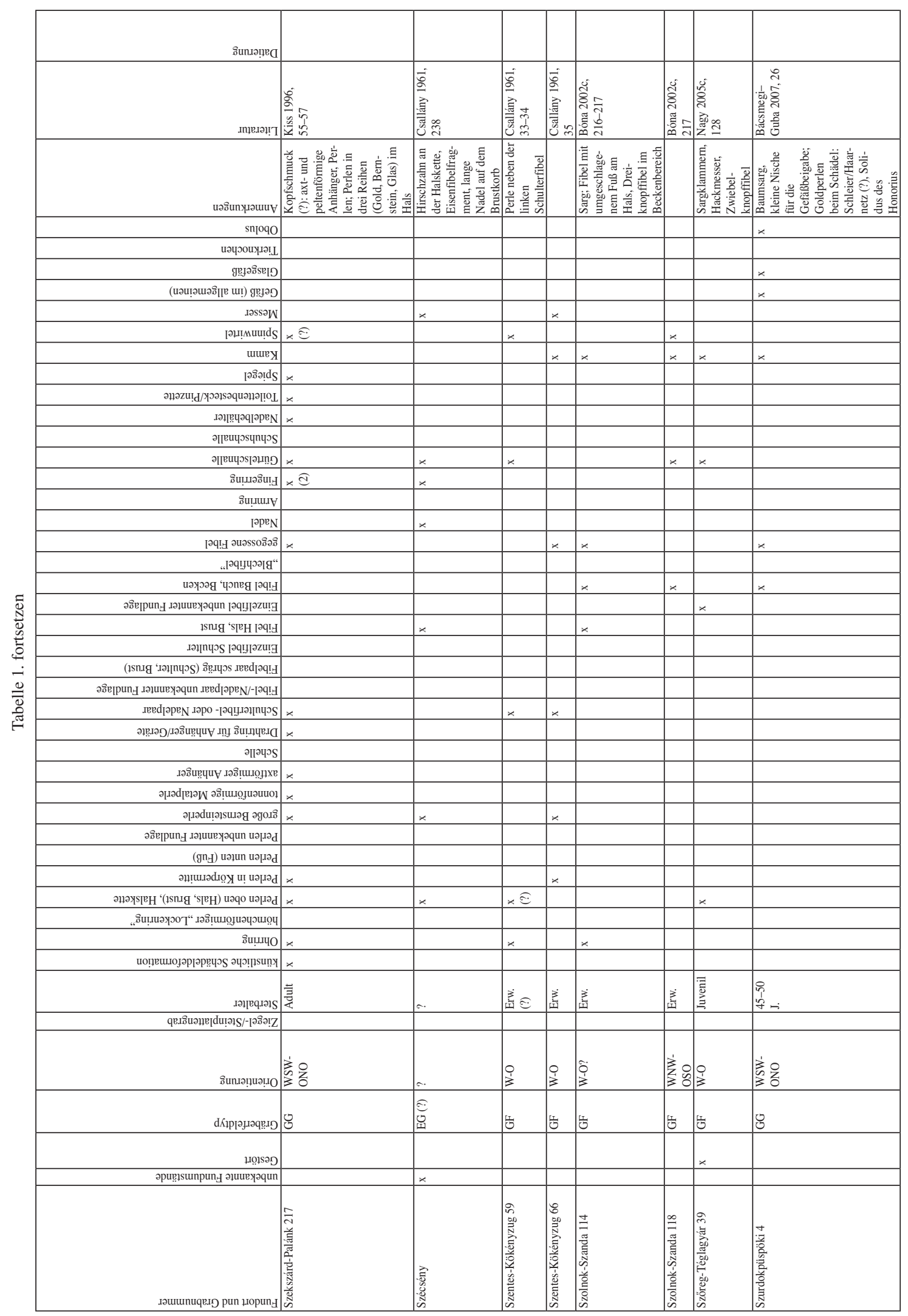




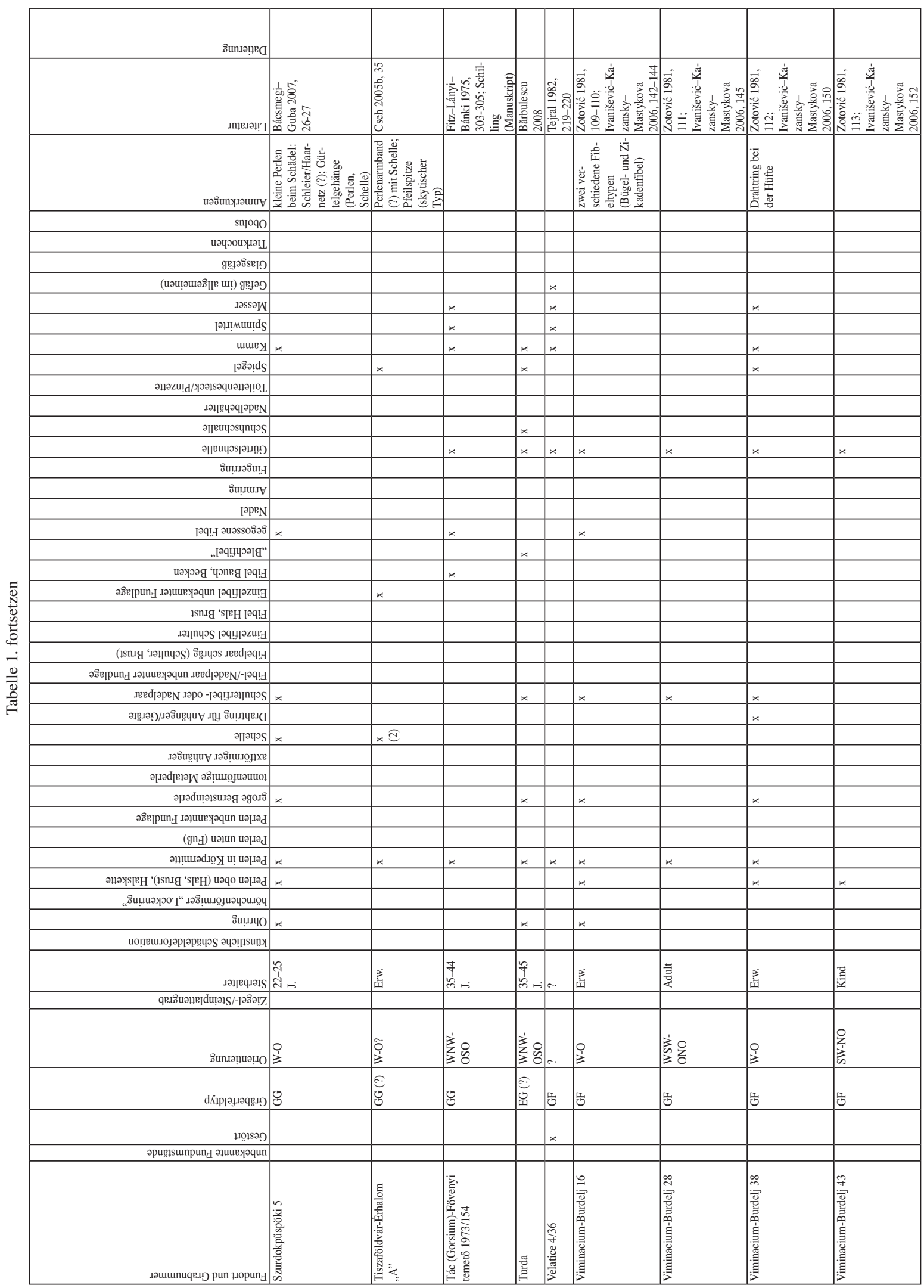




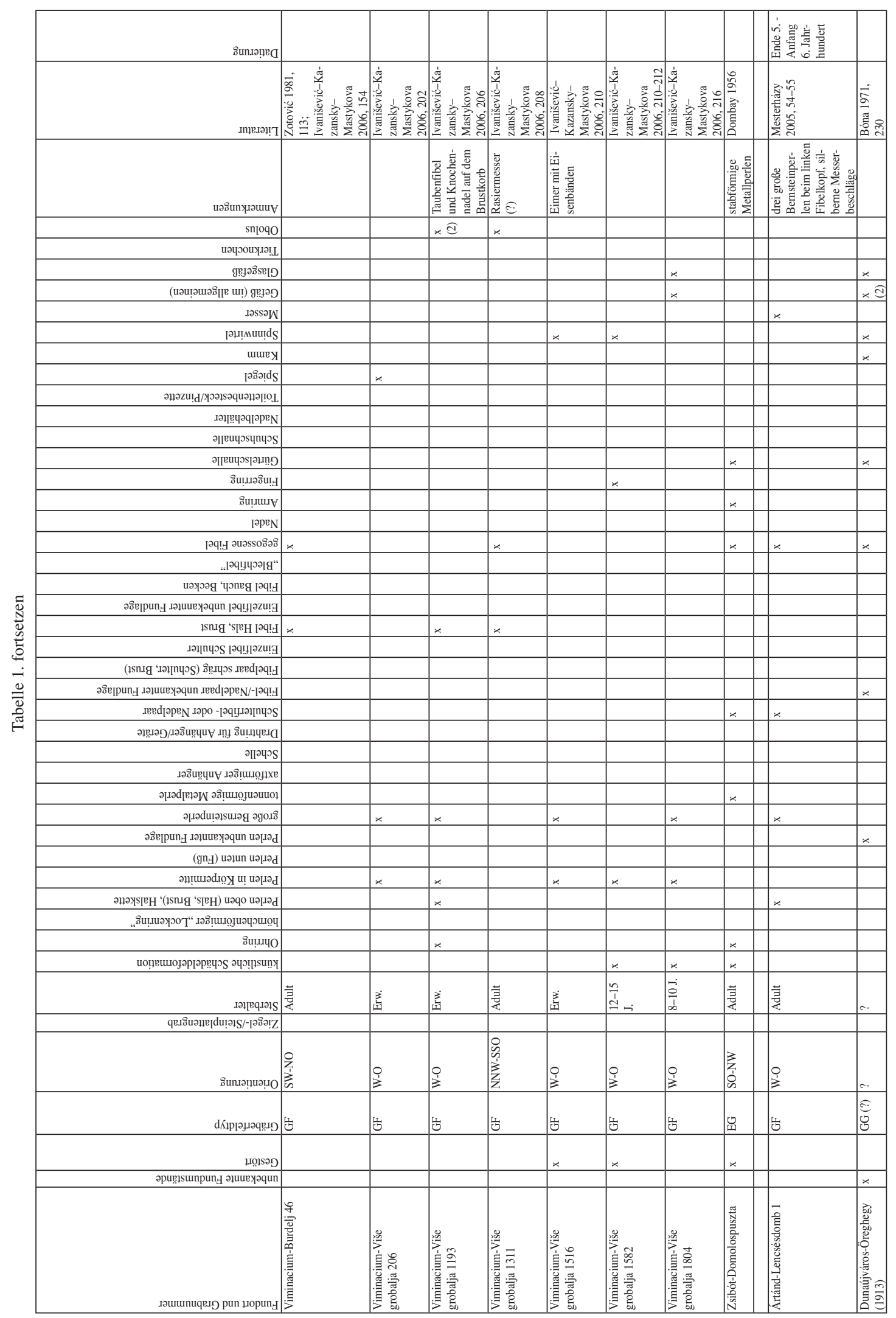




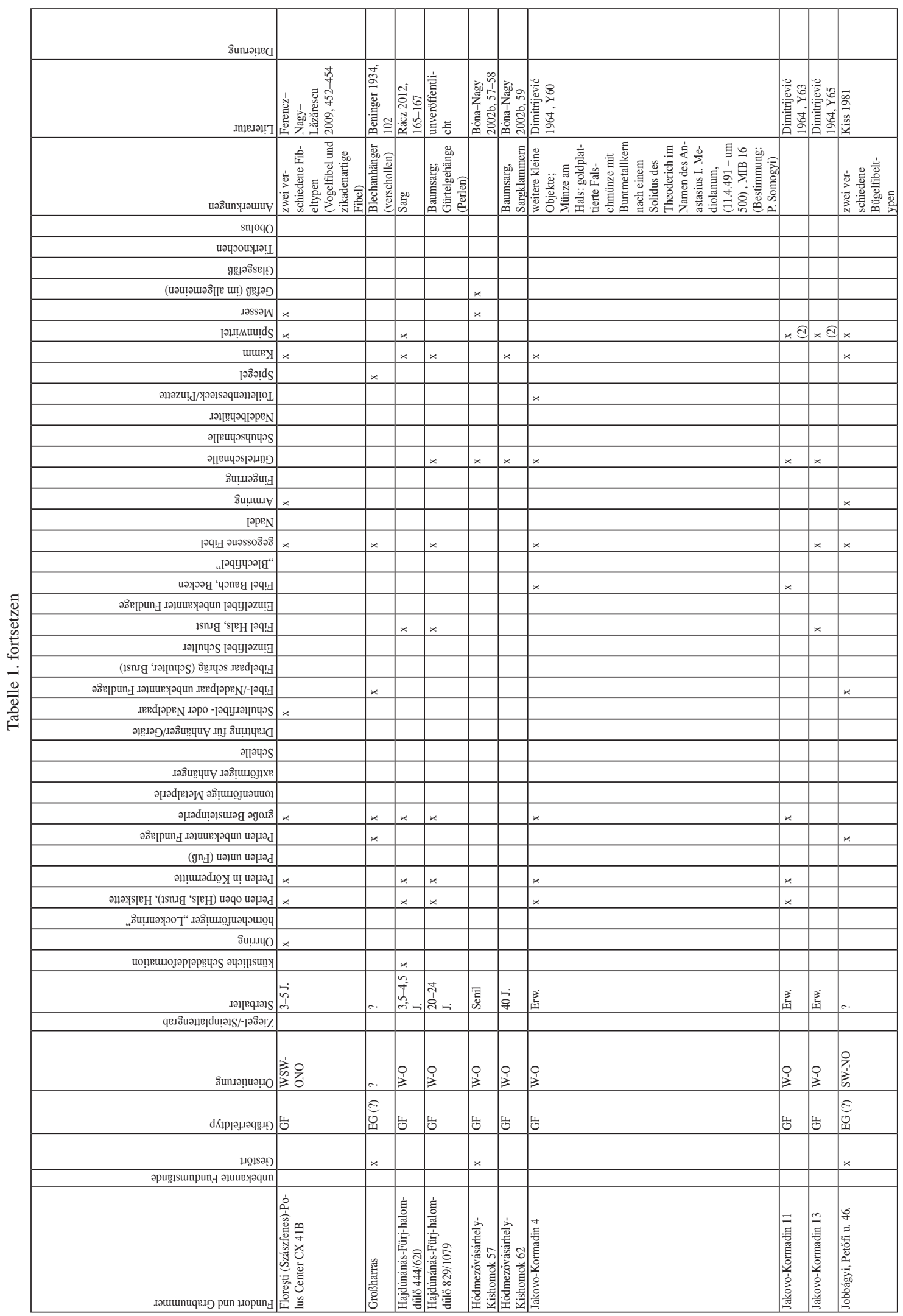




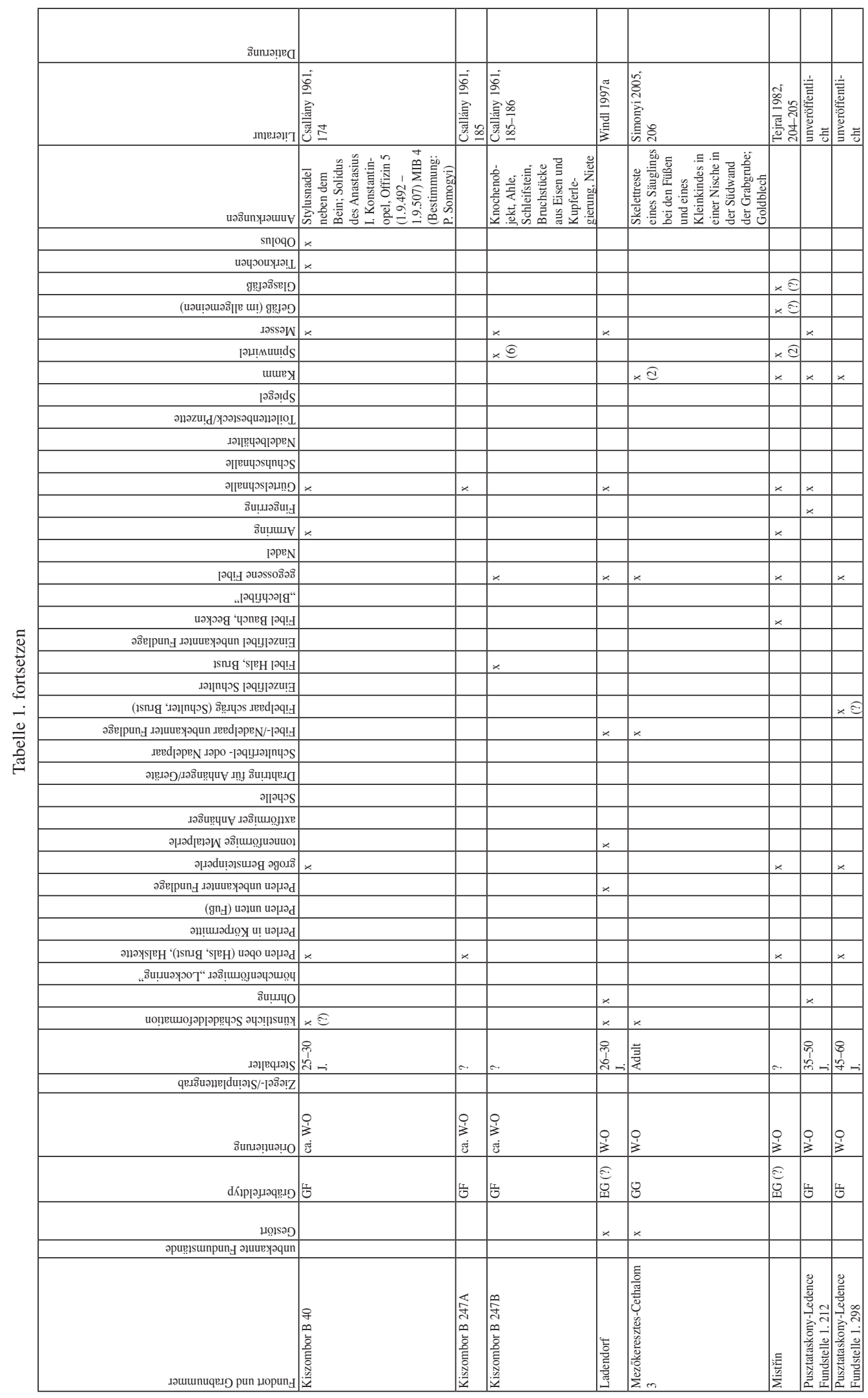




\begin{tabular}{|c|c|c|c|c|c|c|c|c|c|c|c|c|c|c|}
\hline Sunıạpa & & & & & & & & & & & & & & \\
\hline .пщเ.э!! & 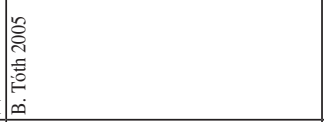 & 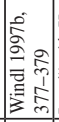 & 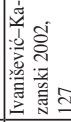 & 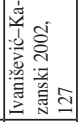 & 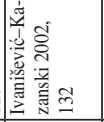 & 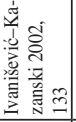 & 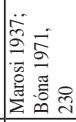 & 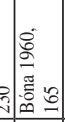 & 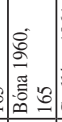 & 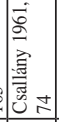 & 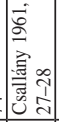 & 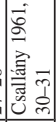 & 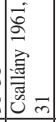 & 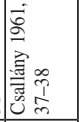 \\
\hline 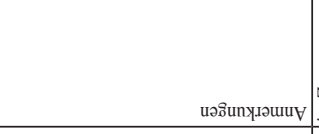 & 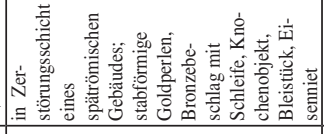 & & & 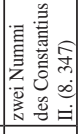 & 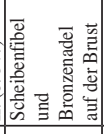 & 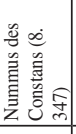 & 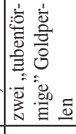 & 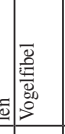 & & & & 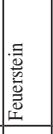 & & 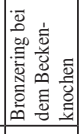 \\
\hline snjoqo & & & & $\times \sqrt{2}$ & & $\star$ & & & & & & & & \\
\hline 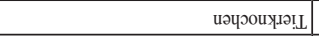 & & & & & & & & 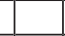 & & & & & & - \\
\hline 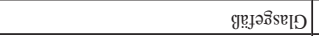 & & & & & & & & & & & & & & \begin{tabular}{|c|ccc} 
\\
\end{tabular} \\
\hline 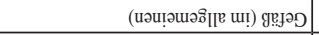 & & & & & & & & - & & & & & & \\
\hline .әәรsә & $x$ & $\times$ & & & & & & 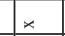 & & 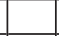 & $\times$ & 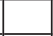 & & \\
\hline 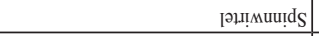 & & $x$ & & & & $x$ & & 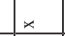 & & $x$ & $x$ & $\times$ & & E \\
\hline шише प्र & $x$ & & $\times$ & & & & & $\times$ & 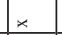 & & & $x$ & & $x$ \\
\hline 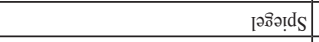 & & & & & & & & & & & & & & \\
\hline 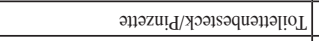 & & & & & & & & & & & 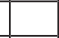 & 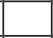 & & $x$ \\
\hline 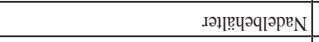 & & & & & & & & & & & 1 & 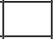 & & 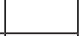 \\
\hline 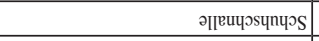 & & & & & & & & & 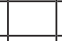 & & & 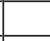 & & 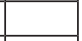 \\
\hline 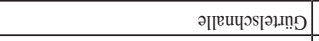 & $x$ & $x$ & $x$ & & & & $x$ & & $\times$ & & 1 & $x$ & $\times$ & $\times$ \\
\hline 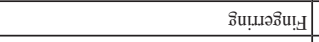 & & & $*$ & & & & & & & & 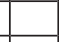 & $x$ & & 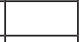 \\
\hline sิب̣ш.лу & & & & & & & $\times$ & & & & t & & 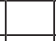 & 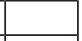 \\
\hline Iәрем & & & & & & & & & & & 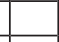 & 1 & 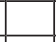 & 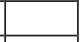 \\
\hline 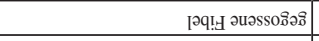 & $x$ & $x$ & $x$ & $x$ & & $x$ & $x$ & & & & $\times$ & $x$ & $x$ & $x$ \\
\hline 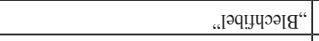 & & & & & & & & & & & & & & 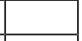 \\
\hline 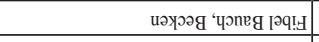 & $x$ & & $x$ & & & & & & & & - & $x$ & & 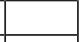 \\
\hline 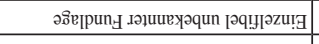 & & & & $x$ & & $x$ & & & & & 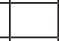 & & & 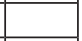 \\
\hline 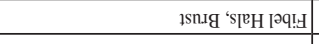 & & & & & 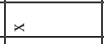 & & & $x$ 字 & & & + & 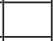 & & . \\
\hline 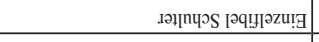 & & & & & & & & & & & - & & & \\
\hline 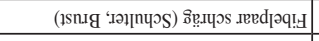 & & & & & & & & & & & - & & & $x$ \\
\hline 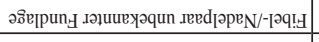 & & & & & & & $x$ & & & & $\times$ & & 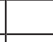 & \\
\hline זвеd[әре & & $x$ & & & & & & & & & & & $x$ & \\
\hline 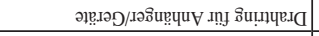 & & & & & & & & & & & 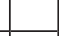 & & & \\
\hline ગાગ્પગડ & & & & & & & & & & & 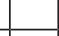 & & & \\
\hline 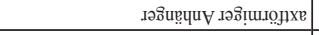 & & & & & & & & & & & & & & \\
\hline 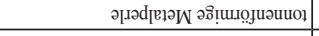 & & & & & & & & & & & $\times$ & & & \\
\hline 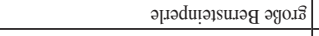 & & & & & & $x$ & $x$ & $\times$ & & & $\times$ & & $\times$ & $\times$ \\
\hline әвิвррии & & & & & & $x$ & $\times$ & & & & $\times$ & & & \\
\hline 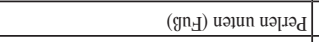 & & & & & & & & & & & & & & \\
\hline 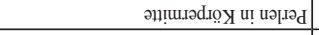 & & $\times$ & & & & & & $\times$ & & & 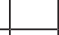 & $x$ & & $x$ \\
\hline 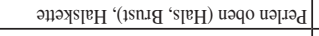 & $x$ & $\times$ & & $x$ & & & & $x$ 专 & & & 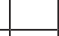 & $x$ & * & $\times$ \\
\hline 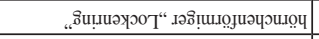 & & & & & & & & & & & & & & \\
\hline รиџџчо & & & & $x$ & * & 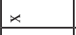 & & & $\times$ & $\times$ & $x$ & & & $x$ \\
\hline 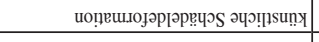 & & $x$ & & & & & & $x$ & $\times$ & + & - & & & \\
\hline 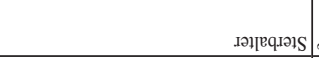 & . & 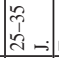 & 密 & $\dot{\vec{\rho}}$ & 屖 & . & . & $\Xi$ & 宗 & . & 。. & 喼 & 密 & 漓 \\
\hline 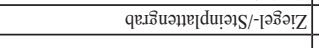 & & & $x$ & $x$ & & & & & & & & & & \\
\hline 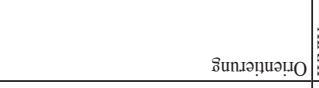 & 童。 & 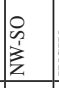 & 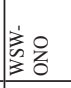 & 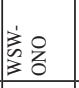 & 紊吕 & . & $\begin{array}{l}0 \\
3 \\
\vdots \\
1\end{array}$ & i & $\begin{array}{l}0 \\
\vdots \\
3\end{array}$ & . & . & 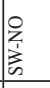 & $\begin{array}{l}3 \\
3 \\
3\end{array}$ & 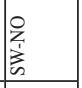 \\
\hline 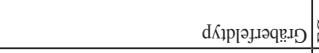 & 舀 & 站 & 出 & 我 & 贸 & 击 & tᄄ & 푼 & 近 & 造 & tri & 풍 & 동 & 击 \\
\hline 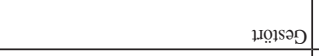 & & & & 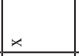 & & $\star$ & & $\star$ & $\times$ & & & & & \\
\hline 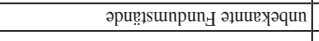 & & & & & & & $x$ & & & $x$ & $x$ & & & \\
\hline 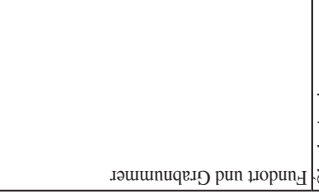 & 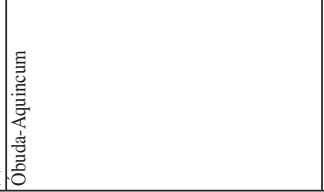 & 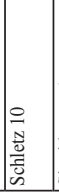 & 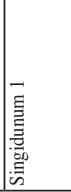 & 章 & 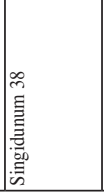 & 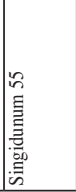 & 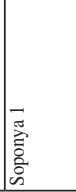 & 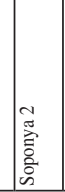 & 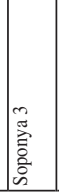 & 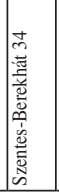 & 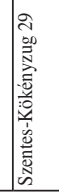 & 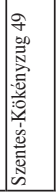 & 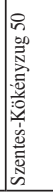 & 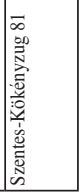 \\
\hline
\end{tabular}




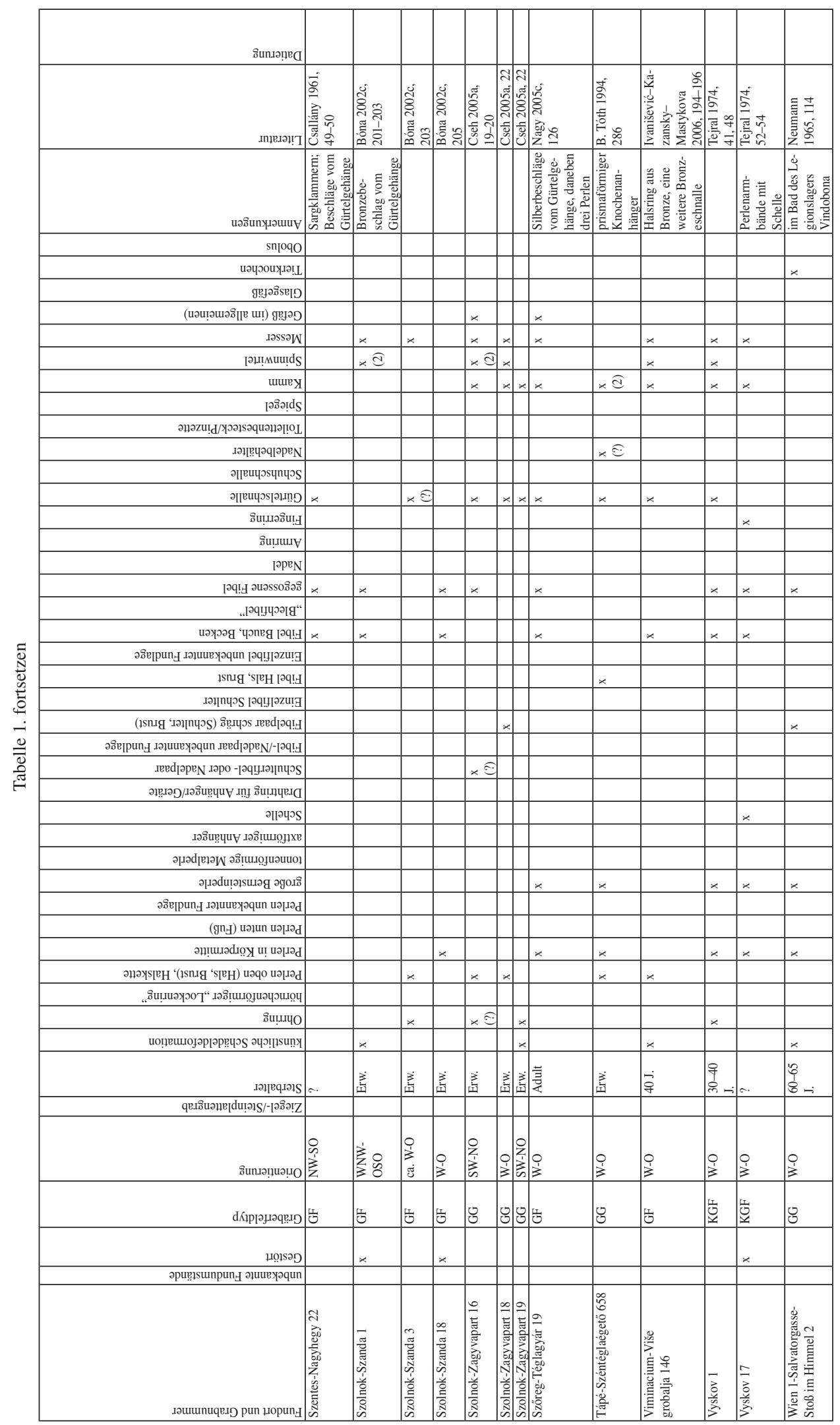









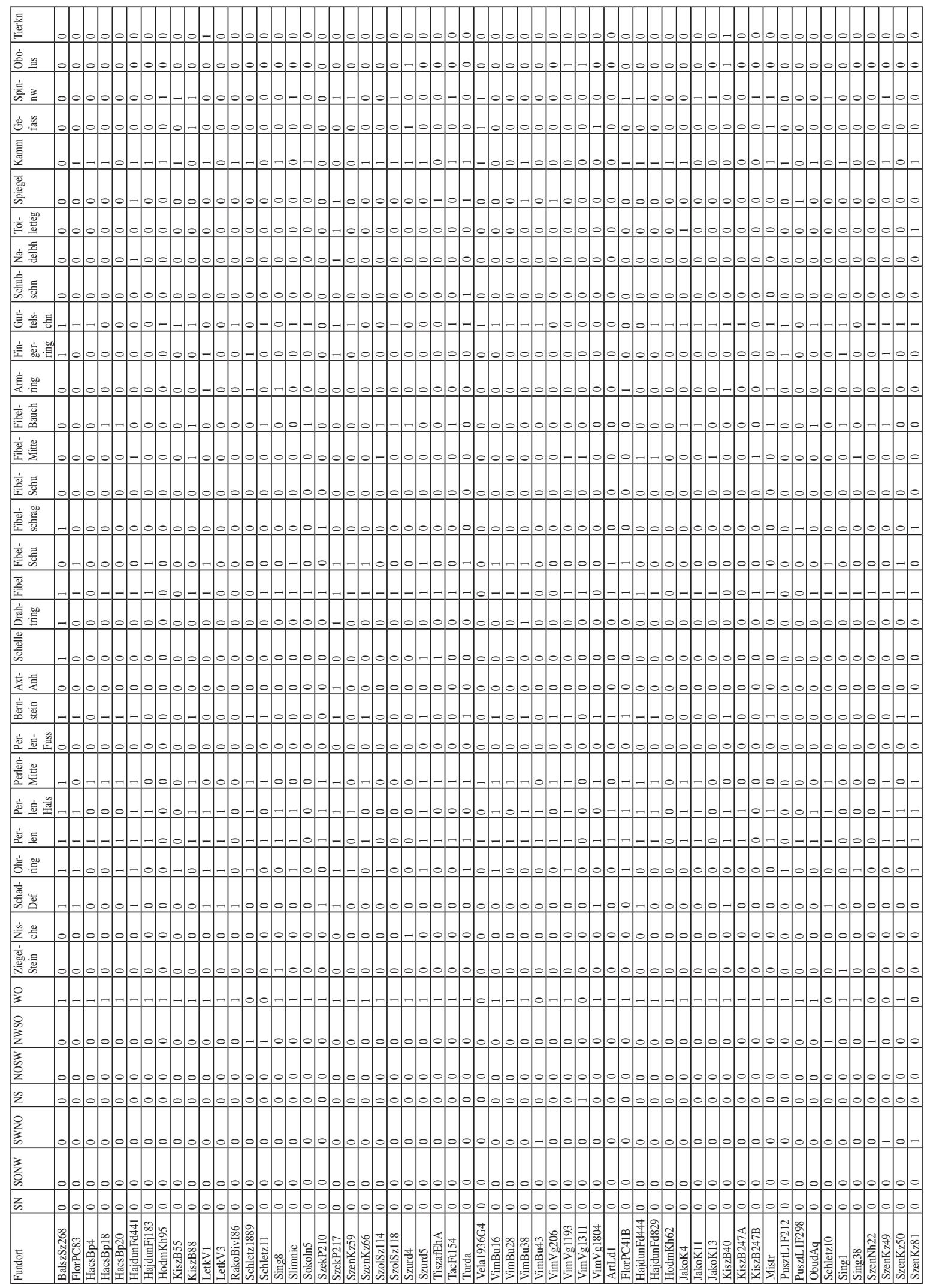




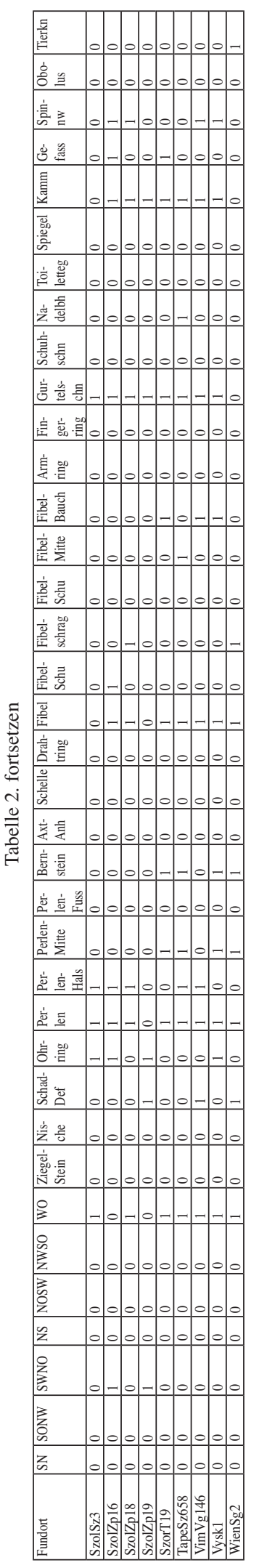

Acta Archaeologica Academiae Scientiarum Hungaricae 67, 2016 